University of Louisville

ThinkIR: The University of Louisville's Institutional Repository

\title{
The role of matrix metalloproteinases induced angiogenesis during transition from compensatory cardiac hypertrophy to cardiac failure : therapeutic effects of hydrogen sulfide.
}

Srikanth Givvimani

University of Louisville

Follow this and additional works at: https://ir.library.louisville.edu/etd

\section{Recommended Citation}

Givvimani, Srikanth, "The role of matrix metalloproteinases induced angiogenesis during transition from compensatory cardiac hypertrophy to cardiac failure : therapeutic effects of hydrogen sulfide." (2010). Electronic Theses and Dissertations. Paper 503.

https://doi.org/10.18297/etd/503

This Doctoral Dissertation is brought to you for free and open access by ThinkIR: The University of Louisville's Institutional Repository. It has been accepted for inclusion in Electronic Theses and Dissertations by an authorized administrator of ThinkIR: The University of Louisville's Institutional Repository. This title appears here courtesy of the author, who has retained all other copyrights. For more information, please contact thinkir@louisville.edu. 
THE ROLE OF MATRIX METALLOPROTEINASES INDUCED ANGIOGENESIS DURING TRANSITION FROM COMPENSATORY CARDIAC HYPERTROPHY TO CARDIAC FAILURE: THERAPEUTIC EFFECTS OF HYDROGEN SULFIDE.

By

Srikanth Givvimani M.D.

\author{
A Dissertation \\ Submitted to the Faculty of \\ Graduate School of the University of Louisville \\ in Partial Fulfillment of the Requirements \\ for the Degree of \\ Doctor of Philosophy \\ Department of Physiology and Biophysics \\ University of Louisville \\ Louisville KY
}

August 2010 
THE ROLE OF MATRIX METALLOPROTEINASES INDUCED ANGIOGENESIS DURING TRANSITION FROM COMPENSATORY CARDIAC HYPERTROPHY TO CARDIAC FAILURE: THERAPEUTIC EFFECTS OF HYDROGEN SULFIDE.

By

Srikanth Givvimani, M.D.

Bachelor of Medicine, Bachelor of Surgery, 2001

M.S., University of Louisville, 2009

A Dissertation Approved on

July $26^{\text {th }}, 2010$

By the Following Dissertation Committee

Suresh C.Tyagi, Ph.D., Mentor

Claudio Matetonado, Ph. $D_{4}$, Co-Advisor

Lxing G.Joshua, Ph.D.

William B. Wead, Ph.D.

Aruni Bhatnagar, Ph.D. 


\section{DEDICATION}

This dissertation is dedicated to my parents Mr. Givvimani Pothappa and Mrs.Givvimani Saroja who always supported their children to succeed in every aspect of life. 


\section{ACKNOWLEDGEMENTS}

I would like to thank God for what I am today. I am a strong believer of Sri Shiridi Saibaba, and his spiritual Preachings.

I thank all my committee members Dr.Suresh C.Tyagi, Dr.Claudio Maldonado, Dr.William B.Wead, Dr.Irving G.Joshua, and Dr.Aruni Bhatnagar for their valuable and encouraging support throughout my Ph.D program. I owe my deepest and sincere gratitude to my advisor Dr.Suresh C. Tyagi, whose continuous support and encouragement allowed me to reach this level in Ph.D program. He is responsible for involving me in this project and guide me at every stage. My sincere thanks to my co-advisor, Dr. Claudio Maldonado who helped me a lot in correcting my thesis and without whom, my thesis wouldn't have attained this shape. I would appreciate his valuable input. A special thanks to Dr.William B.Wead, our vice chair and my Ph.D committee member, who is always supportive and helpful throughout my academic program. I sincerely appreciate his valuable guidance. My sincere thanks to Dr. Irving G. Joshua, professor and chair, who also serves as my committee member. I am grateful and honored for having Dr.Aruni Bhatnagar in my committee who accepted to be one of my committee member despite of his busy schedule. 
My sincere thanks to all my colleagues, Dr.Utpal Sen, Dr.Neetu Tyagi, Dr.Paras Mishra, Dr.Soumi Kundu, Charu Munjal, Riyad Gargoum, Jonathan and Dr.Natia, for their valuable help in the laboratory. Special thanks to Charu, who helped me in doing western blots. I thank Ms.Naira Metreveli, who is all in one in this lab and who always offer her help to others.

Special thanks to Dr.Sathnur Pushpakumar, my fellow Ph.D student and very good friend who is very helpful to me throughout my Ph.D program.

My sincere thanks to three special ladies in the department of physiology, Ms.Denise Hughes, Ms.Gisel D.Murphy. and Ms. Carol Nall. Denise, thank you so much for all the help.

Last but not least, I would like to thank my beloved wife Dr.Rama Jala, who is always supportive in every step of my life. 


\begin{abstract}
THE ROLE OF MATRIX METALLOPROTEINASES INDUCED ANGIOGENESIS DURING TRANSITION FROM COMPENSATORY CARDIAC HYPERTROPHY TO CARDIAC FAILURE: THERAPEUTIC EFFECTS OF HYDROGEN SULFIDE.
\end{abstract}

\title{
Dr.Srikanth Givvimani M.D \\ July $26^{\text {th }} 2010$
}

Background: Although matrix metalloproteinase (MMPs) and tissue inhibitor of metalloproteinase (TIMPs) play a vital role in tumor angiogenesis and TIMP-3 causes apoptosis, their role in cardiac angiogenesis is unknown. Interestingly, a disruption of coordinated cardiac hypertrophy and angiogenesis contributes to the transition to heart failure, however, the proteolytic and anti-angiogenic mechanisms of transition from compensatory hypertrophy to decompensatory heart failure are unclear. Previous studies have shown the cardio protective role of hydrogen sulfide $\left(\mathrm{H}_{2} \mathrm{~S}\right)$ in myocardial ischemia, infarction and heart failure, but its role during transition from compensatory cardiac hypertrophy to heart failure is yet to be unveiled. We hypothesize that in pathological pressure overload of the heart, cardiac matrix remodeling is induced by an increase in angiogenic growth factors during the compensatory hypertrophy phase and an increase in antiangiogenic factors during the decompensatory heart failure phase. $\mathrm{H}_{2} \mathrm{~S}$ mitigates 
the transition from compensatory hypertrophy to decompensatory heart failure by increasing angiogenesis and decreasing fibrosis.

Methods: In the first set of experiments, we have created ascending aortic banding $(A B)$ in the mice to mimic pressure overload on the heart and studied the ventricular remodeling events associated with chronic pressure overload. Male wild type mice were used and all animal procedures were performed in accordance with National Institute of Health guidelines for animal research and were reviewed and approved by the Institute Animal Care and use Committee of University of Louisville. Sham animals underwent similar procedures except for aortic banding. Animals were studied at 3 weeks (compensatory phase) and 8 weeks period (decompensatory phase) and compared with sham groups.

In the second set of experiment, similar protocol was followed, and animals were treated with hydrogen sulfide $\left(\mathrm{H}_{2} \mathrm{~S}\right)$ for 6 weeks by giving sodium hydrosulfide (NaHS) in drinking water and compared with untreated groups. Molecular and functional data were assessed by echocardiography, pressurevolume $(P-V)$ study, immunohistochemistry, histology, western blot, and $x$-ray angiography.

Results: We found that in the first set of experiments, expression of MMP-2 increased along with angiogenic growth factor, vascular endothelial growth factor (VEGF) during compensatory phase (AB 3 weeks group). Expression of MMP-9, TIMP-3 and anti-angiogenic factors, angiostatin, and endostatin increased during decompensatory phase (AB 8 weeks group). There was increased deposition of 
fibrosis during the decompensatory phase. By treating with $\mathrm{H} 2 \mathrm{~S}$, we noticed that there was increased expression of VEGF and MMP-2 in AB 8 weeks group than in untreated AB 8 weeks group. Interestingly, the expression of MMP-9, TIMP-3 and anti-angiogenic factors angiostatin and endostatin decreased in $\mathrm{H} 2 \mathrm{~S}$ treated AB 8 weeks group than in the untreated group. There was significant reduction of fibrosis in treated $A B 8$ weeks group. Left ventricular function also improved in H2S treated AB 8 weeks group.

Conclusion: we conclude that under chronic pressure overload, expression of MMP-2 is induced which in turn increases the release of angiogenic growth factors in compensatory cardiac hypertrophy. The expression of MMP-9 and TIMP-3 is also increased leading to a release of anti-angiogenic factors in decompensatory heart failure. Hydrogen sulfide mitigates this transition to decompensatory heart failure not only by inducing MMP-2/NEGF but also inhibiting MMP-9/TIMP-3 and anti-angiogenic factors. 


\section{TABLE OF CONTENTS}

TITLE PAGE

SIGNATURE PAGE ii

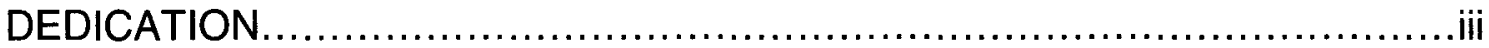

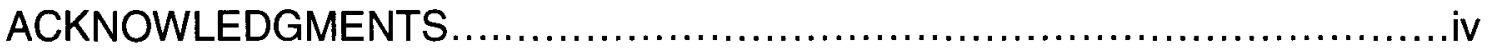

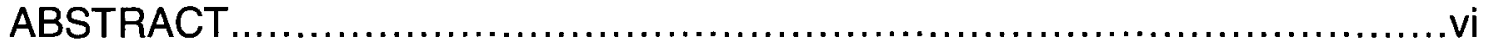

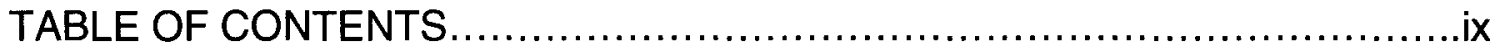

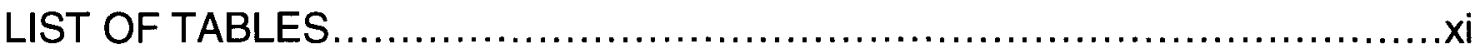

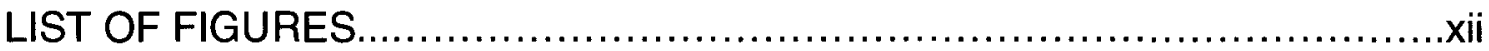

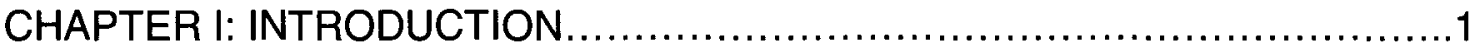

CHAPTER II: BACK GROUND

a) Structure and function of the Heart............................ 5

b) Pathological conditions of the heart...........................

c) Extra cellular matrix........................................

d) Matrix metalloproteinases.................................... 20 
e) Tissue inhibitor of matrix metalloproteinases.

f) Angiogenesis.

g) Angiogenic growth factors.................................... 32

h) Anti-angiogenic growth factors................................ 35

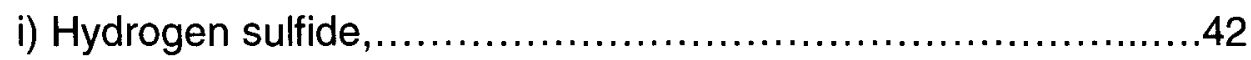

CHAPTER III: Hypothesis and Specific aims.................................45

CHAPTER IV: Mechanism of transition from compensatory hypertrophy to

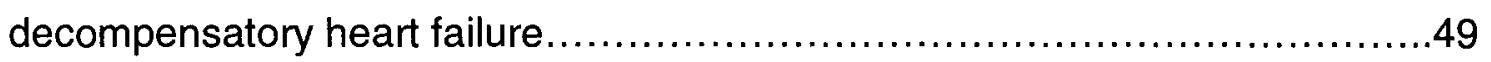

CHAPTER V: Role of hydrogen sulfide during transition to heart failure.........80

CHAPTER VI: Summary, Conclusion and future directions....................110

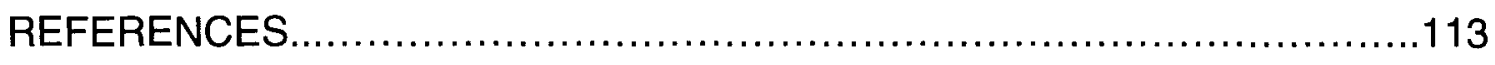

LIST OF ABBREVIATIONS.................................................133

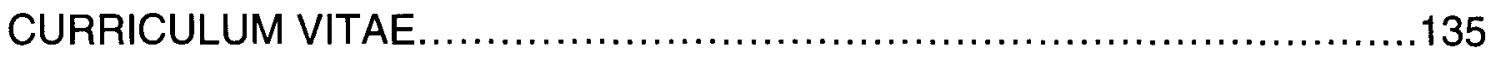




\section{LIST OF TABLES}

TABLE

PAGE

1. Table 1. Major classification of MMPs and their role in cardiac

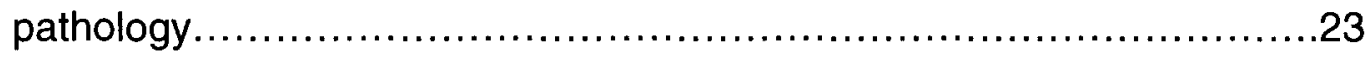

2. Table 2. Classification of TIMPs and their role in cardiac

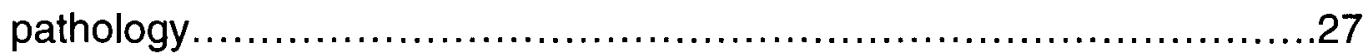

3. Table 3. Promoters and inhibitors of angiogenesis. .33

4. Table 4. Experimental animal groups..................................48 


\section{LIST OF FIGURES}

FIGURE

PAGE

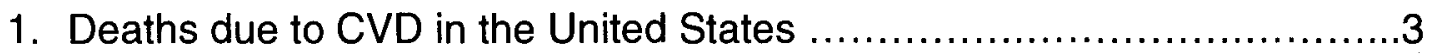

2. Prevalence of CVD in adults .............................................. 4

3. Blood supply of the heart...............................................

4. Conduction system of the heart.........................................

5. Capillary fiber relationship..........................................................

6. Histology of normal and CHF heart ......................................14

7. Morphological and functional changes in the heart failure.................17

8. ECM remodeling in the heart failure .....................................19

9. Structure of Matrix metalloproteinase ..................................22

10. Tertiary structure of Tissue inhibitor of matrix metalloproteinase ..........26

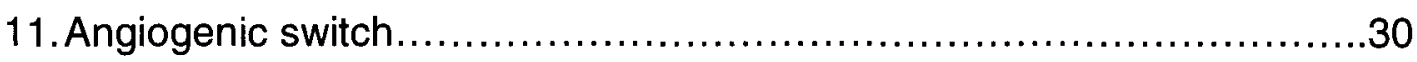

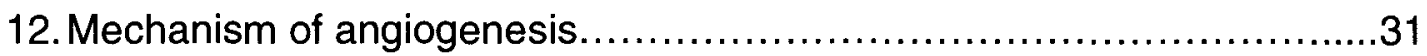

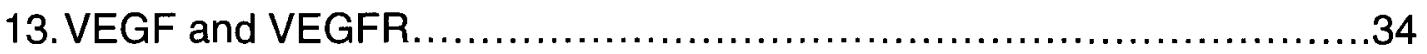

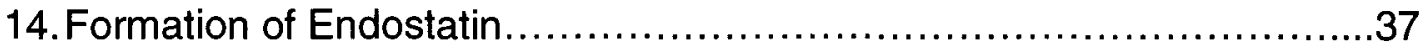

15. Mechanism of action of Endostatin.....................................38

16. Formation of Angiostatin...............................................40

17. Mechanism of action of Angiostatin ....................................41

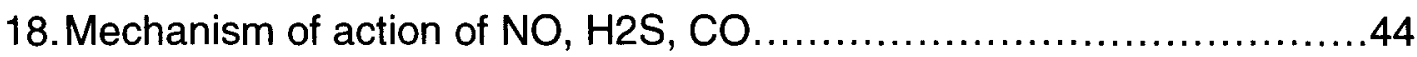

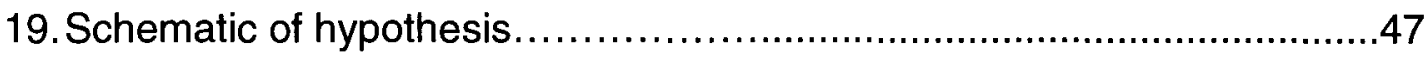

20. Image of intubated mouse with ventilator support.........................57 
21. Image of mouse undergoing aortic banding surgery ...................58

22. Image of barium contrast coronary angiogram in the mouse .............59

23. Aortic banding induced changes in cardiac function......................64

24. Changes in cardiac function due to aortic banding......................65

25. Aortic banding increases cardiac mass ...............................66

26. Aortic banding induces changes in cardiac morphology................67

27. Western blot analysis of MMP-9 and MMP-2 in the animal

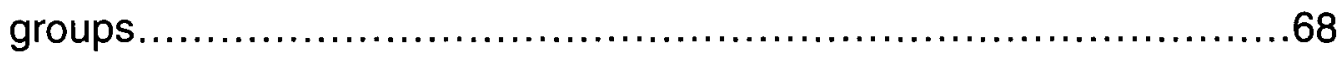

28. Western blot analysis of TIMP-2 and TIMP-4 in the animal

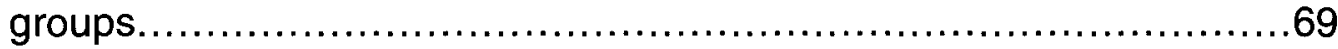

29. IHC staining of TIMP-3 and MMP-2 in the animal groups................................................................ 70

30. Western blot analysis of VEGF-A, Angiostatin and Endostatin

31. IHC staining of Endostatin in the animal groups.

32. IHC staining of CD 31(PECAM) in the animal groups.

33. Barium contrast $x$-ray angiogram in the animal groups.

34. Hypothetical presentation of latent MMP activation

35. M-mode echocardiography data of control and $\mathrm{H} 2 \mathrm{~S}$ treated groups.

$36 . \% \mathrm{FS}$ and \%EF in control and $\mathrm{H} 2$ s treated groups.

37. Mason's trichrome staining of heart in control and H2s treated groups

38. Quantification of collagen in the control and H2S treated groups. 
39. IHC staining of VEGF in control and treated

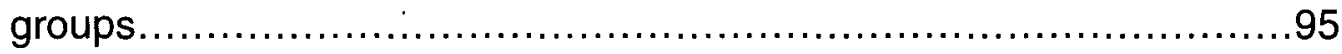

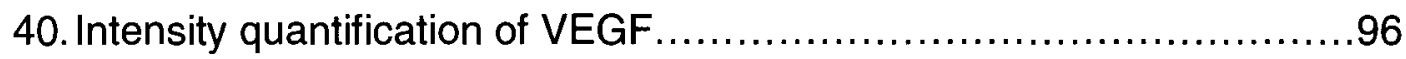

41. IHC staining of Endostatin in control and treated groups.................97

42. Intensity quantification of endostatin.................................98

43. IHC staining of MMP-2 in control and treated groups....................99

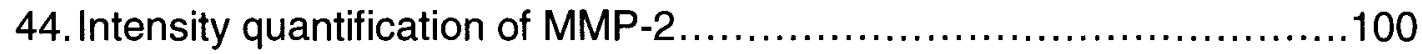

45. IHC staining of MMP-9 in control and treated groups....................101

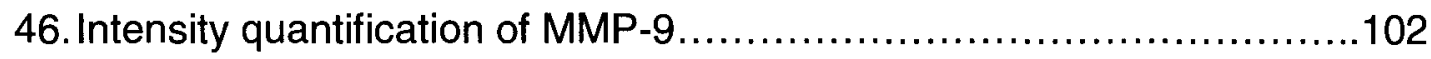

47. IHC staining of TIMP-3 in control and treated groups....................103

48. Intensity quantification of TIMP-3..................................... 104

49. Western blot analysis of VEGF-A, Angiostatin and Endostatin...........105

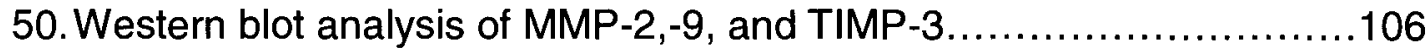




\section{CHAPTER I}

\section{INTRODUCTION}

Worldwide, cardiovascular disease (CVD) is the leading cause of mortality for both men and women (Figures 1 and 2) (1). It includes hypertension, ischemia, infarction, heart failure and stroke. Hypertension is one of the major risk factors of heart failure. Nevertheless, it is unclear, why every hypertensive does not develop heart failure. To develop treatment of CVD, it is important to determine the mechanism(s) of heart failure. In 1941 Roberts et al. report that there is a decreased ratio of capillary density to number of myofibers in hypertrophied hearts, stressing the importance of angiogenesis in the pathogenesis of heart failure. Since then wide range of research is ongoing to unravel the pathogenic mechanism of heart failure.

Chronic heart failure (CHF) could be due to pressure overload and/or volume overload. Systemic hypertension is the main risk factor of pressure overload heart failure. Previous studies have shown that during chronic stress, the heart undergoes remodeling resulting in compensatory hypertrophy initially, and progressing to decompensatory heart failure in later stage. Remodeling by its very nature implies synthesis and degradation of extracellular matrix (ECM). The matrix metalloproteinase (MMP) and their natural tissue inhibitors (TIMPS), 
play a major role in ECM remodeling and the pathogenesis of heart failure. Proper angiogenesis/vasculogenesis is important to supply nutrients to the remodeling tissue. It has been shown that disruption in the angiogenic process leads to decompensatory heart failure, however, the exact mechanism of transition from compensatory hypertrophy to decompensatory heart failure has not been elucidated. Although angiogenic and anti-angiogenic factors have been extensively studied, and a critical role of MMP/TIMP axis in cancer has been demonstrated, their role in cardiac pathology has not been studied. In contrast to cancer, angiogenesis or inhibition of anti-angiogenic factors may play a beneficial role in ischemic cardiovascular diseases including heart failure, and therefore pro-angiogenic therapy is a promising strategy for the treatment of cardiovascular disease.

Hydrogen sulfide has recently been found to be an endogenous gaseous transmitter similar to nitric oxide (NO) and carbon monoxide (CO). Several mechanisms have been proposed to show the cardio protective vasodilatory and pro-angiogenic mechanisms of hydrogen sulfide. Nevertheless, it is not known whether hydrogen sulfide can have a therapeutic role in hypertension-induced heart failure. In the present study, we examined the mechanisms involved in the transition from compensatory to decompensatory heart failure, and the therapeutic effects of hydrogen sulfide during this transition. 


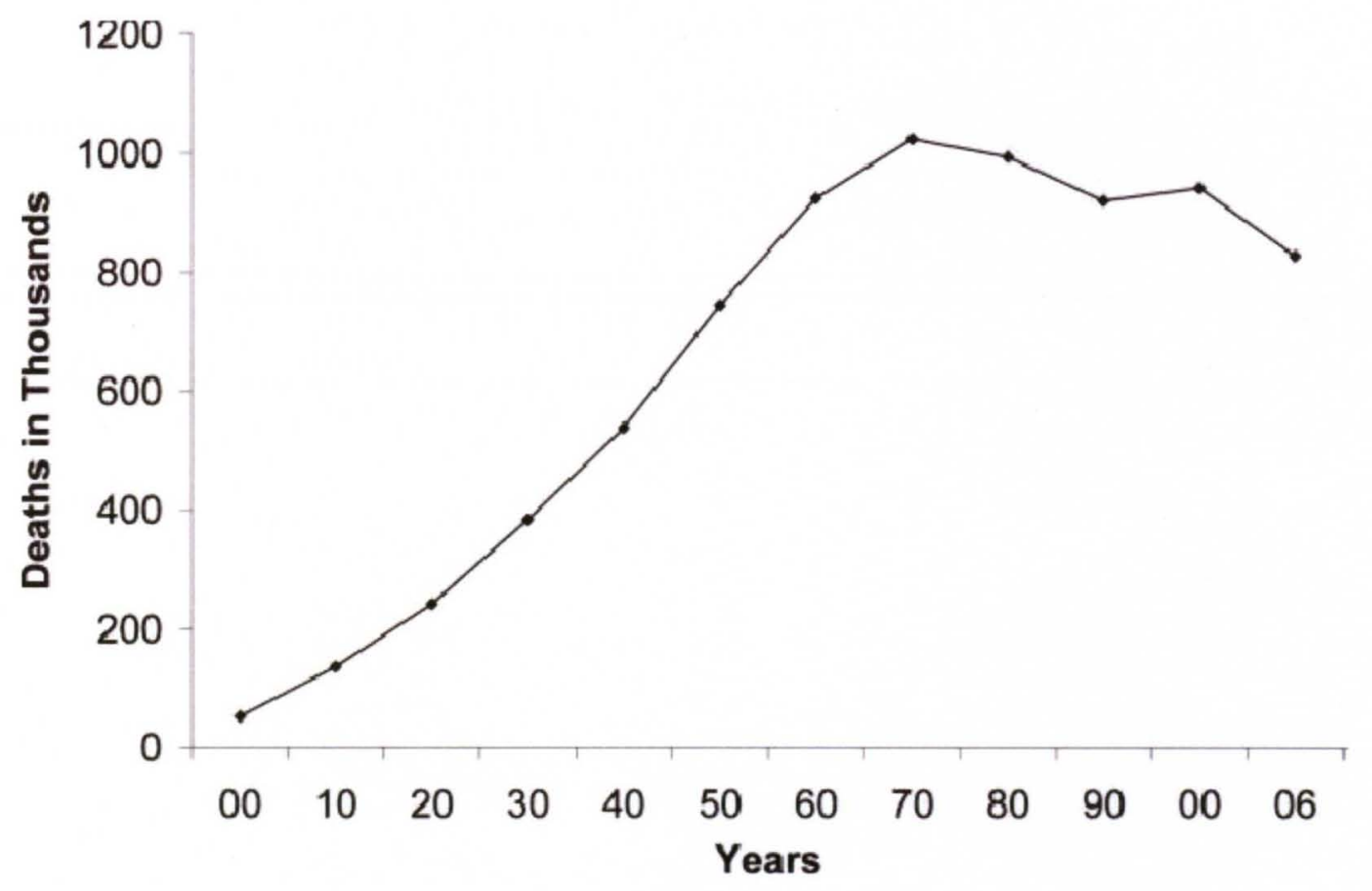

Figure 1: Deaths due to cardio vascular disease in United States from 19002006 (AHA statistical update). The plateau during 1980 could be due to awareness of healthy nutrition and advances in the medical management. 


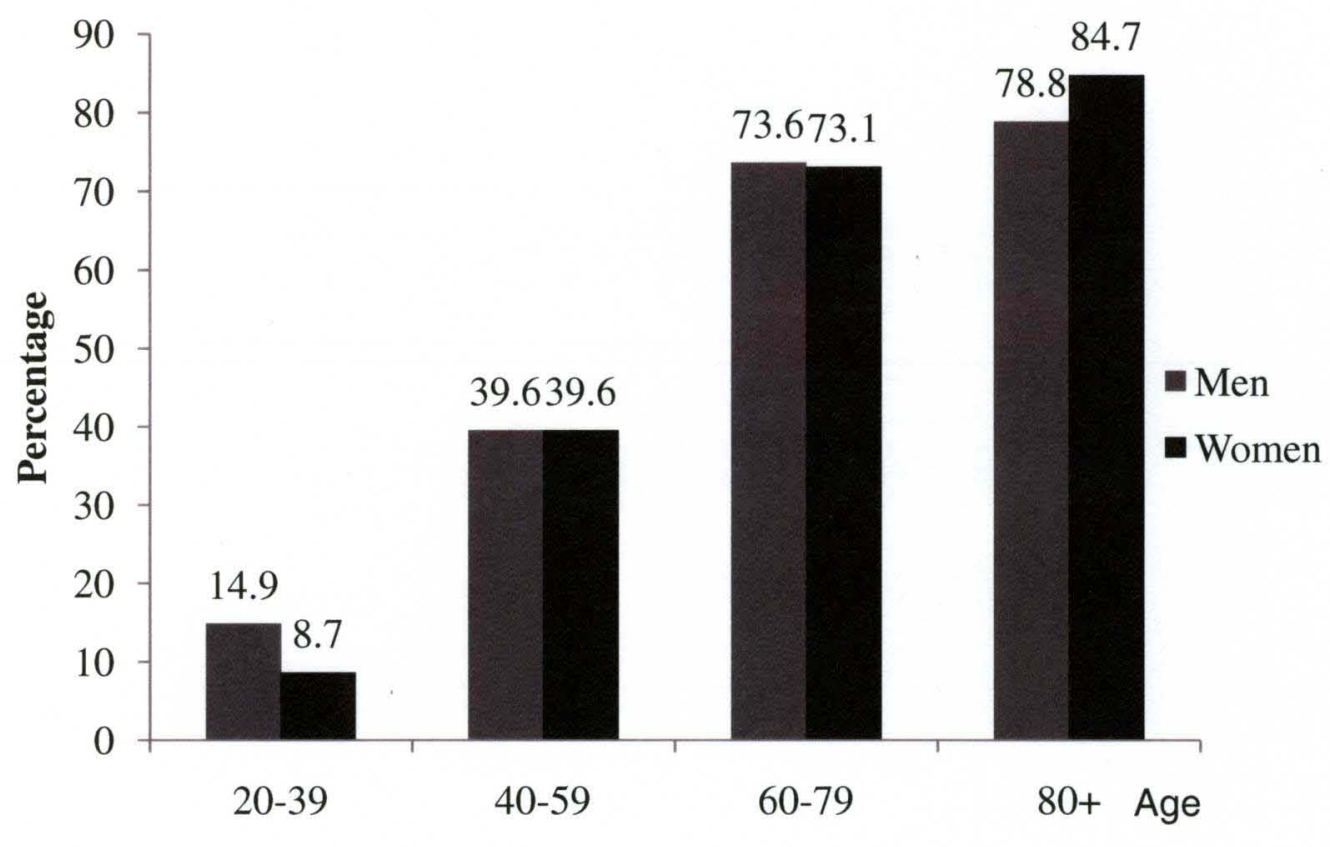

Figure 2: Prevalence of cardio vascular disease in adults $\geq 20$ years of age by age and sex (NHANES: 2005-2006). Source NCHS (National center for health statistics) and NHLBI (National Heart, Lung and Blood Institute). 


\section{CHAPTER II}

\section{BACKGROUND}

\section{a) Structure and function of the heart}

The heart is a four chambered pumping organ (upper right and left atria and lower right and left ventricles) in which the left side of the heart receives oxygenated blood through pulmonary veins from the lungs and pumps it to the rest of the body through the aorta. The right side of the heart receives deoxygenated through the superior and inferior venacava, and pumps it to the lungs via the pulmonary artery. The main function of the heart is to receive and pump blood in a rhythmic manner (2). During contraction, the heart pumps blood against the aortic pressure (afterload) which reflects vascular resistance. The work load on the heart can be increased either by an increase in vascular resistance (pressure overload) or by an increase in venous return (volume overload). As the work load increases, the heart muscle has an intrinsic compensatory mechanism to overcome the load and remodel accordingly.

Anatomically the heart can be differentiated into three layers: an inner endocardial layer, middle myocardial layer and an outer epicardial layer. The heart is surrounded by a pericardial sac and in the pericardial space there is pericardial fluid that provides protection to the heart from external force or 
friction. The cellular structure of the heart consists of myocytes, fibroblasts, smooth muscle cells, endothelial cells and extracellular matrix. Ventricular myocytes contribute to $70-80 \%$ of the total cardiac mass (3) and the contractile proteins of the heart lie within the myocytes. A group of myocytes held together by collagenous connective tissue (a major component of extracellular matrix), is called a myofiber. Approximately $50 \%$ of each ventricular cell is comprised of myofibers and $25-33 \%$ consists of mitochondria (4). Vascular supply to the heart is mainly by the right and left coronary arteries which arise from the aorta just above the aortic valves. The left coronary artery divides into the left anterior descending and the left circumflex arteries which supply most of the anterior region, septum and posterior regions. The right coronary artery supplies the lateral region of the right ventricle, right atrium and part of the posterior wall of right ventricle (Figure 3). The specialized conduction system of the heart originates in the sino atrial node (intrinsic pacemaker) in the high right atrium. Impulses from the sino atrial node traverses through the atria to the atrio ventricular node and then through the common bundle of His, which divides in the ventricular septum as right and left bundle branches and terminates in Purkinje fibers (Figure 4). 


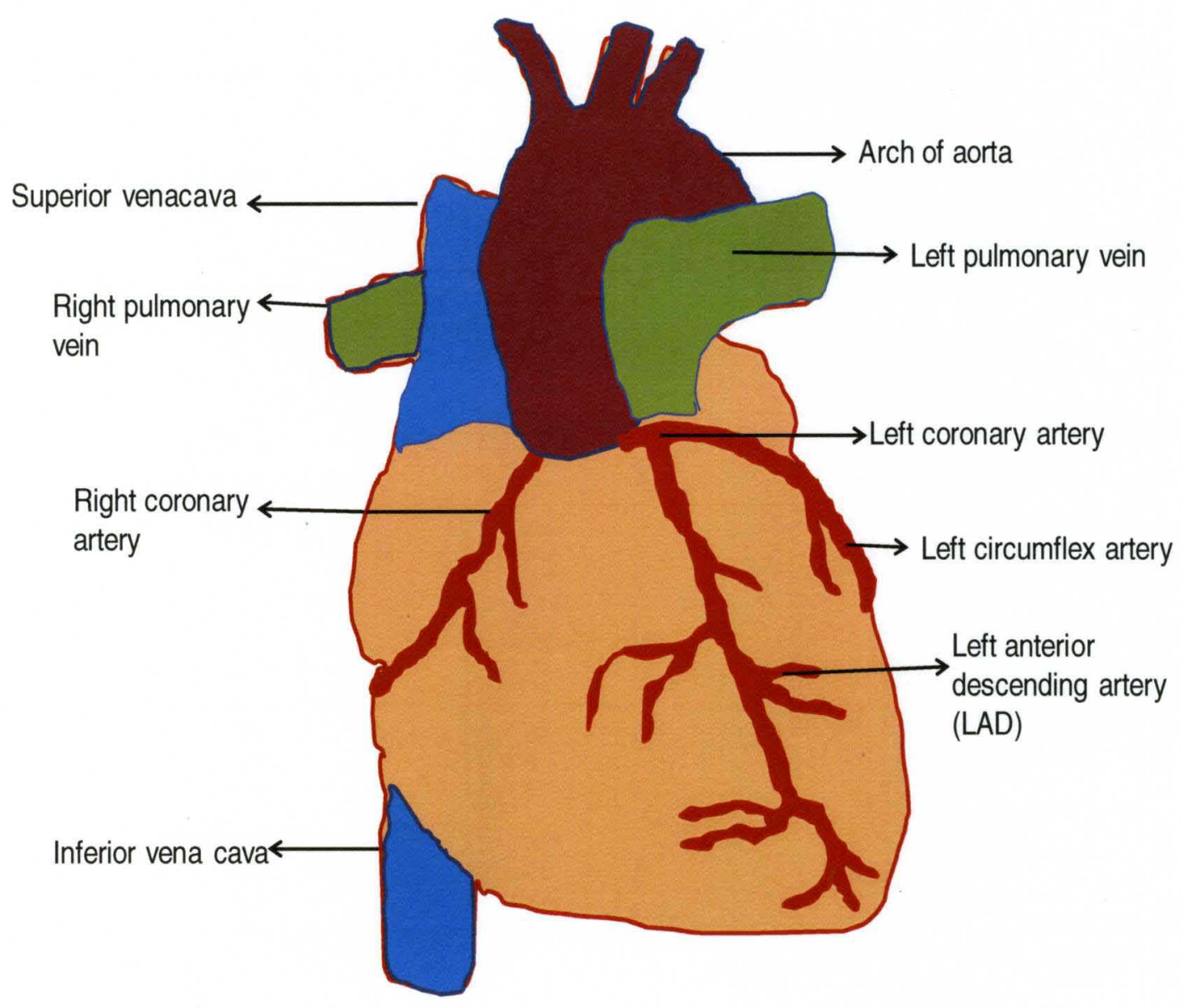

Figure 3: Blood supply of the heart. Left coronary artery divides into left anterior descending and left circumflex arteries which supply most of the anterior region, septum and posterior regions. Right coronary artery supplies lateral region of the right ventricle, right atrium and some part of the posterior wall of right ventricle. 


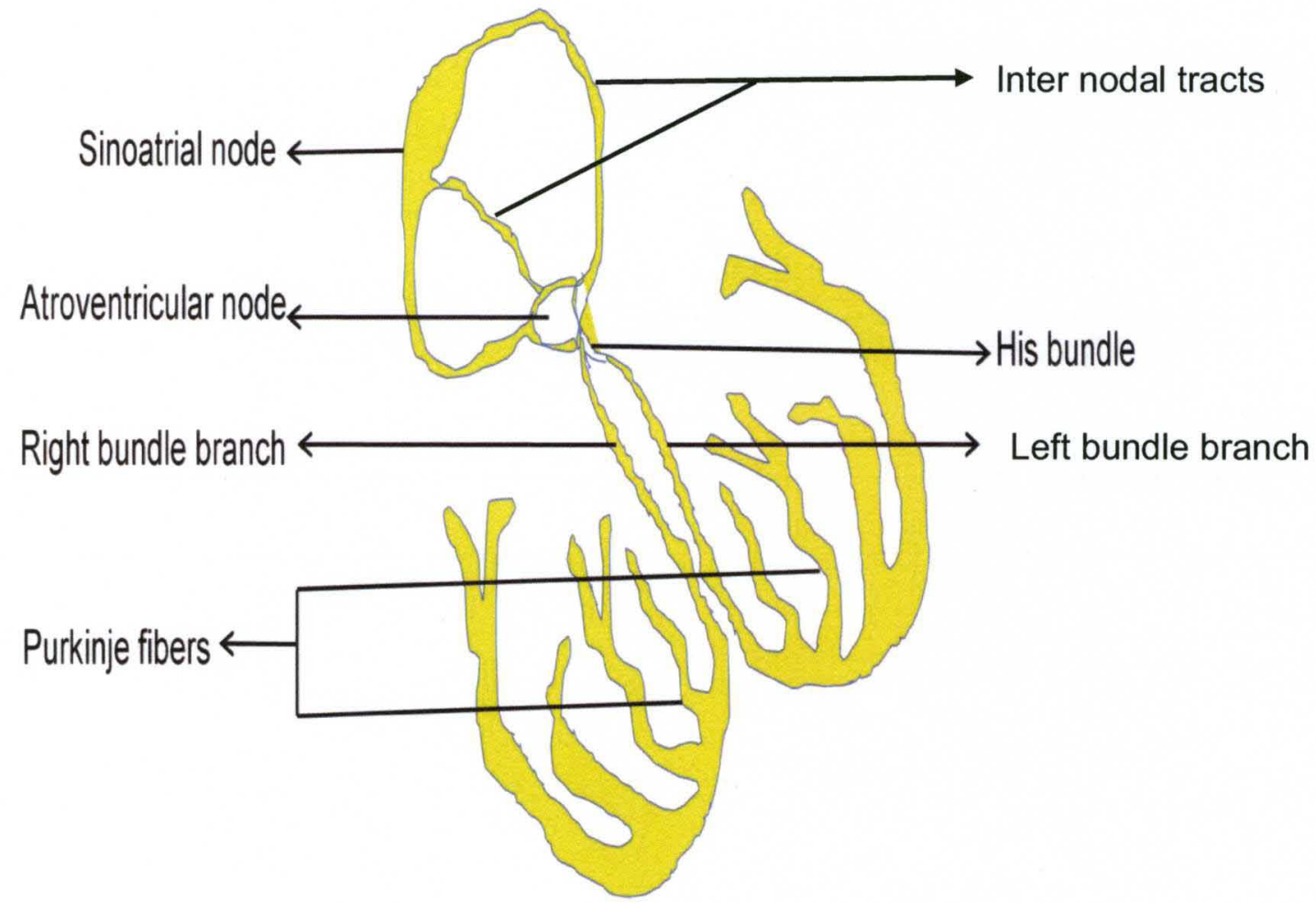

Figure 4: Conduction system of the heart. Sino atrial node-- $\rightarrow$ Atrioventricular node $--\rightarrow$ His bundle--- $\rightarrow$ Right and left bundle branches-- $\rightarrow$ Purkinje fibers. 


\section{b) Pathological conditions of the heart}

\section{Hypertension}

High blood pressure / hypertension is a major risk factor of cardiovascular diseases. According to the guidelines of the American heart association (AHA), hypertension is defined as a systolic blood pressure (SBP) of $\geq 140 \mathrm{~mm} \mathrm{Hg}$ or a diastolic blood pressure (DBP) of $\geq 90 \mathrm{~mm} \mathrm{Hg}$. One in three adults in United States is hypertensive $(1,5)$ and it is estimated that direct and indirect health care cost associated with treatment of hypertension is $\$ 73.4$ billion per year (1). Increase in blood pressure during hypertension leads to adverse events in the brain, heart, and kidneys through two related mechanisms. The first is the effect of increased pressure on the structure and function of the heart and arteries, and the second is the acceleration of atherogenesis. The former is directly related to the blood pressure, whereas the latter requires an interaction with other CVD risk factors, most importantly cholesterol (6). Hypertension increases pressure overload (afterload) on the heart and influences cardiac remodeling. At the onset of hypertension, the heart rate increases to compensate for the increase in overload. Over time myocytes increase in size to further compensate for the increased afterload by increasing the force of contraction to maintain stroke volume. As the overload is sustained long-term, myocardial remodeling progresses to an increase in wall thickness and chamber size that leads to contractile dysfunction and heart failure (7-8). The structural abnormalities in the hypertensive heart are not only limited to myocyte hypertrophy but also include 
medial hypertrophy of the intramyocardial coronary arteries as well as collagen deposition leading to cardiac interstitial fibrosis (4). 


\section{Cardiac hypertrophy}

Hypertrophy of the cardiac myocyte can be either physiological, during growth and exercise or it can be pathological, due to a persistent increase in mechanical overload (9). Pathological hypertrophy has been associated with pressure overload, volume overload, and ischemic cardiomyopathy (4). Unlike physiological cardiac hypertrophy, pathological hypertrophy results in the loss of myocytes and their fibrotic replacement leading to cardiac dysfunction and sudden cardiac death (10-11). Pressure overload produces a disproportionate increase in systolic wall stress, and results in concentric ventricular hypertrophy. At the cellular level, cardiomyocyte cross-sectional area is increased, predominantly because of the parallel addition of new sarcomeres. Volume overload can induce either systolic or diastolic wall stress and result in eccentric ventricular hypertrophy. Eccentric hypertrophy results in an overall increase in myocyte length without a substantial increase in myocyte cross-sectional area and is caused by the addition of new sarcomeres in series (12-13).

Sustained pressure overload results in excessive collagen deposition, an increase in myocyte size, and a decrease in capillary density leading to heart failure (Figure 6) (14). In 1941 Roberts et al. demonstrated a decrease in capillary to myocyte diameter ratio in hypertrophied human hearts compared with normal adult hearts (Fig 5) (15). The coronary blood flow is normal during diastole in the hypertrophied heart but the vasodilatory reserve becomes impaired, when the myocyte mass surpasses the blood supply. This impairment 
in the coronary reserve leads to subendocardial ischemia and in combination with cardiac fibrosis impairs diastolic relaxation leading to diastolic heart failure. 


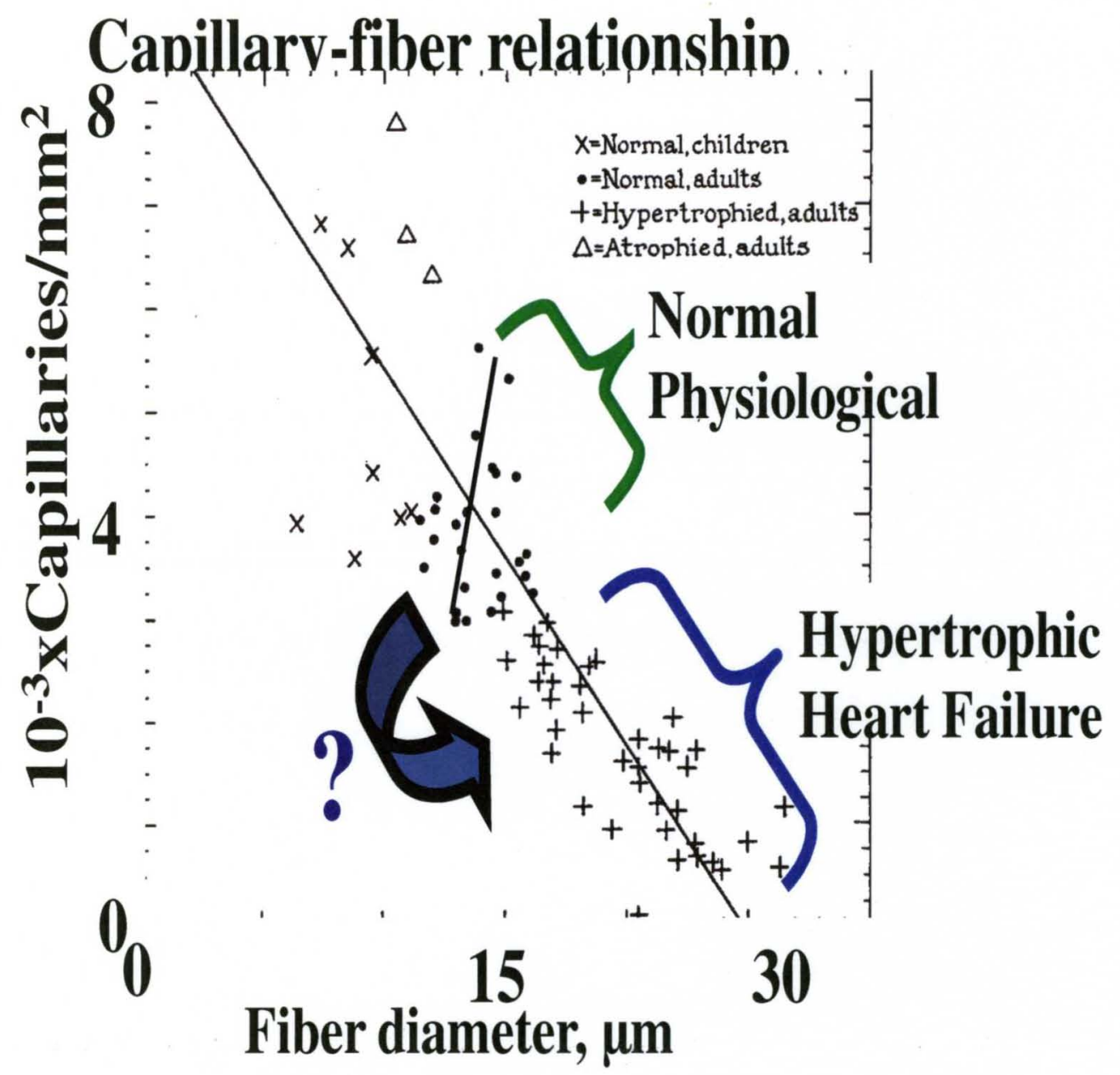

Figure 5: The relationship between capillary density and myofiber diameter in normal, hypertrophied and atrophied hearts (reproduced from 1941 article by Dr.Roberts et al., Am Heart journal). The data show that as the fiber diameter increases in hypertrophied heart there is a decrease in capillary density. 


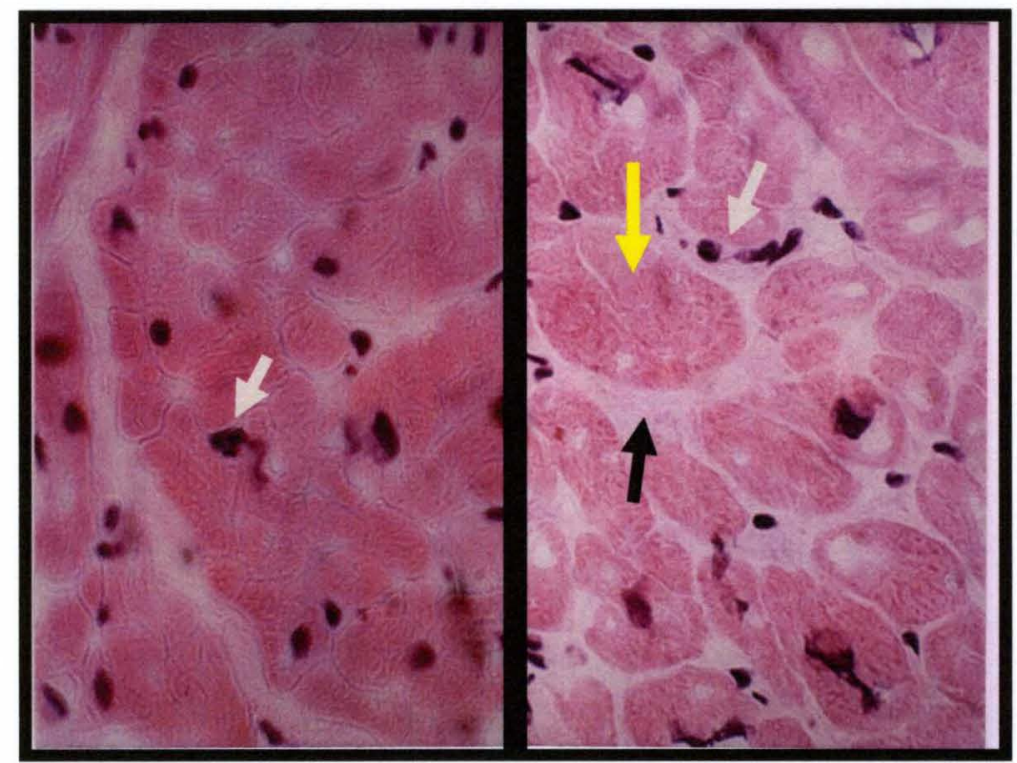

Normal

CHF

Figure 6: Relationship of capillary endothelial cell density to the cardiac myocyte hypertrophy (14). There is lower capillary density and excessive deposition of ECM in congestive heart failure heart (CHF) than in normal heart. Arrows point to the capillaries (white), hypertrophied myocyte (yellow), and fibrosis (black). 


\section{Heart failure}

According to the American Heart Association (AHA), an estimated 5.7 million of Americans are suffering with heart failure and 670, 000 new cases are diagnosed each year. The estimated direct and indirect cost of treating heart failure in the United States in 2009 was $\$ 37.2$ billion per year (1).

Heart failure is defined as a pathophysiological state in which an abnormality of cardiac function decreases the ability of the heart to pump blood at a rate commensurate with the requirements of the metabolizing tissues (4). Heart failure can also be better defined as a complex clinical syndrome that can result from any structural or functional cardiac disorder that impairs the ability of the ventricle to fill with or eject blood (16).

Heart failure can be due to: a) loss of myocytes (e.g., myocardial infarction) or disorientation of cells (e.g., hypertrophic), b) an increase in afterload (e.g., hypertension) c) valvular abnormalities d) arrhythmias, e) pericardial abnormalities, and f) congenital deformities of the heart (6). A clinical study performed in 1993, reported changes in wall stress, wall thickness and ventricular volume (Figure 7) (17), associated with the progression of compensatory hypertrophy to decompensatory heart failure.

\section{Cardiac structural adaptations and maladaptations during remodeling} Under chronic pressure overload, compensatory hypertrophy occurs with addition of sarcomeres in parallel, leading to thickening of myocytes without a change in length. Sustained overload leads to the addition of new sarcomeres in 
series, resulting in the dilatation of the ventricles. Also excessive stretch of myocytes can lead to myocyte death, resulting in the deposition of collagen (fibrosis) in heart failure (6). 


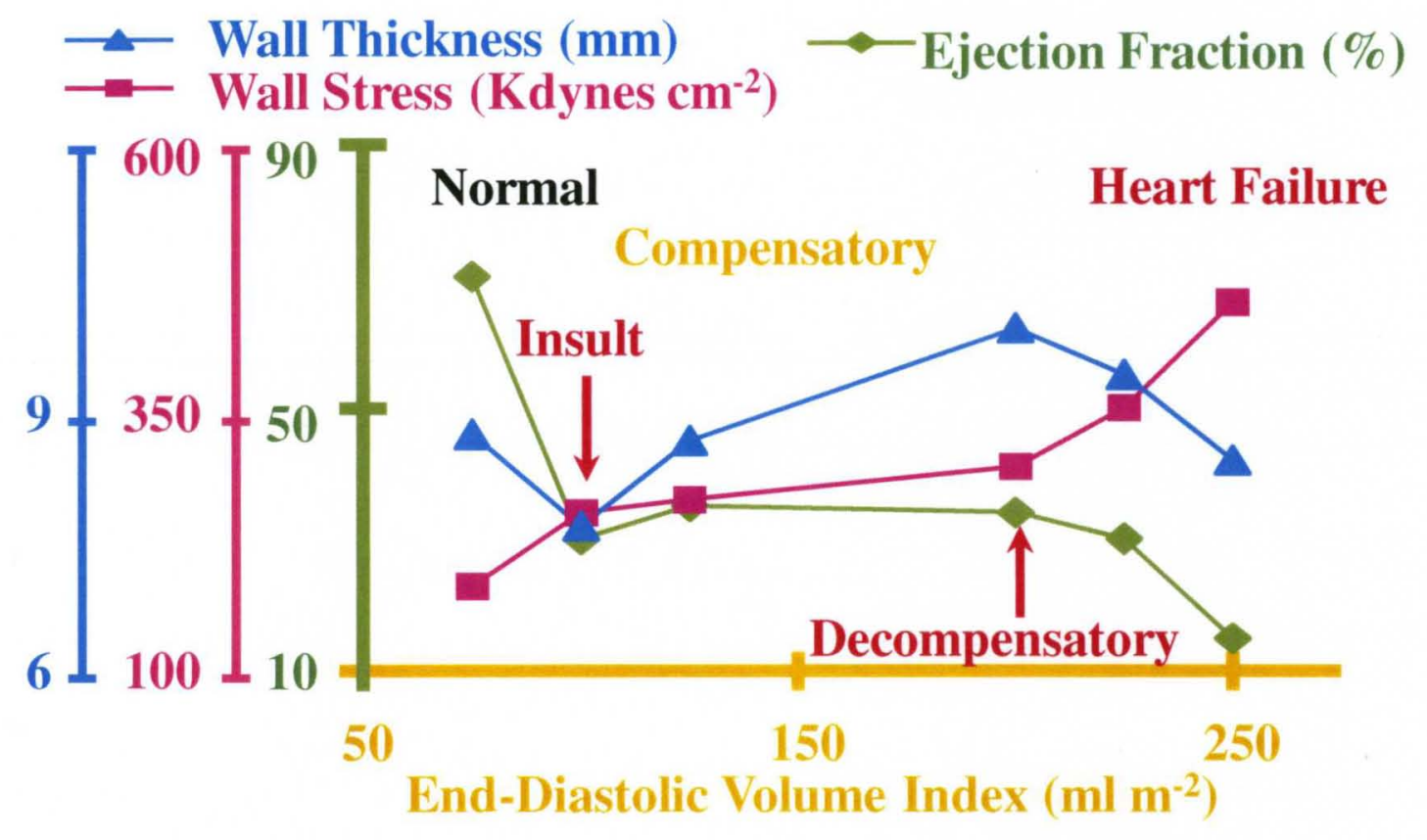

Figure 7: Morphological and functional changes during progression of heart failure: clinical study by Pouler HG et al., (1993) showing the morphological and functional changes associated with progression of heart failure. During the compensatory period, the wall thickness gradually increases while the wall stress and ejection fraction remain constant, whereas during decompensatory stage the wall thickness and ejection fraction decrease while the wall stress increases. 


\section{c) Extracellular matrix}

Cardiac extracellular matrix (ECM) is the collagenous structural foundation which entangles cardiac myocytes, vascular smooth muscle cells and endothelial cells to form a network in the heart. In the myocardium, cellular structures are connected to ECM through integrins which provide a physical connection between the cell surface and surrounding proteins in the matrix (Figure 8) (1819). The main components of myocardial ECM are type I and type III collagen, which provide the structural integrity of the heart. Abnormal turnover of collagen results in interstitial and perivascular fibrosis, leading to stiffening of the ventricle (20-21).

It has been identified that not only the poor contractile nature of myocytes but also the disturbance in the ECM contributes to the pathogenesis of cardiac failure (22-23). Chronic heart failure is characterized by an imbalance in ECM turnover leading to an accumulation of collagen in the myocardium, loss of myocytes, and disruption of collagen fibrils (23-25). Remodeling, by its very nature, implies synthesis and degradation of ECM, leading to alterations in the ECM composition and concentration, but it is the aberrant remodeling in the myocardial ECM that results in heart failure. The integrity of the ECM is regulated by matrix metalloproteinases (MMPs) and their tissue inhibitors called tissue inhibitors of matrix metalloproteinases (TIMPs). 

A) Normal
B) Compensatory Hypertrophy (Pressure overload)
C) Decompensatory heart failure

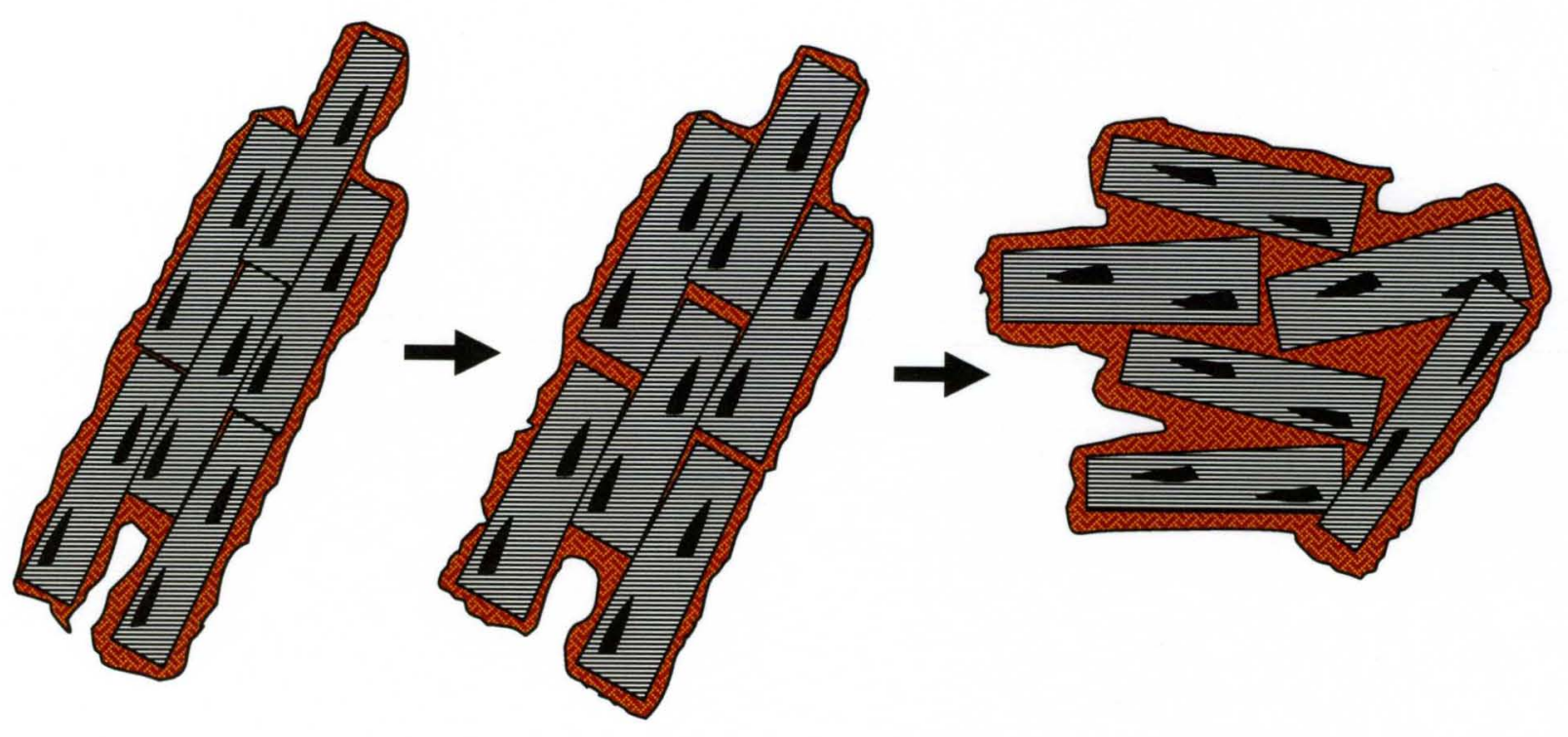

Figure 8: Representation of extracellular matrix remodeling in the pathogenesis of heart failure. A) Normal myocytes with intact matrix B) Hypertrophied myocytes with disrupted matrix and C) Disordered myocytes with excessive interstitial matrix. 


\section{d) Matrix metalloproteinases}

Matrix metalloproteinases (MMPs) were first discovered by Jerome Gross and Charles Lapiere in 1962 who observed the enzymatic activity in tadpole tail metamorphosis (26). MMPs are calcium and zinc dependent extracellular endopeptidases which are synthesized as inactive pro enzymes that need to be activated either by auto proteolysis or by another MMP or serine proteases (23). To date nearly $30 \mathrm{MMPs}$ have been identified and are mainly classified as collagenases, gelatinases, stromelysins, and membrane type (Figure 9) $(23,27-$ 28). Collectively MMPs can process and degrade all components of extracellular matrix (29-30).

Tyagi and colleagues have demonstrated that myocardial latent MMPs can be activated by oxidative stress during heart failure (31). MMPs associated with myocardial remodeling are, a) Collagenases: MMP-1 and MMP-13, b) stromelysins: MMP-3, c) gelatinases: MMP-2 and MMP-9 and d) membrane type matrix metalloproteinase: MMP-14 (Table 1) $(23,32)$. Rodents lack MMP-1, however, MMP-13 replaces its function and degrades collagen types I, II, and III (33). MMP-14 cleaves fibronectin, gelatin, and laminin-1 (34). MMP-2 and -9, degrade collagen types I, IV, V. MMP-2 also cleaves collagen type III fragments (35-36). MMPs act not only on ECM proteins but also on various cytokines and growth factors. MMPs also influence cell proliferation, migration, differentiation during embryogenesis, angiogenesis, and apoptosis. They are also involved in

host defense as well as tissue remodeling (37-40). MMPs play a role in 
regulation of angiogenesis by altering the balance between angiogenic and antiangiogenic factors (41-43).

Brooks and colleagues report that an angiogenic stimulus induces vascular remodeling and defines the role of MMP-2 and integrin ( $a v \beta 3)(44-45)$. During hypertrophic remodeling and angiogenesis, MMP-2 is constitutively expressed $(41,46)$. Alternatively, MMP-9 is expressed in heart failure and induces the expression of anti-angiogenic factors, endostatin and angiostatin (41, 47-48). 
A

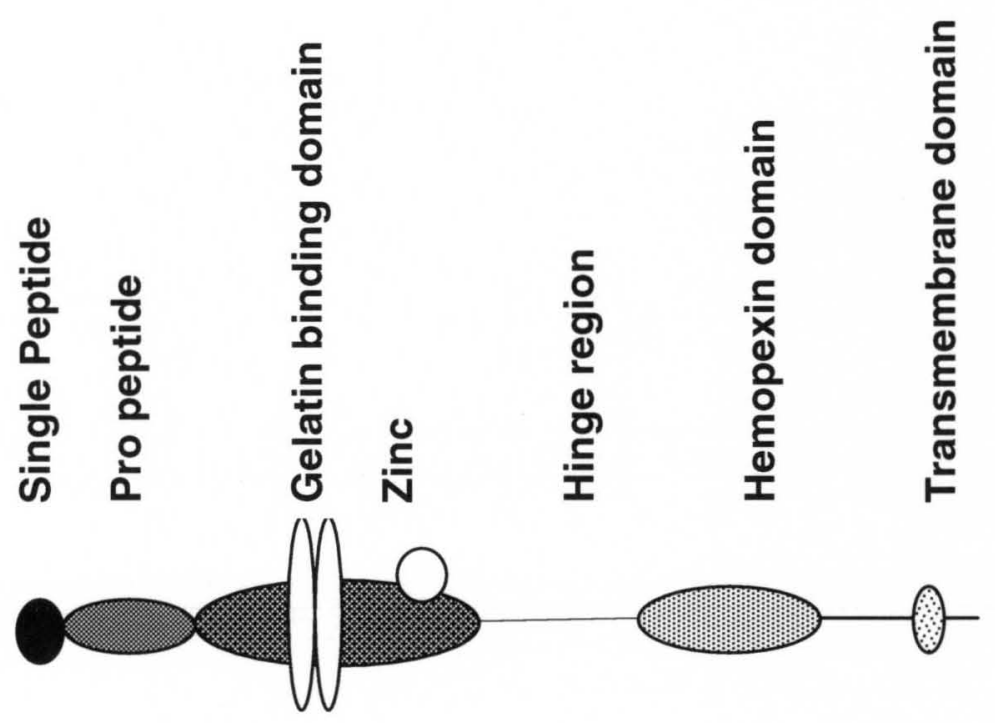

B

Collagenases

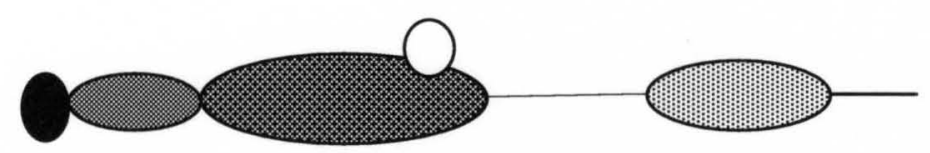

Gelatinases

Stromelysins

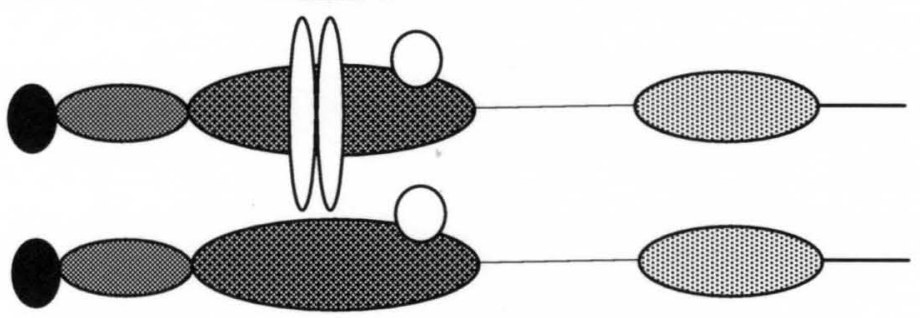

Membrane type MMPs
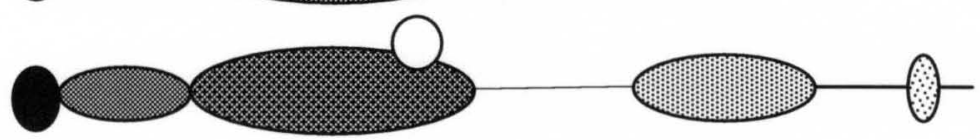

Figure 9: A Basic domain structure of Matrix metalloproteinase is shown with the three most important domains: single peptide domain, pro peptide domain, and gelatin binding domain. Hemopexin domain plays an important role in substrate binding and interactions with TIMPs (49). B: Basic structural differences between different MMP types. 
Table 1: Major classification of matrix metalloproteinases (MMPs)

\begin{tabular}{|l|l|l|}
\hline MMPs & Cellular source & Role in cardiac pathology \\
\hline $\begin{array}{l}\text { Collagenases } \\
\text { MMP-1,-13 }\end{array}$ & $\begin{array}{l}\text { Fibroblasts,VSMCs, endothelial } \\
\text { cells }\end{array}$ & $\begin{array}{l}\text { Left ventricular systolic } \\
\text { dysfunction }\end{array}$ \\
\hline $\begin{array}{l}\text { Gelatinases } \\
\text { MMP-2 }\end{array}$ & $\begin{array}{l}\text { VSMCs, fibroblasts, } \\
\text { macrophages cardiomyocytes, } \\
\text { VSMCs, neutrophils, fibroblasts, } \\
\text { cardiomyocytes, macrophages }\end{array}$ & $\begin{array}{l}\text { Pro angiogenic, improves } \\
\text { cardiac function } \\
\text { Anti-angiogenic, promotes } \\
\text { collagen deposition and } \\
\text { fibrosis, cardiac dysfunction }\end{array}$ \\
\hline $\begin{array}{l}\text { Stromelysins } \\
\text { MMP-3,-7 }\end{array}$ & $\begin{array}{l}\text { VSMCs,fibroblasts,cardiomyocyt } \\
\text { es and macrophages }\end{array}$ & $\begin{array}{l}\text { MMP-7 increases connexin } \\
\text { processing and promotes } \\
\text { arrhythmia }\end{array}$ \\
\hline $\begin{array}{l}\text { Membrane } \\
\text { type MMPs } \\
\text { MT1- MMP }\end{array}$ & $\begin{array}{l}\text { VSMCs, fibroblasts and } \\
\text { cardiomyocytes }\end{array}$ & $\begin{array}{l}\text { Adverse left ventricular } \\
\text { remodeling and dysfunction }\end{array}$ \\
\hline
\end{tabular}

VSMCs-vascular smooth muscle cells. 


\section{e) Tissue inhibitor of matrix metalloproteinases}

TIMPs are natural endogenous inhibitors of MMPs found in most tissues and body fluids that play an important role in extracellular matrix remodeling. TIMPs are 21-34 kDa proteins possessing 12 conserved cysteine residues. Cysteine residues form six disulfide bonds that fold the protein into two domains (Figure 10). TIMPs inhibit proteolytic activity of MMPs by forming non covalent 1:1 stoechiometric complexes that are resistant to heat and proteolytic degradation (50). In humans, four TIMPs have been described namely, TIMP-1, 2,-3, and -4 . TIMP-1,-2, and -4 are present in soluble forms where as TIMP-3 is tightly bound to the matrix. TIMPs have differential action on matrix metalloproteinases (MMPs) and pro MMPs (51).

TIMPs not only inhibit MMPs but also have the ability to form complexes with proMMPs and regulate the MMP activation process (52-56). TIMPs have a wide variety of actions such as promotion of cell growth, anti-apoptotic activity, steroidegenic activity, anti-angiogenic activity and embryogenic activity. The antiangiogenic activity of TIMPs was first demonstrated in chick embryo yolk sac (51, 57). TIMP-3 exhibits strong anti-angiogenic activity that can be seen in all stages of angiogenesis (58).

TIMPs in cardiac remodeling

TIMPs have cellular actions that are independent of MMP inhibition. Studies report that the inhibitory actions of TIMP-1 to -3 on endothelial cell migration and/or angiogenesis in response to VEGF stimulation, is independent 
of MMP inhibition (59). TIMPs induce proliferation of cardiac fibroblasts, which play an important role in cardiac remodeling. TIMP-3 shows differential action on cardiac fibroblasts depending on the time and localization of its expression after tissue injury. Table 2 summarizes the role of TIMPs during cardiac remodeling (60). 


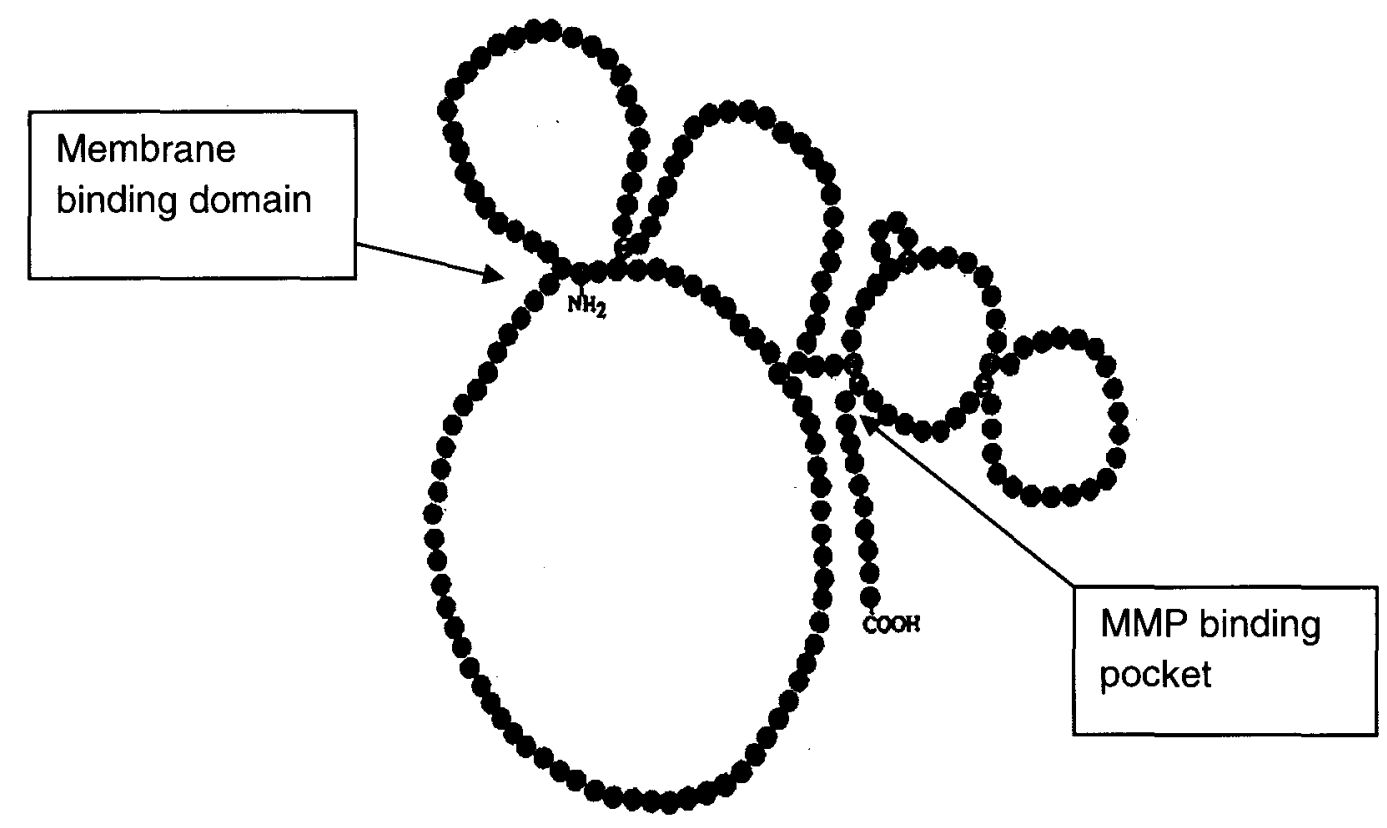

Figure 10: Tertiary structure of Tissue inhibitor of Matrix metalloproteinase (TIMP). Cysteines are linked to form six disulfide bridges 
Table 2: Classification of tissue inhibitor of matrix metalloproteinases (TIMPs)

\begin{tabular}{|l|l|l|}
\hline TIMPs & Cellular source & Role in cardiac pathology \\
\hline TIMP-1 & $\begin{array}{l}\text { VSMC, EC, cardiomyocytes } \\
\text { fibroblasts and macrophages }\end{array}$ & $\begin{array}{l}\text { Induces fibrosis, inhibits all } \\
\text { MMPs except MMP-2 and MT1- } \\
\text { MMP }\end{array}$ \\
\hline TIMP-2 & $\begin{array}{l}\text { VSMC, EC, cardiomyocytes } \\
\text { fibroblasts and macrophages }\end{array}$ & $\begin{array}{l}\text { Induces cell proliferation, } \\
\text { inhibits all MMPs except MMP- } \\
9, \text { activates pro MMP-2 }\end{array}$ \\
\hline TIMP-3 & $\begin{array}{l}\text { Cardiomyocytes,VSMC, } \\
\text { fibroblasts }\end{array}$ & $\begin{array}{l}\text { Induced apoptosis, anti- } \\
\text { angiogenic. Inhibits MMP-1,-2, } \\
-13\end{array}$ \\
\hline TIMP-4 & $\begin{array}{l}\text { VSMC,fibroblasts, } \\
\text { cardiomyocytes }\end{array}$ & $\begin{array}{l}\text { Cardiac specific and induce } \\
\text { apoptosis in transformed cells. } \\
\text { Inhibits MMP-1,-3,-9. }\end{array}$ \\
\hline
\end{tabular}

VSMC-vascular smooth muscle cell; EC-endothelial cell; MT1-MMP- membrane type matrix metalloproteinase. 


\section{f) Angiogenesis}

The sprouting of new capillaries from the existing blood vessels defines angiogenesis (61-62). It occurs in hypoxic areas and in areas with high metabolic demand and low perfusion. In hypoxic tissue, the initiation of angiogenesis arises from the production of angiogenic factors which upon binding with the receptors on the endothelial surface cause endothelial cell activation. Further proliferation and migration of activated cells into the surrounding matrix along with the degradation of ECM by MMPs allow formation of tubular outgrowths from the preexisting blood vessels. Finally, smooth muscle cells and pericytes stabilize these newly formed tubular structures to form a complete vascular structure (Figure 12) (63). As new capillaries sprout and increase in density, the distance between the adjacent vessels decrease causing increased diffusion, restoring oxygen and nutrient supply to the hypoxic tissue (62). The term "angiogenic switch" was introduced for a better representation of the initiation of angiogenesis depending on the availability of promoting factors and inhibiting factors (Figure 11) (64).

Under normal physiological conditions, the regulation of angiogenesis occurs by a fine balance between growth promoting and inhibitory factors. An imbalance in these factors can result in increased angiogenesis as seen in cancer, or decreased angiogenesis as seen in myocardial ischemia or coronary artery disease. Previous studies demonstrate that the therapeutic angiogenesis using growth promoting factors can increase blood supply to the ischemic myocardium (65-67). Studies in cardiac specific inducible protein kinase B (AKT- 
1) transgenic mice show decreased angiogenesis during pathological remodeling and report that both heart size and cardiac function are angiogenesis dependent. The study further reported that the disruption of coordinated cardiac hypertrophy and angiogenesis plays a role in the pathogenesis of heart failure (68). 
A

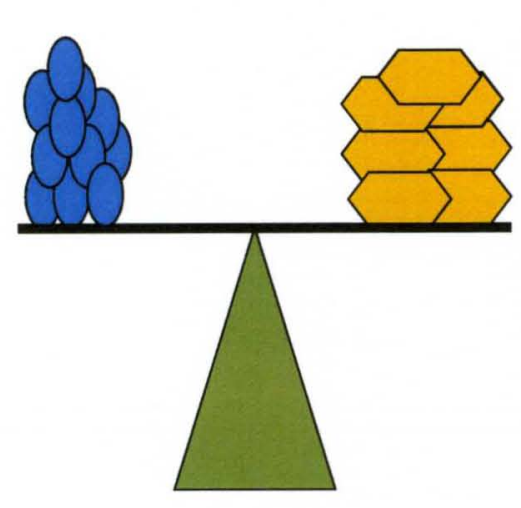

B

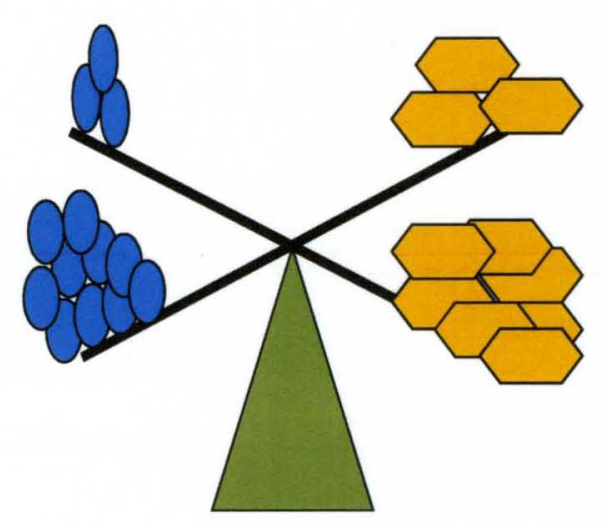

ON

】

ANGIOGENIC

SWITCH

OFF
PRO ANGIOGENIC FACTORS

VEGF, bFGF

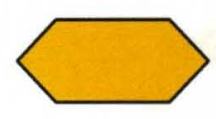

ANTI-ANGIOGENIC FACTORS ENDOSTATIN, ANGIOSTATIN

Figure 11: Representation of "angiogenic switch" mechanism. Under physiological conditions a balance exists between angiogenic and anti angiogenic factors ensuring normal angiogenesis (A). An imbalance in these factors results in the angiogenic switch turning 'ON' or 'OFF' (B). 


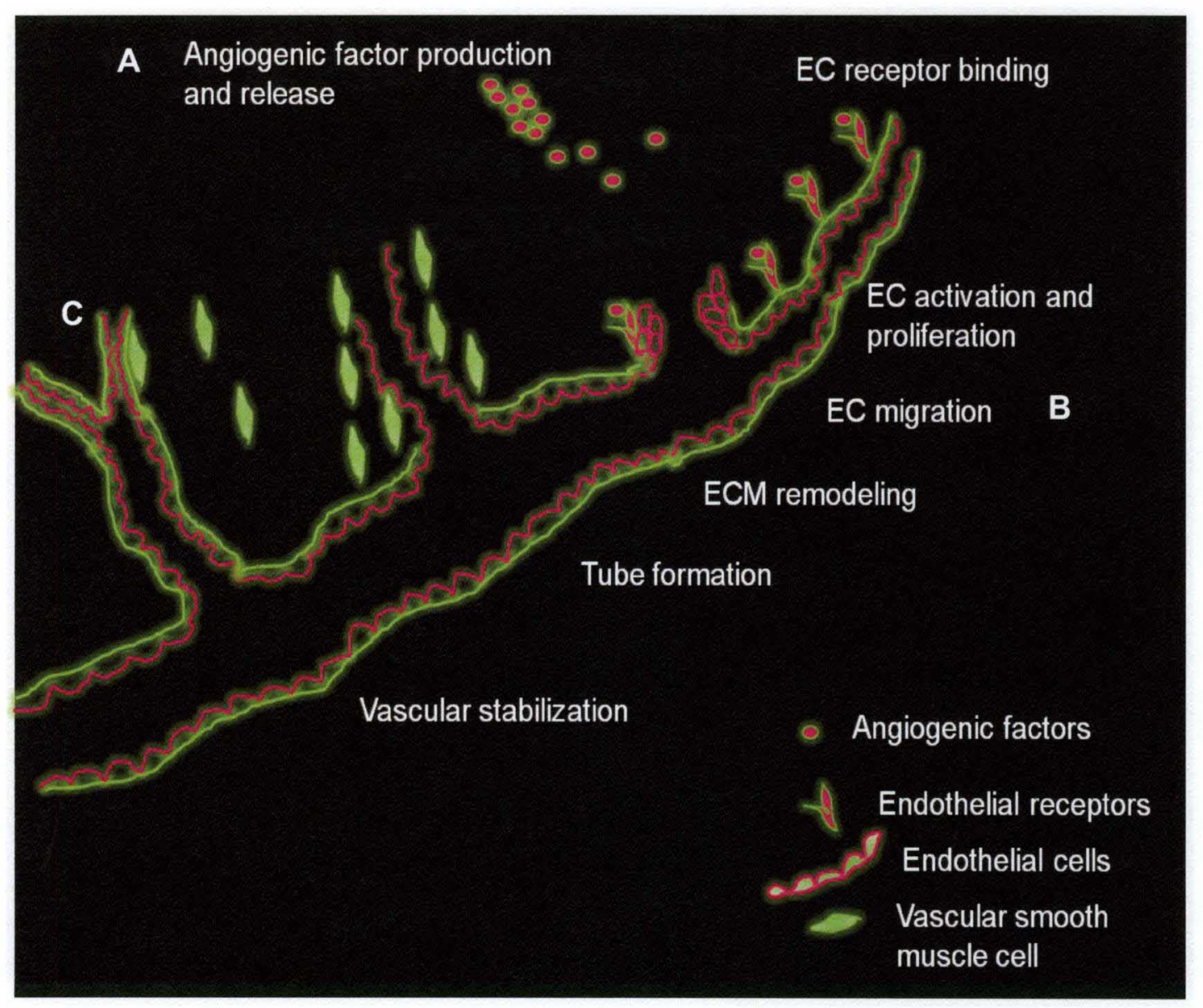

Figure 12: Schematic representation of the mechanism of angiogenesis. A) Angiogenic factors produced during hypoxia bind to the receptors on the endothelial cells activating them. B) Proliferation and migration of activated cells to form tube like structures. C) Smooth muscle cells provide structural support to these structures and thus stabilizing them into new functional blood vessel. 


\section{g) Angiogenic growth factors}

During hypoxia, transcription factors such as hypoxia-inducible factor (HIF-1) promote the synthesis of angiogenic growth factors (Table 3). Among these factors, vascular endothelial growth factor (VEGF) is a highly potent stimulator of capillary formation in vivo and has direct mitogenic actions on endothelial cells $(62-63,69-70)$.

VEGF was first described in 1983 as a vascular permeability factor, which is secreted by tumor cells and induces vascular permeability (71). In 1989, cDNA cloning established that both vascular permeability factor and VEGF were the same molecule $(70,72)$. The up-regulation of VEGF mRNA during hypoxia shows that its production is induced to recruit blood vessels in ischemic tissue (73-74). VEGF binds to its receptors on the vascular endothelial cell surface. Tyrosine kinase receptors, Flt-1 and Flk-1 known as VEGF receptor-1 (VEGFR1) and VEGF receptor-2 (VEGFR-2) respectively, have strong affinity for the VEGF molecule (75-77).

In the literature five types of VEGF are described, of which, VEGF-A is the key regulator of angiogenesis, VEGF-C and VEGF-D regulate lymphangiogenesis (Figure 13) (74, 78-79). During myocardial ischemia, administration of angiogenic growth factor VEGF into the perivascular or intracoronary areas improves coronary collateral flow in animal models (80). 
Table 3: Promoters and inhibitors of angiogenesis

\begin{tabular}{|c|c|}
\hline Endogenous angiogenic growth factors & Endogenous inhibitors of angiogenesis \\
\hline $\begin{array}{l}\text { Vascular endothelial growth factor } \\
\text { (VEGF) Angiogenin } \\
\text { Angiopoietin-1 } \\
\text { Fibroblast growth factors: } \\
\text {-acidic (aFGF) } \\
\text {-basic (bFGF) } \\
\text { Follistatin } \\
\text { Hepatocyte growth factor (HGF) } \\
\text { Interleukin-8 (IL-8) } \\
\text { Placental growth factor } \\
\text { Platelet-derived endothelial cell growth } \\
\text { factor (PD-ECGF) } \\
\text { Platelet-derived growth factor-BB } \\
\text { (PDGF-BB) } \\
\text { Pleiotrophin (PTN) } \\
\text { Progranulin } \\
\text { Proliferin } \\
\text { Transforming growth factor-alpha } \\
\text { (TGF-alpha) } \\
\text { Transforming growth factor-beta (TGF- } \\
\text { beta) } \\
\text { Tumor necrosis factor-alpha (TNF- } \\
\text { alpha) }\end{array}$ & $\begin{array}{l}\text { MATRIX DERIVED: } \\
\text { Endostatin } \\
\text { Arresten } \\
\text { Thrombospondin-1and-2 } \\
\text { Tumstatin } \\
\text { Canstatin } \\
\text { Fibulin } \\
\text { NON-MATRIX DERIVED: } \\
\text { Angiostatin } \\
\text { Parstatin } \\
\text { Anti thrombin-III } \\
\text { Interferons } \\
\text { Interleukins } \\
\text { Platelet factor } 4 \\
\\
\text { OTHERS: } \\
\text { Tissue inhibitor of MMPs (TIMP) } \\
\text { Prolactin fragments } \\
\text { Chondromodulin } \\
\text { Troponin-I } \\
\text { Vasostatin }\end{array}$ \\
\hline
\end{tabular}




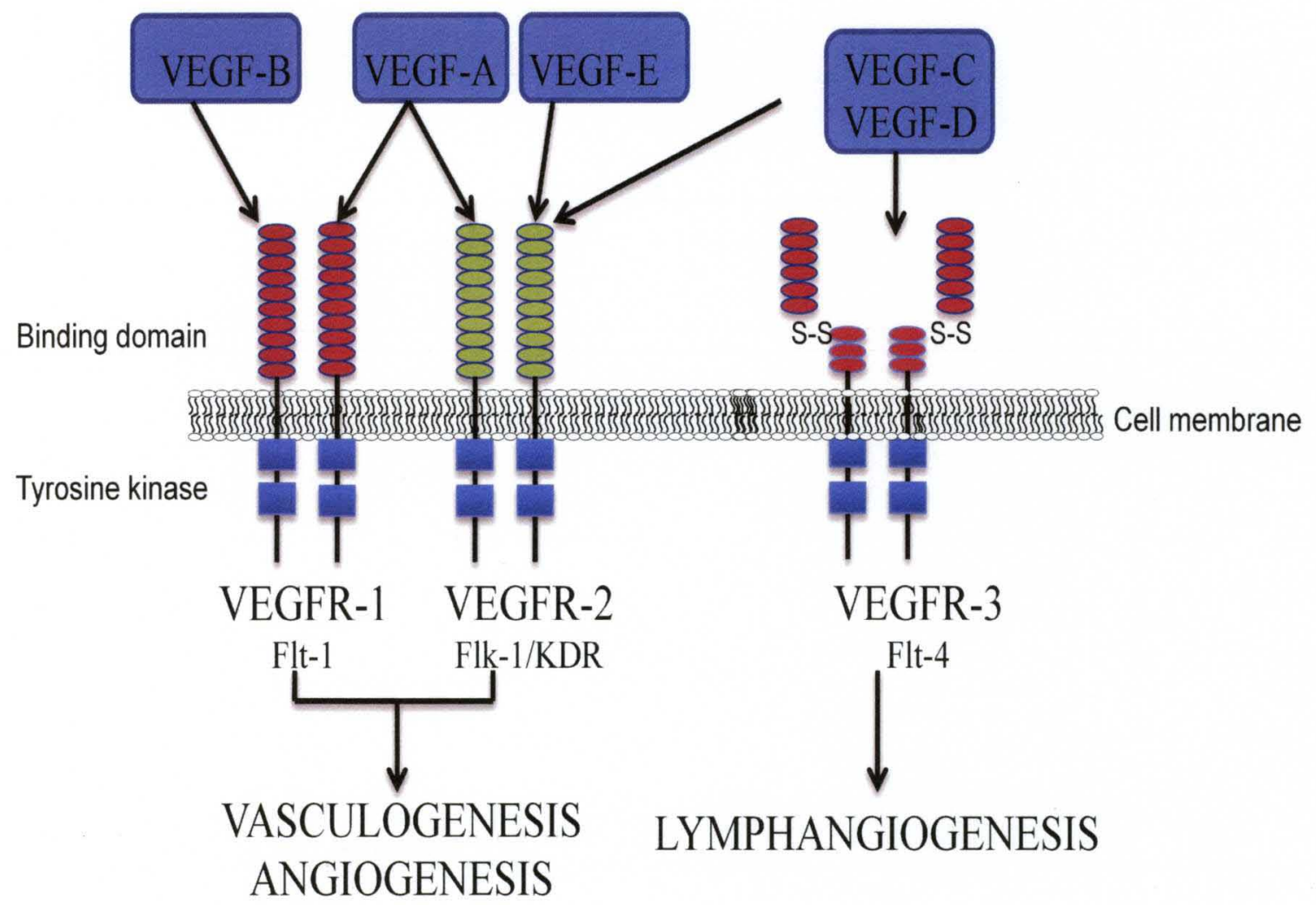

Figure 13: Downstream effects of vascular endothelial growth factors (VEGF) following binding to their corresponding receptors (VEGFR). 


\section{h) Anti-angiogenic factors}

Anti-angiogenic factors are naturally produced as endogenous proteins, embedded in the matrix. Their release from the matrix regulate angiogenesis under physiological conditions (81). Endogenous angiogenic inhibitors are released by the action of MMPs and serine proteinases on ECM and vascular basement membrane (82). Although most of the angiogenic inhibitors are matrix derived, some are also fragments of ECM metabolites, hormones, clotting factors or proteins synthesized by the immune system $(81,83)$. While anti-angiogenic factors are extensively studied in cancer research, their role in cardiovascular disease is not well known $(41,48)$. Endostatin, arrestin, and tumstatin are some of the angiogenic inhibitors derived from the ECM. Angiostatin, interferons and antithrombin III are non-matrix derived anti-angiogenic factors (83). A list of endogenous anti-angiogenic factors is presented in Table 3.

A recent study reports the relationship between angiostatin, endostatin and coronary collateral formation in which myocardial tissue is harvested from diabetic and nondiabetic coronary artery disease (CAD) patients (48). Results from the study show that the expression of angiostatin and endostatin increases in diabetic CAD patients compared with non-diabetic patients and negatively correlates with coronary collateralization. This data suggest the necessity of new approaches towards pro-angiogenic therapy or inhibition of anti-angiogenic mechanism in heart failure patients. 


\section{Endostatin}

Endostatin, first isolated by O'Reilly in 1997, is a $20-22 \mathrm{kDa}$ C-terminal fragment of collagen type XVIII (Figure 14) (83-84). The direct actions of endostatin include, inhibition of vascular endothelial cell proliferation and migration, apoptosis, and cell cycle arrest at G1 stage of cell division (85-86). Indirectly, endostatin inhibits angiogenesis by blocking MMP-2 activity and preventing the binding of VEGF to its receptor (Figure 15). It also stabilizes cell to cell and cell to matrix adhesions preventing degradation of ECM junctions (8789). Although endostatin is extensively studied in cancer, its role in the pathogenesis of heart failure is not clear. In a study involving coronary heart disease patients, serum levels of endostatin are elevated along with the decreased coronary collateral formation (90). These results suggest that endostatin might play an important role in decreasing angiogenesis during decompensatory heart failure. 


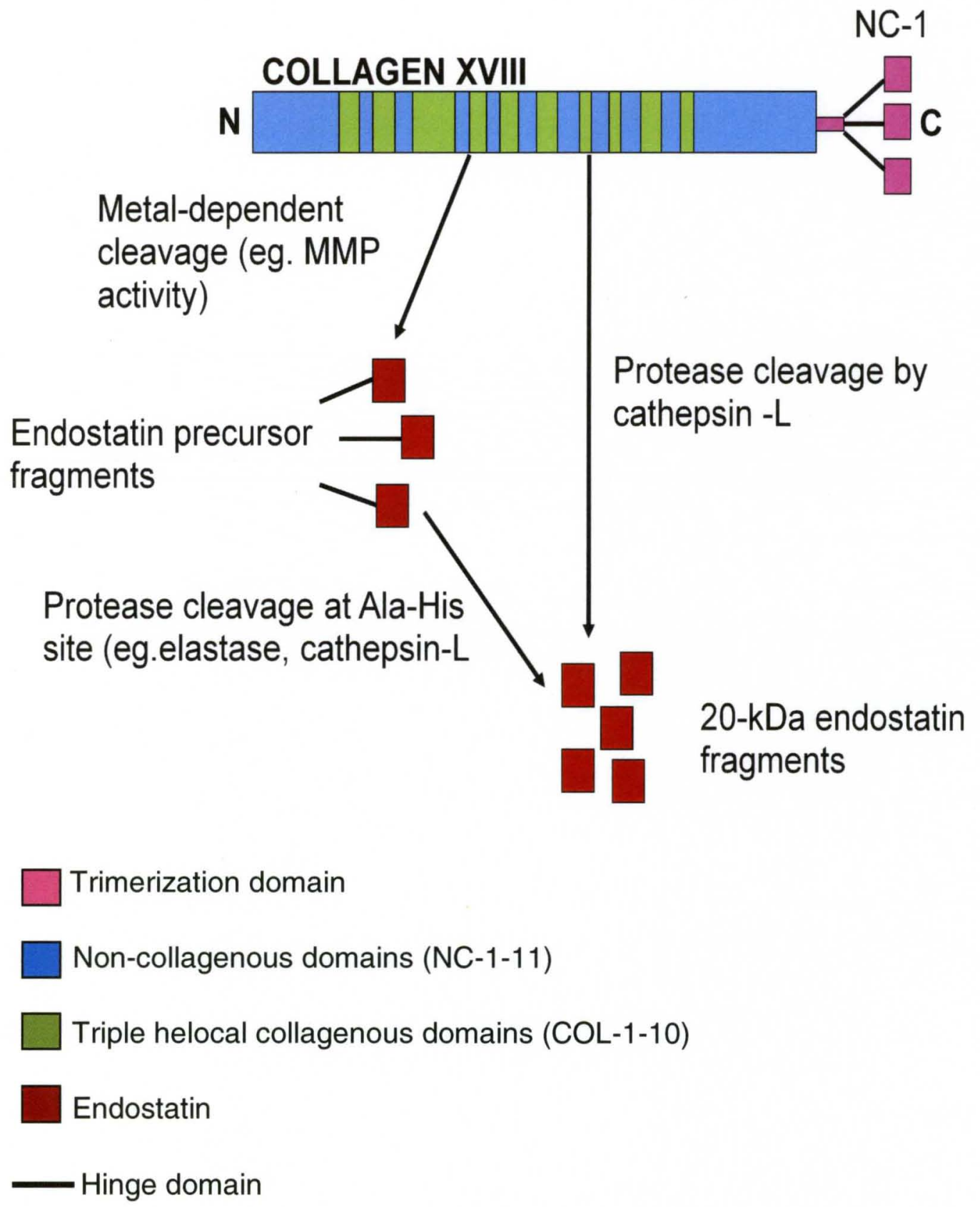

Figure 14: Formation of endostatin fragments from collagen XVIII by metaldependent cleavage, elastase and protease cleavage by cathepsin-L. 


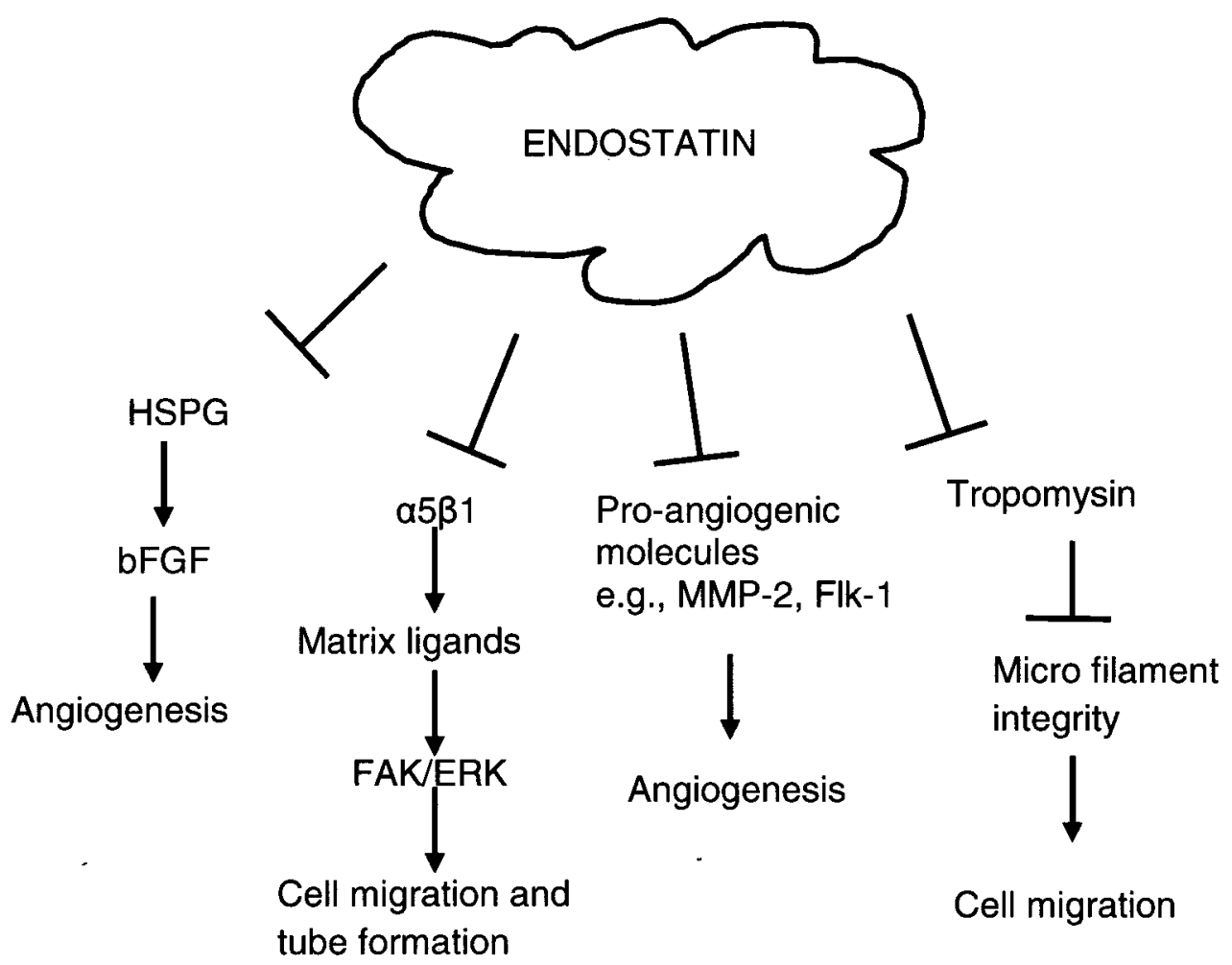

Figure 15: Mechanism of inhibition of angiogenesis by endostatin.

HSPG-heperan sulfate proteoglycans; b FGF- fibroblast growth factor; $\alpha 5 \beta 1$ integrin; Flk-1-VEGF receptor; FAK-focal adhesion kinase; ERK-extracellular signal regulated kinase. 


\section{Angiostatin}

Angiostatin is a proteolytic fragment of plasminogen, released by the action of matrix metalloproteinases. It is a $38 \mathrm{kDa}$ endogenous polypeptide that has inhibitory action on angiogenesis. It was first discovered by O'Reilly and colleagues in 1994 (91) and its structure consists of four Kringle domains (K1-4) (Figure 16) (92-93). Angiostatin inhibits angiogenesis by blocking the proliferation and migration of endothelial cells (Figure 17). The inhibitory action of angiostatin occurs through several mechanisms- a) blocking the integrins and angiomotin, preventing endothelial cell migration, b) binding to the $\alpha$ and $\beta$ subunits of ATP synthase, reducing energy resources (93), c) blocking the actions of VEGF and bFGF on the vascular endothelial cells, and d) inhibiting the proliferation of vascular endothelial cells (VECs) by arresting mitosis at G2M transition (93-95). Angiostatin also promotes apoptosis of VECs by increasing the tyrosine kinase activity of focal adhesion kinase (FAK) (96). Yamahara et al., report elevated levels of angiostatin as well as MMP-9 activity, in the serum of heart failure patients (97). Their results suggest that angiostatin plays a pathological role in the progression of heart failure. 


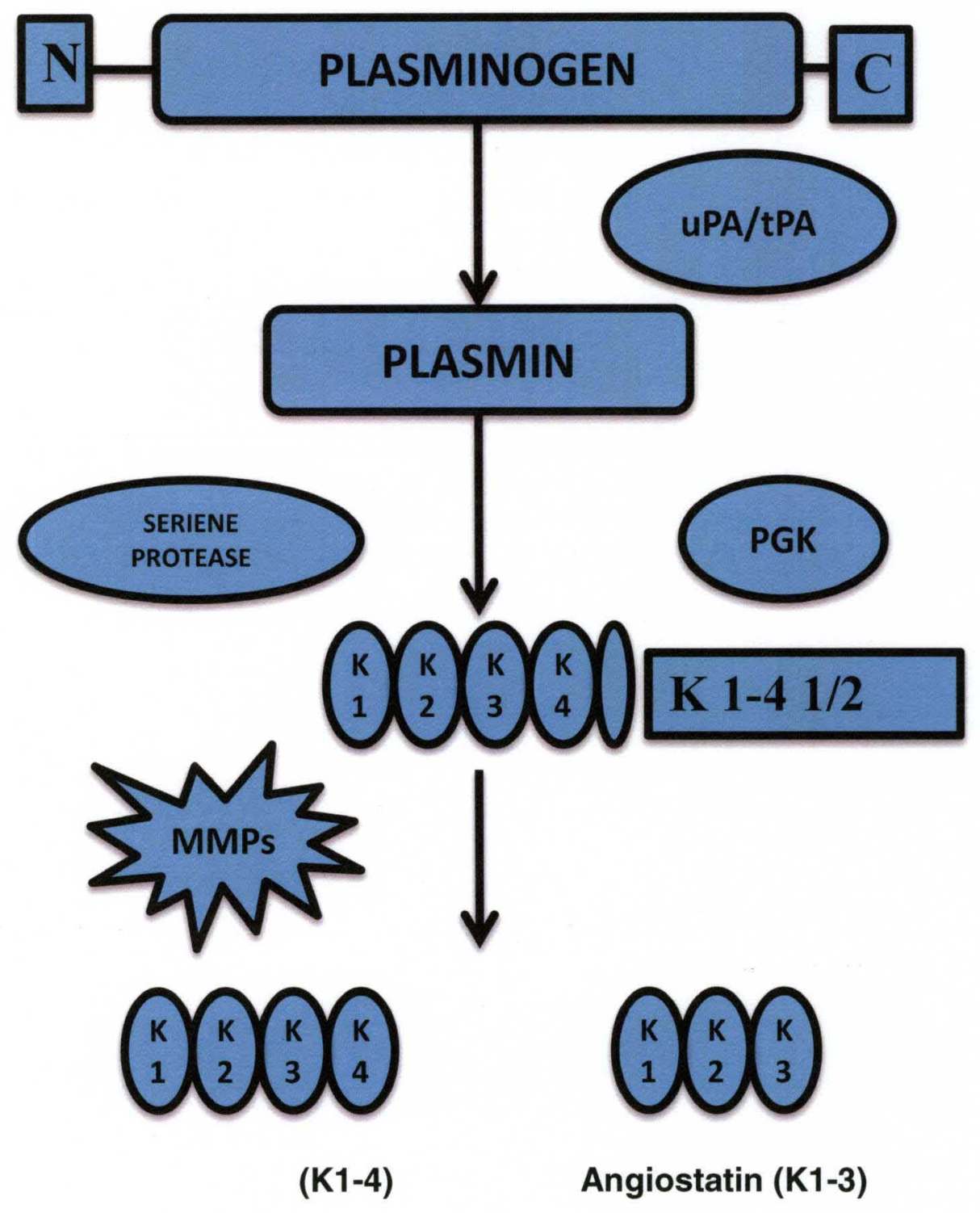

Figure 16: Formation of angiostatin from plasminogen (98). tPA- tissue plasminogen activator; uPA- urikinase plasminogen activator; PGKphosphoglycerate kinase; K-Kringle domains of plasminogen. 


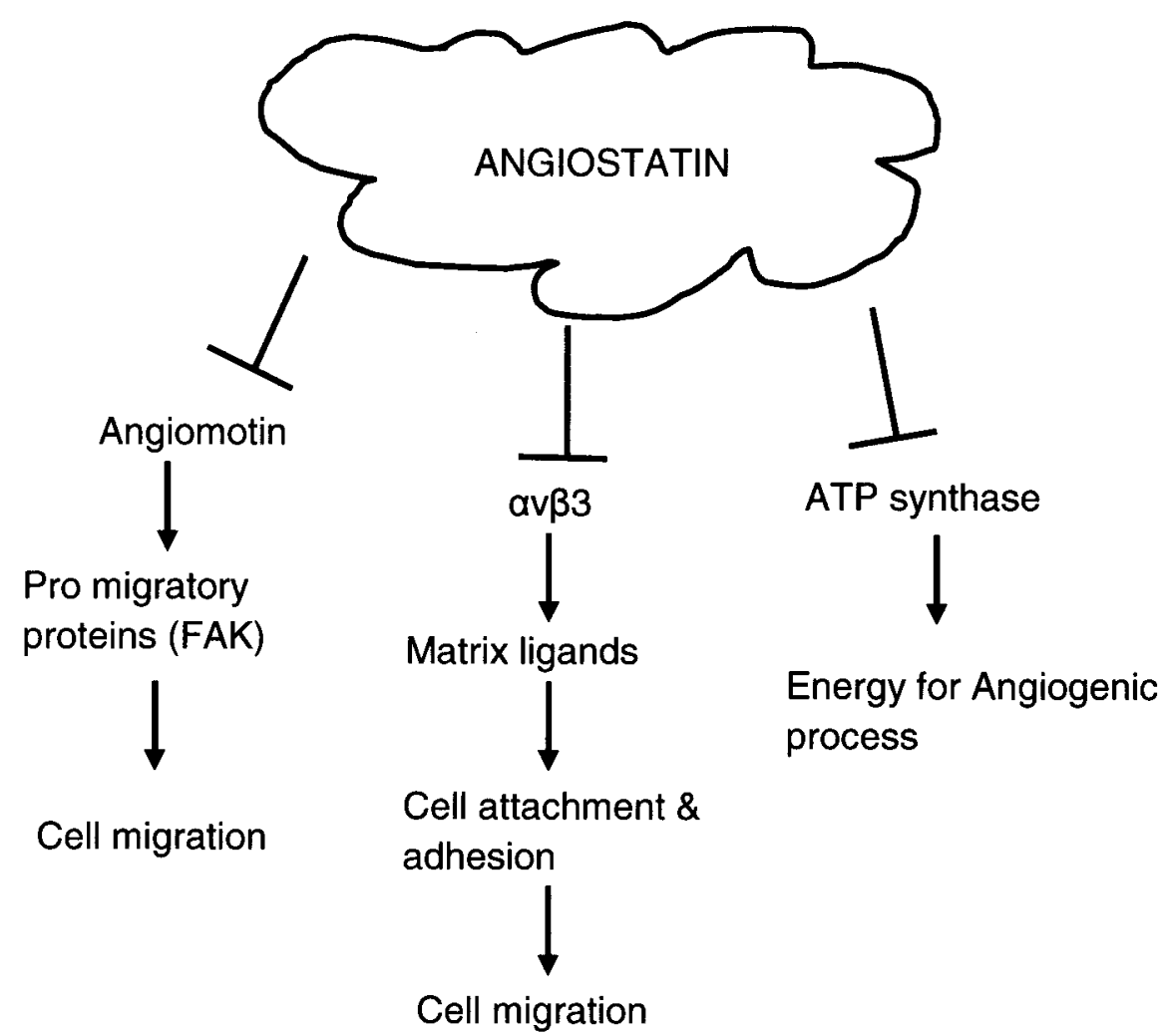

Figure 17: Mechanism of action of Angiostatin. $\alpha \vee \beta 3$ - integrin. 


\section{i) Hydrogen sulfide}

Although hydrogen sulfide $\left(\mathrm{H}_{2} \mathrm{~S}\right)$ was considered as a toxic gas with rotten egg smell, it has been recently recognized as a novel endogenous gaseous transmitter similar to nitric oxide (NO) and carbon monoxide (CO). $\mathrm{H}_{2} \mathrm{~S}$ exerts various beneficial actions in the cardiovascular system (99-102). These three gaseous transmitters effectively dilate blood vessels through different mechanisms (Figure 18). $\mathrm{H}_{2} \mathrm{~S}$ is an emerging gaseous transmitter of interest due to its protective role in brain, kidney, gastro intestinal tract, and more importantly, the cardiovascular system. $\mathrm{H}_{2} \mathrm{~S}$ is endogenously generated by pyridoxal-5' phosphate dependent enzymes cystathione $\beta$ synthase (CBS) and cystathione $Y$ lyase (CSE) using L-cysteine as a substrate (103). CBS is highly expressed in the brain whereas CSE is mostly found in the vasculature (104-105). A defect in $\mathrm{CSE} / \mathrm{H}_{2} \mathrm{~S}$ pathway is associated with many cardiovascular diseases suggesting its importance in physiological functions (106-111).

Under physiological concentration, $\mathrm{H}_{2} \mathrm{~S}$ exerts its cardioprotective effect by opening ATP sensitive potassium channels ( $\mathrm{K}_{\text {ATP }}$ channels) in vascular smooth muscle cells and as well as in the myocardium (107). The heart is considered to be one of the major sources of endogenous hydrogen sulfide, based on mRNA expression of CSE and amount of $\mathrm{H}_{2} \mathrm{~S}$ generated (108). CSE knockout mice are profoundly hypertensive, indicating the vasodilatory role of $\mathrm{H}_{2} \mathrm{~S}$ (112). Besides vasorelaxation, $\mathrm{H}_{2} \mathrm{~S}$ promotes vascular endothelial cell related angiogenesis both invitro and invivo. This action is based on opening of $\mathrm{K}_{\mathrm{ATP}}$ channels that in turn 
activate mitogen activated protein kinase (MAPK) pathway and AKT phosphorylation (113).

The vasoprotective role of $\mathrm{H}_{2} \mathrm{~S}$ is demonstrated in spontaneously hypertensive rats (SHR), by daily administration of sodium hydrosulfide (NaHS), a $\mathrm{H}_{2} \mathrm{~S}$ donor, for 8 weeks (114). A significant reduction, in blood pressure, hypertrophy of intramyocardial arterioles, and ventricular fibrosis is observed with NaHS treatment (114). In addition, supplementation of $\mathrm{H}_{2} \mathrm{~S}$ shows cardio protective effects in animal models of ischemia and myocardial infarction (115116). Based on these findings, we sought to examine the therapeutic effects of $\mathrm{H}_{2} \mathrm{~S}$ during the transition from compensatory cardiac hypertrophy to heart failure. 


\section{Endothelial Cell}

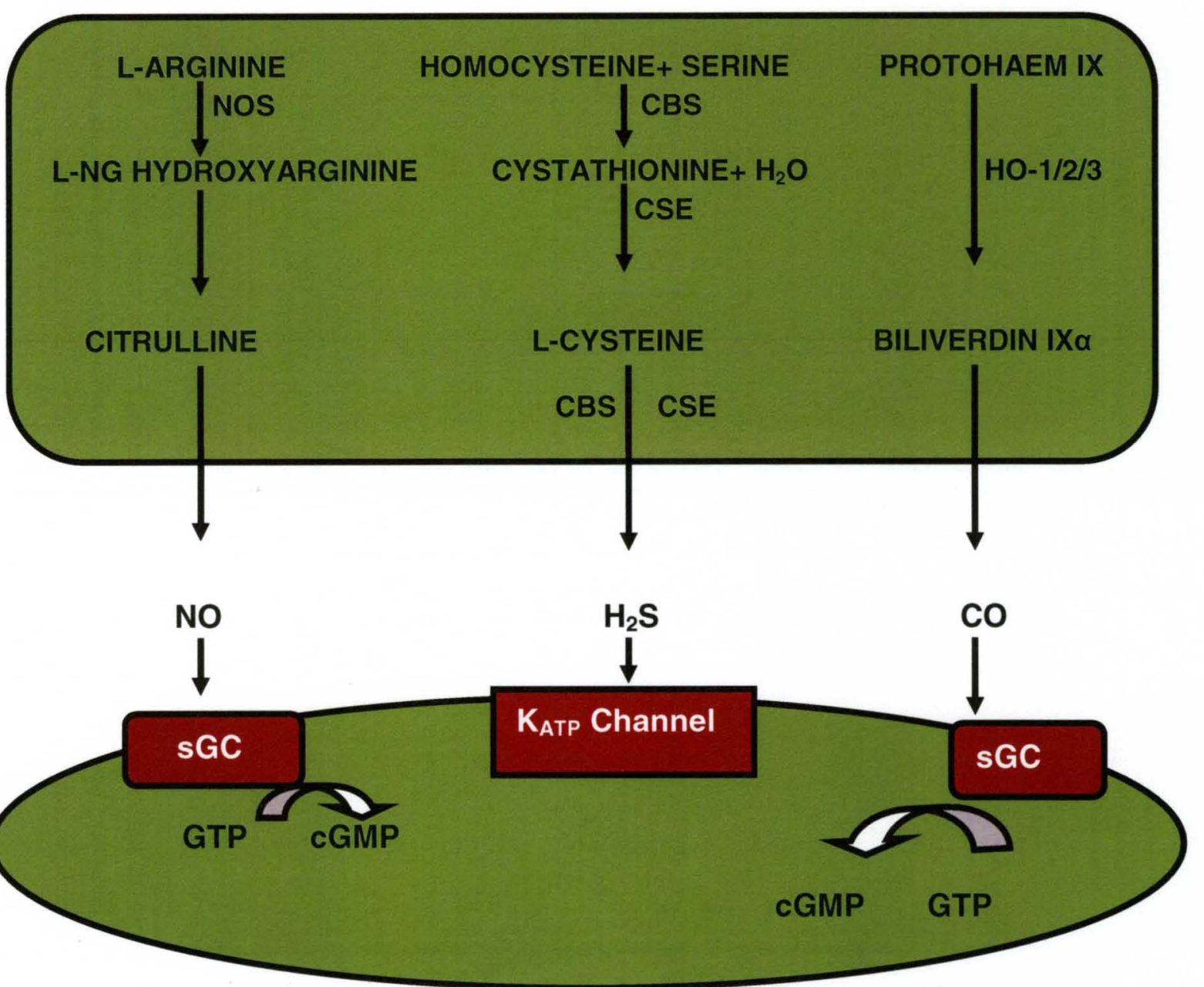

Smooth muscle cell relaxation

Figure 18: Mechanism of action of endogenous gaseous transmitters-nitric oxide (NO), hydrogen sulfide $\left(\mathrm{H}_{2} \mathrm{~S}\right)$ and carbon monoxide $(\mathrm{CO})$. All three gases cause vasorelaxation but by different mechanism of action. NO and $\mathrm{CO}$ act by activation of soluble guanylyl cyclase ( $\mathrm{sGC}$ ) and $\mathrm{H}_{2} \mathrm{~S}$ acts by opening of potassium ATP sensitive ( $\mathrm{K}_{\mathrm{ATP}}$ ) channels. CBS-cystathionine $\beta$ synthase; NOSnitric oxide synthase; CSE-cystathionine y lyase; HO-1/2/3-heme oxygenase1/2/3; GTP-guanosine triphosphate; cGMP-cyclic guanosine monophosphate. 


\section{CHAPTER III}

\section{HYPOTHESIS}

OVERALL HYPOTHESIS: Chronic pressure overload instigates compensatory cardiac hypertrophy, matrix remodeling (fibrosis), and increase in angiogenic growth factors. Persistent overload leads to an increase in anti-angiogenic factors resulting in decompensatory heart failure. Treatment with $\mathrm{H}_{2} \mathrm{~S}$ mitigates the transition from compensatory hypertrophy to decompensatory heart failure by increasing angiogenesis and decreasing fibrosis.

\section{Specific aims:}

Hypothesis 1: A chronic increase in pressure overload induces MMP-2, which in turn, induces the release of angiogenic growth factors during the compensatory hypertrophy phase, while MMP-9/TIMP-3 releases anti-angiogenic factors during decompensatory heart failure phase.

Aim 1: To determine whether chronic pressure overload induces MMP-2, which induces the release of angiogenic growth factors during compensatory cardiac hypertrophy.

Aim 2: To determine whether MMP-9/TIMP-3 are induced during decompensatory heart failure and these in turn, induce the release of anti- 
angiogenic factors angiostatin and endostatin, during decompensatory heart failure.

In chapter IV, experiments associated with Aims 1 and 2 are presented.

Hypothesis 2: Treatment with $\mathrm{H}_{2} \mathrm{~S}$, during chronic pressure overload induces MMP-2 expression and inhibits MMP-9/TIMP-3 thereby, promoting angiogenesis which mitigates the transition from compensatory cardiac hypertrophy to heart failure.

Aim 3: To determine whether the $\mathrm{H}_{2} \mathrm{~S}$ induces MMP-2 expression and promotes the release of angiogenic growth factors, leading to angiogenesis.

Aim 4: To determine whether the $\mathrm{H}_{2} \mathrm{~S}$ inhibits MMP-9/TIMP-3 expression and blocks the release of anti-angiogenic factors, leading to a decrease in fibrosis.

In chapter $\mathrm{V}$, experiments associated with Aims 3 and 4 are presented. 


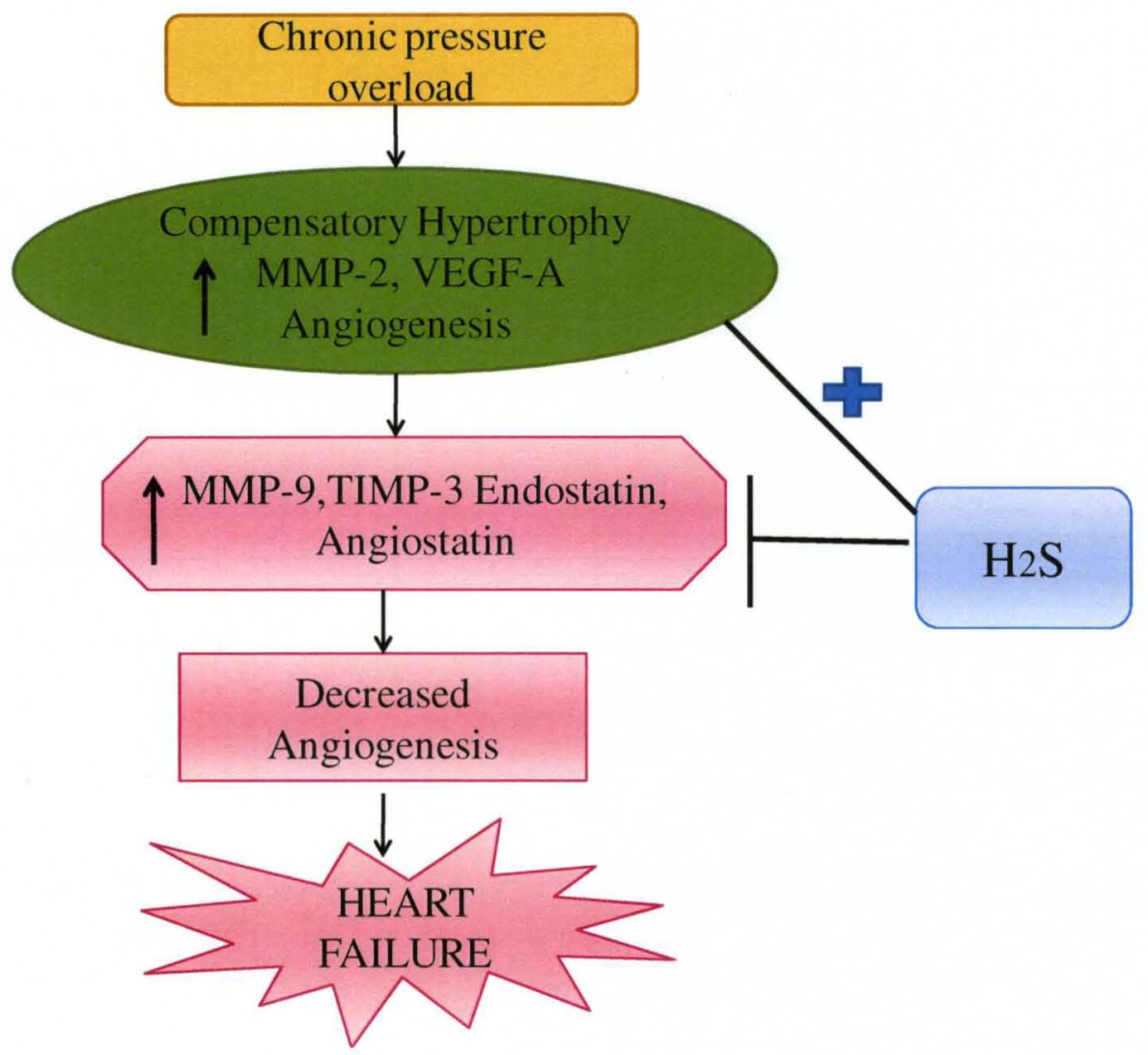

Figure 19: Hypothetical representation of pressure overload heart failure and intervention by hydrogen sulfide. MMP-matrix metalloproteinase, TIMP-tissue inhibitor of matrixmetalloproteinase, VEGF-vascular endothelial growth factor, $\mathrm{H}_{2} \mathrm{~S}$-hydrogen sulfide. 


\section{ANIMAL GROUPS}

\begin{tabular}{|l|l|l|}
\hline & CONTROL & H2S \\
\hline SHAM & $\mathrm{N}=15$ & $\mathrm{~N}=9$ \\
\hline AB 3 weeks & $\mathrm{N}=12$ & $\mathrm{~N}=8$ \\
\hline AB 8 weeks & & $\mathrm{N}=8$ \\
\hline
\end{tabular}

Table 4 : Experimental animal groups used for the study. 


\section{CHAPTER IV}

\section{MECHANISM OF TRANSITION FROM CARDIAC HYPERTROPHY TO HEART FAILURE}

The primary causes of heart failure are myocardial infarction, ischemia, and chronic pressure overload (i.e. systemic hypertension and valvular diseases). To overcome the initial stress, the heart undergoes compensatory hypertrophy and left ventricular remodeling (117). However, if the overload is sustained it results in decompensation and end-stage heart failure (118). During cardiac hypertrophy, there is an imbalance in the ratio of capillary bed to the cardiomyocytes, resulting in hypoxia, which increases the hypoxia-inducible factors (119). The hypoxia inducible factors stimulate the release of proangiogenic factors, such as vascular endothelial growth factor (VEGF) (120-121). VEGF is a highly potent angiogenic factor that promotes endothelial cell proliferation, migration, extracellular matrix $(\mathrm{ECM})$ remodeling and capillary formation $(69,122-125)$. These cellular events are essential processes of angiogenesis. The increase in production of VEGF and simultaneous decrease in anti-angiogenic factors, such as endostatin and angiostatin cause a net increase in angiogenesis (126). VEGF, fibroblast growth factor (FGF) and anti-angiogenic factors like angiostatin and endostatin, regulate the process of angiogenesis through activation of matrix metalloproteinases (MMPs) (42-43). 
The transition from compensatory hypertrophy to decompensatory heart failure is regulated by discoordination of angiogenesis and hypertrophy during heart failure (68). Angiostatin and endostatin significantly inhibit tumor growth and vascularity in mice models by down regulating VEGF expression at both mRNA and protein levels (127). Interestingly, systemic administration of recombinant angiostatin and endostatin in tumor models demonstrates tumor regression by inhibition of angiogenesis (127). In another study on wound healing, endostatin suppresses ischemia induced neo-vascularization (128) and mediates its anti-angiogenic actions by inhibiting the function of pro-angiogenic molecules, such as VEGF receptor (89) and activation of MMPs (88).

Alterations in cardiac gene expression during the transition from stable hypertrophy to heart failure elicit marked up-regulation of genes encoding ECM proteins (129-130). MMP-2 is constitutively expressed, and releases growth factors from the matrix during constitutive remodeling/hypertrophy/angiogenesis (46). MMP-9 is induced during heart failure (47) and generates collagen-matrix fragments; such as endostatin and angiostatin (48). TIMPs have various effects other than inhibiting MMPs. TIMP-1 induces fibrosis (131). TIMP-2 induces cell proliferation (132). TIMP-3 induces apoptosis (133). TIMP-4, a cardiac specific TIMP, induces apoptosis in transformed cells, but has no effect on normal cells (134). Although the role of pro-angiogenic and anti-angiogenic factors in the process of neo-vascularization is well-known; the differential role of these factors during the transition from compensatory cardiac hypertrophy to decompensatory heart failure remains obscure. The present work examines the role and 
interaction of pro and anti-angiogenic factors during transition from compensatory hypertrophy to heart failure. We hypothesize that a chronic increase in pressure overload induces MMP-2, which in turn, induces the release of angiogenic growth factors during the compensatory hypertrophy phase while MMP-9/TIMP-3 release anti-angiogenic factors during the decompensatory heart failure phase. 


\section{MATERIAL AND METHODS:}

\section{Animals}

Wild type (WT, C57BL6/J) and MMP-9-/- (MMP-9KO) mice were obtained from Jackson Laboratories (Bar Harbor, Maine), housed in the animal care facility with access to water and standard chow. All animals were 12 weeks old and between 26-30 grams. All animal procedures were performed in accordance with National Institute of Health guidelines for animal research and were reviewed and approved by the Institute Animal Care and use Committee of University of Louisville.

\section{Pressure overload animal model}

Under pentobarbital anesthesia, $(70 \mathrm{mg} / \mathrm{kg}$ body weight dose, through intraperitoneal route) animals were intubated and ventilated. A left parasternal thoracotomy was performed and the ascending aorta is identified and dissected. Banding of the ascending aorta was done by placing a $26 \mathrm{~g}$ needle on the anterior surface of aorta and a 6-0 silk suture was then ligated around the aorta and the needle, and needle quickly removed resulting in constriction of aorta to create pressure overload on the heart (130). The thoracotomy was then closed in layers using 6-0 vicryl and 5-0 silk sutures for skin. Postoperative analgesia was given through intraperitoneal injection of keoprofen at the dose of $5 \mathrm{mg} / \mathrm{kg}$ body weight for 48 hours. Sham animals underwent similar procedure except banding of aorta. To perform a longitudinal study, starting at time zero, all experimental results were compared with sham-operated mice at the same time post-surgery. 
We compared mice at 3 and 8 weeks post-operation to their corresponding sham controls ( $n=5$ per group).

\section{Left ventricular weight and body weight ratio (LV Wt/BW)}

Animals were euthanized according to the IACUC protocol, and the hearts were excised, rinsed in phosphate buffer saline (PBS), and right and left ventricles were divided. Ratio of left ventricular weight and body weight was measured and represented in bar diagram (Figure 25).

\section{Antibodies and Reagents}

The following primary antibodies were used for protein analysis: rabbit polyclonal anti-angiostatin, mouse monoclonal anti-endostatin, rabbit polyclonal MMP-2, and rabbit polyclonal MMP-9. These antibodies were purchased from abcam (Cambridge, MA). Rabbit polyclonal antibody against VEGF (A-20), rabbit polyclonal antibody against TIMP-2, -3 , and TIMP-4, and HRP-conjugated secondary antibodies were from Santa Cruz Biotechnology (Santa Cruz, CA). Mouse monoclonal anti-GAPDH and all analytical reagents were from SigmaAldrich (St. Louis, MO).

\section{Western blot analysis}

Heart tissue from mice was harvested and washed thoroughly in PBS and snap-frozen in liquid nitrogen. Protein extraction was done using 1X RIPA buffer (Tris-HCl 50 mM,pH7.4; NP-40 1\%; Na-deoxycholate 0.25\%; NaCl $150 \mathrm{mM}$; EDTA $1 \mathrm{mM}$; PMSF $1 \mathrm{mM}$; Na3VO4 $1 \mathrm{mM}$; NaF $1 \mathrm{mM}$; protease inhibitor cocktail 
$1 \mu \mathrm{g} / \mathrm{ml}$ ). Estimation of protein was done by Bradford method (Bio-Rad, Hercules, CA). $10-25 \mu \mathrm{g}$ of protein was fractionated by SDS-PAGE and transferred onto PVDF membrane (BioRad, Hercules, CA) by wet transfer method. The transferred proteins were processed for immunodetection of specific antigens. Briefly, non-specific sites were blocked with $5 \%$ non-fat dry milk in TBS-T $(50 \mathrm{mM}$ Tris- $\mathrm{HCl}, 150 \mathrm{mM} \mathrm{NaCl}, 0.1 \%$ Tween- 20, $\mathrm{pH}$ 7.4) for 1 hour at room temperature. The blot was then incubated with appropriate primary antibody in blocking solution according to the supplier's specific instructions. The blots were washed with TBS-T (three times, 10 minutes each) and incubated with appropriate HRP-conjugated secondary antibody for 1 hour at room temperature. After washing, ECL Plus substrate (Amersham Biosciences, Pittsburgh, PA) was applied to the blot for 1 minute. The blot was developed using X-ray film (RPI Corp, Inc., Mount Prospect, IL) with a Kodak 2000A developer (Eastman Kodak, Rochester, NY). The blots were stripped and re-probed with GAPDH. The immuno-reactive bands were scanned and densitometrically analyzed by UnScan-It software (Silk Scientific, Orem, UT).

\section{Echocardiography}

Two dimensional trans-thoracic echocardiography images of left ventricle from a four chambered apical view were taken with a phased-array echocardiography machine (SONOS 1500 or 2500; Hewlett-Packard, Inc.) using a $12.5-\mathrm{MHz}$ transducer in anesthetized mice at baseline, 3 and 8 week post operation. Animals were given intraperitoneal injection of Tri-bromo ethanol 
anesthesia (TBE) (135) at a dose of $240 \mathrm{mg}$ per kilogram body weight, depilated and placed on a self regulating heating pad to maintain normal body temperature. Cardiac function, left ventricular internal dimension in diastole (LVIDd), left ventricular internal dimension in systole (LVIDs), left ventricular posterior wall dimension (LVPWD), and \%left ventricular fractional shortening (\%FS) were assessed.

\section{Histological analysis of cardiac sections}

Frozen sections were cut at $8 \mu \mathrm{m}$ thickness using cryocut 1800 (ReichertJung). Cryosections were placed on superfrost plus microscope slides and air dried. Histological analysis was done in all three groups using Masson's trichrome blue staining for detection of fibrosis, hematoxylin and eosin $(\mathrm{H}$ and $\mathrm{E})$ staining for overall morphology.

\section{Immunohistochemistry}

Immunohistochemistry was performed on $5 \mu \mathrm{m}$ thick frozen sections of the heart using standard Immunohistochemistry (IHC) protocol. Anti-Endostatin (Abcam) and anti-TIMP-2, secondarily conjugated with Texas Red (Chemicon International, St. Charles, MO) were used for immunodetection of these two proteins, respectively. Anti-platelet endothelial cell adhesion molecule (PECAM) (also called CD31) clone-390, secondarily conjugated with FITC (Chemicon international, St.Charles, Missouri) was used to detect collateral density of microvessels. 


\section{Coronary Angiograms}

Barium sulfate contrast coronary angiograms were done on excised hearts to visualize the differences in vascular density between all three groups of mice and MMP-9 Ko AB 8 weeks mice. Barium sulphate was mixed in $5.5 \mathrm{pH}$ buffer and perfused via carotid artery into the heart at a constant flow rate using syringe pump (Chemyx Inc,Stafford,TX) and x-ray angiograms were taken with KODAK MM4000 mm imaging system (Carestream Health Inc, Rochester,NY).

\section{Pressure volume loop study (P-V loop)}

Using Millar Pressure-Volume system (Millar Instruments Inc, Houston,TX), following standard Millar protocol, steady state P-V loops were recorded followed by saline bolus and cuvette calibration for the conversion of RVU (relative volume units ) to $\mu \mathrm{L}$. Hemodynamic variables obtained were analyzed by PVAN software. The results were used to substantiate echocardiography findings.

\section{Statistical analysis}

All data were expressed as mean $\pm \mathrm{SE}$. Data were analyzed using a oneway analysis of variance (ANOVA) to test for treatment effects, and differences between groups were determined using Tukey's post hoc test. A p value $<0.05$ was considered significant. 


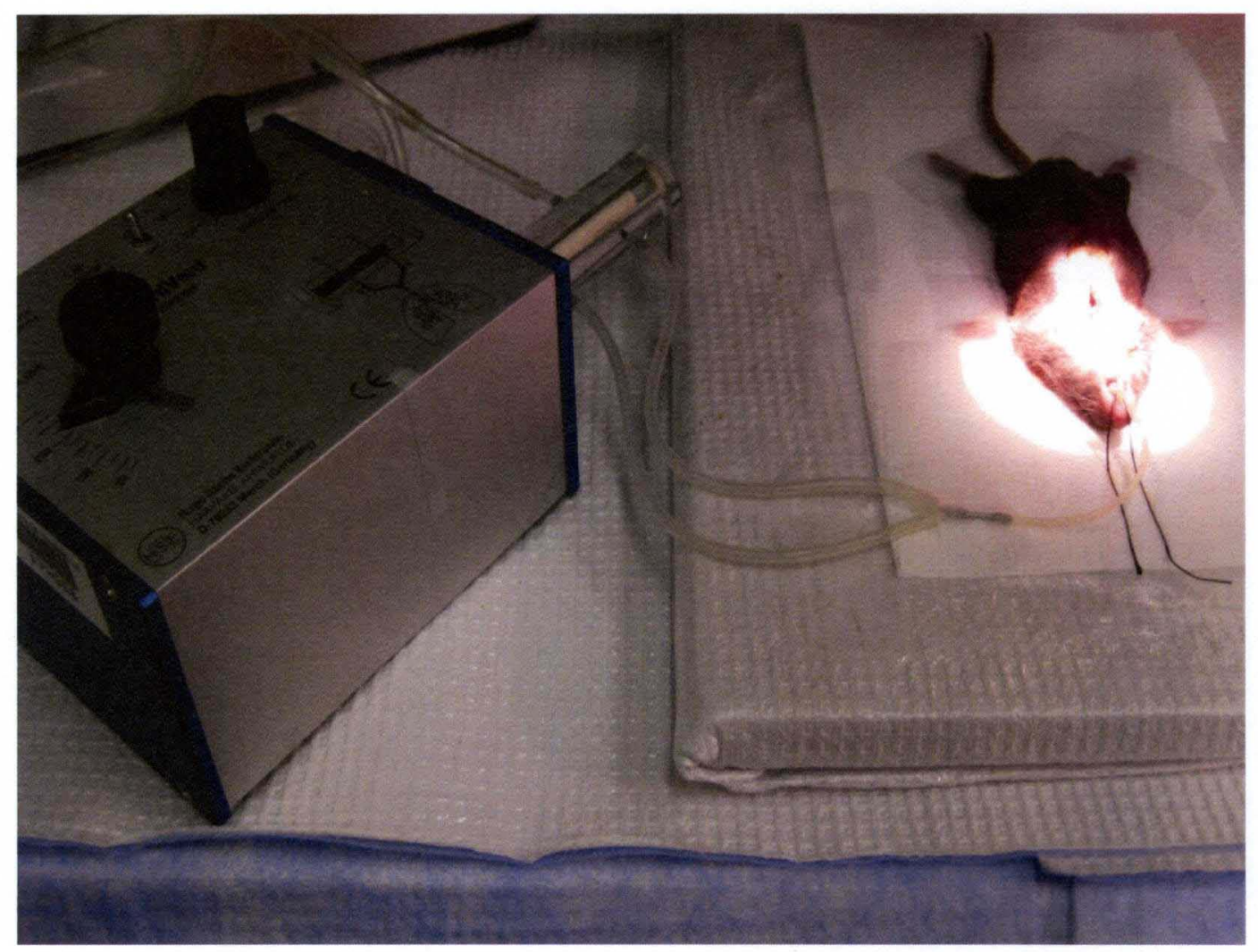

Figure 20: Image showing an intubated mouse under ventilator support for the aortic banding procedure. 


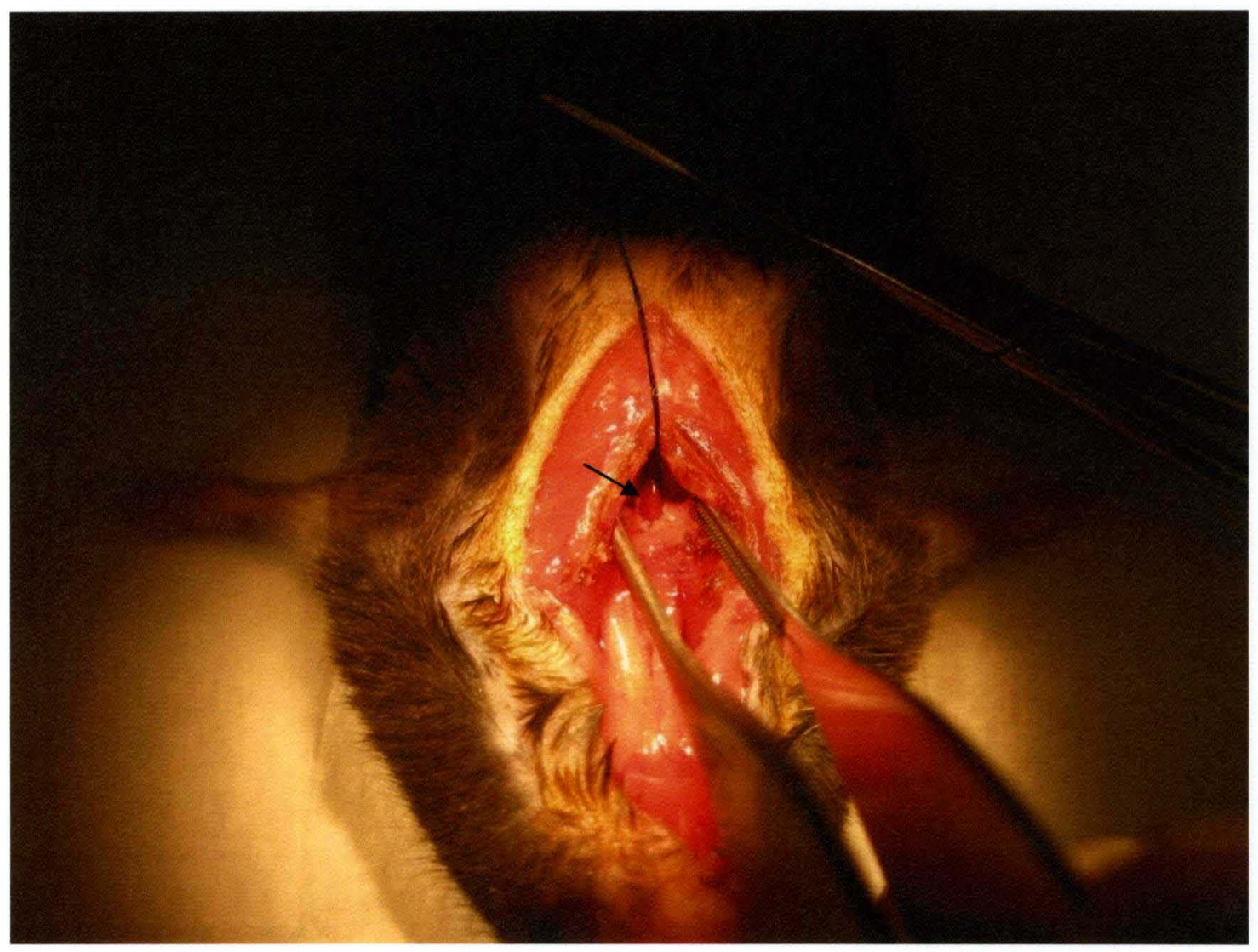

Figure 21: Photograph of mouse undergoing the aortic banding procedure. The segment of ascending aorta to be ligated is shown by arrow. 


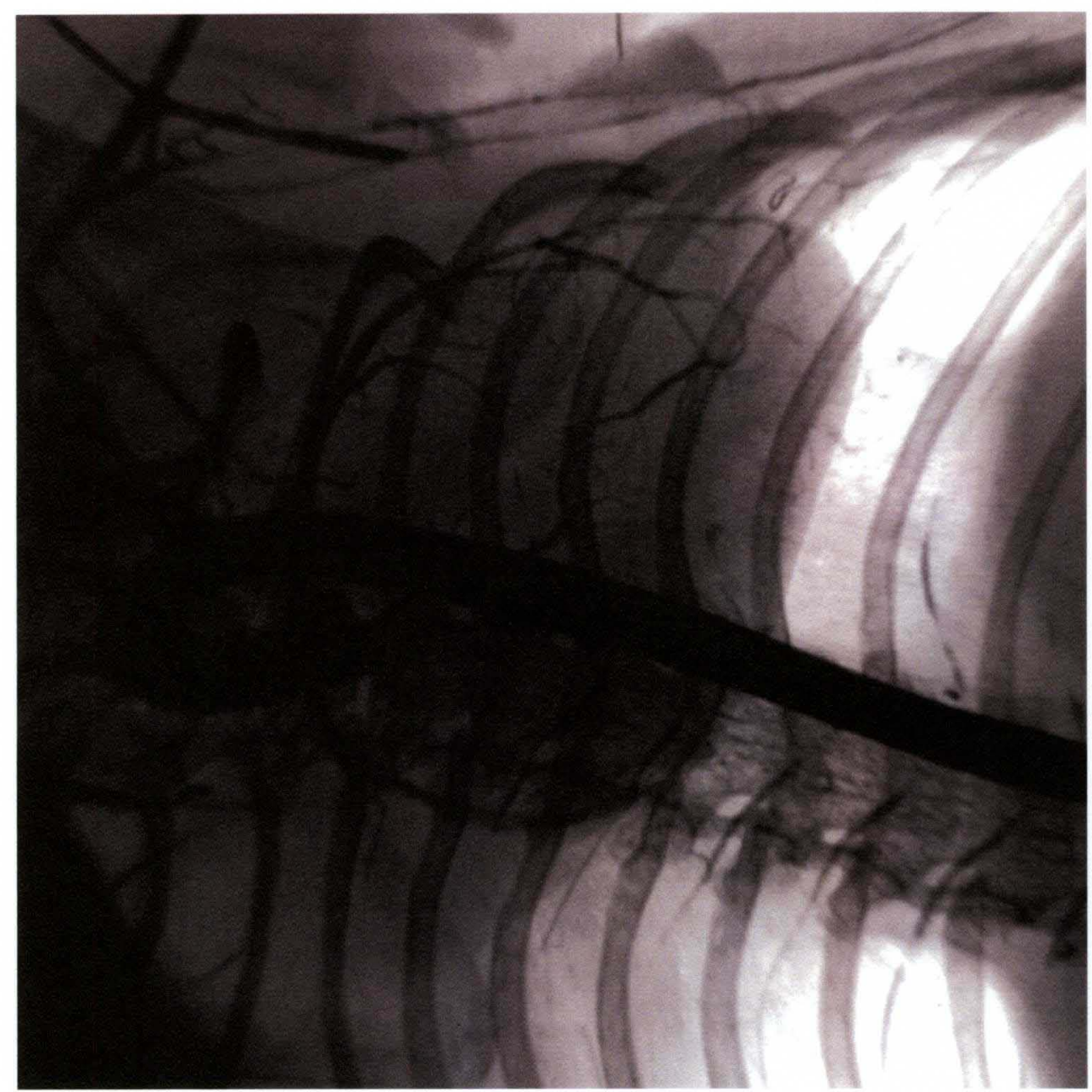

Figure 22: Image of barium contrast coronary angiogram in mouse using Kodak 4000 MM image station. 


\section{RESULTS:}

Echocardiography data showed an increase in septal and left ventricular posterior wall thickness following 3 weeks of aortic banding (Figure 23). Fractional shortening was significantly decreased after 8 weeks of aortic banding compared with sham animals and/or mice 3 weeks post aortic banding. LVIDd increased after 3 weeks aortic banding and LVPWd increased after 8 weeks of aortic banding compared with sham controls. Interestingly, the left ventricular chamber size was increased after 8 weeks of aortic banding, suggesting that the heart had become dilated. The increase in ventricular wall thickness after 3 weeks aortic banding suggests LV hypertrophy (Figure 23). These data demonstrate the transition from the compensatory phase observed at 3 weeks to decompensatory heart failure after 8 weeks of aortic banding.

The P-V relationship data revealed that LV function was decreased after 8 weeks of aortic banding in comparison with sham controls. Quantitative data obtained by P-V loop analysis, shows a decrease in ejection fraction and stroke volume after 8 weeks aortic banding. Also end systolic volume was increased after 8 weeks in comparison to sham controls (Figure 24).

Gravimetric data revealed increase in LV weight/body weight ratio at 3 weeks aortic banding and decrease at 8 weeks of aortic banding (Figure 25). These data suggest compensatory hypertrophy at 3 weeks and decompensatory heart failure at 8 weeks of aortic banding. To determine interstitial and 
pericapillary fibrosis, trichrome-blue collagen histological staining was performed. Although basal level of collagen was detected in the sham group (Figure 26), there was increased collagen deposition at 3 weeks post aortic banding. The fibrosis was abundant at both the interstitial and epicardial regions of the hearts from 8 weeks aortic banding mice.

\section{MMPs/TIMPs axis and angiogenic/anti-angiogenic factors in compensatory to decompensatory heart failure}

The expression of MMP-9 showed very little increase at 3 weeks aortic banding compared with sham (Figure 27). However, the expression was robust at 8 weeks post banding compared with either sham and/or 3 weeks banding. Contrary to MMP-9, MMP2 was increased at 3 weeks. Interestingly, this increase was almost normalized at 8 weeks post aortic banding (Figure 27). These results suggested a differential role of MMP-2 versus MMP-9 during transition from compensatory cardiac hypertrophy to decompensatory heart failure.

The expression of TIMP-2 is decreased at 3 and 8 weeks, compared with sham control (Figure 28). However, a gradual decrease in TIMP-4 expression was observed from 3 weeks to 8 weeks post aortic banding (Figure 28). This suggested that TIMP-2 and TIMP-4 levels are decreased in decompensatory heart failure.

Since TIMP-3 instigates apoptosis, we measured the levels of TIMP-3 along with MMP-2, in situ. Although MMP-2 and TIMP-3 co-localized, contrary to TIMP-2/TIMP-4, the immunohistochemistry data revealed an increase in TIMP-3 
levels at 3 weeks, however, interestingly, at 8 weeks of aortic banding hearts the decrease in TIMP-3 was robust (Figure 29). In situ data also revealed that MMP2 was elevated during 3 weeks with tendency to decrease at 8 weeks of aortic banding compared with sham (Figure 29).

Since MMP-2 releases growth factors from the matrix and promotes angiogenesis, we measured the levels of angiogenic VEGF and anti-angiogenic (endostatin and angiostatin) levels. The levels of VEGF-A were increased in 3 weeks group compared with sham controls (Figure 30). However, the expression of VEGF-A was diminished during 8 weeks post aortic banding, suggesting the decrease in angiogenic factors in decompensatory heart failure (Figure 30). The expression of anti-angiogenic factors like endostatin and angiostatin increased significantly at 8 weeks post aortic banding when compared with sham and/or 3 weeks banding (Figure 30). The increase in expression of endostatin at 8 weeks aortic banding was further evidenced by immunohistochemical staining (Figure $31)$.

\section{Angiogenesis/vasculogenesis}

The CD31 staining (an endothelial cell marker) showed increased density of endothelial cells during 3 weeks compared with sham and 8 weeks aortic banding groups, suggesting increased endothelial cell density (Figure 32). Interestingly, staining with CD31 also visualized the capillary density, represented by endothelial cells density and was also increased at 3 weeks compared with sham or 8 weeks aortic banding. 
To corroborate CD-31 endothelial/capillary data with vasculogenesis, we performed in vivo real-time soft-tissue $\mathrm{x}$-ray angiography using barium as contrasting agent. The angiography data showed increased in vascular density at 3 weeks aortic banding; whereas capillary rarefaction was observed at 8 weeks post aortic banding (Figure 33). To determine the role of MMP-9 as inducers of anti-angiogenic factors (endostatin and angiostatin), we created aortic banding in MMP-9-/- (MMP-9KO) mice. The results suggested increase in vascular density in MMP-9KO after 8 weeks aortic banding compared with sham controls (Figure 33). 

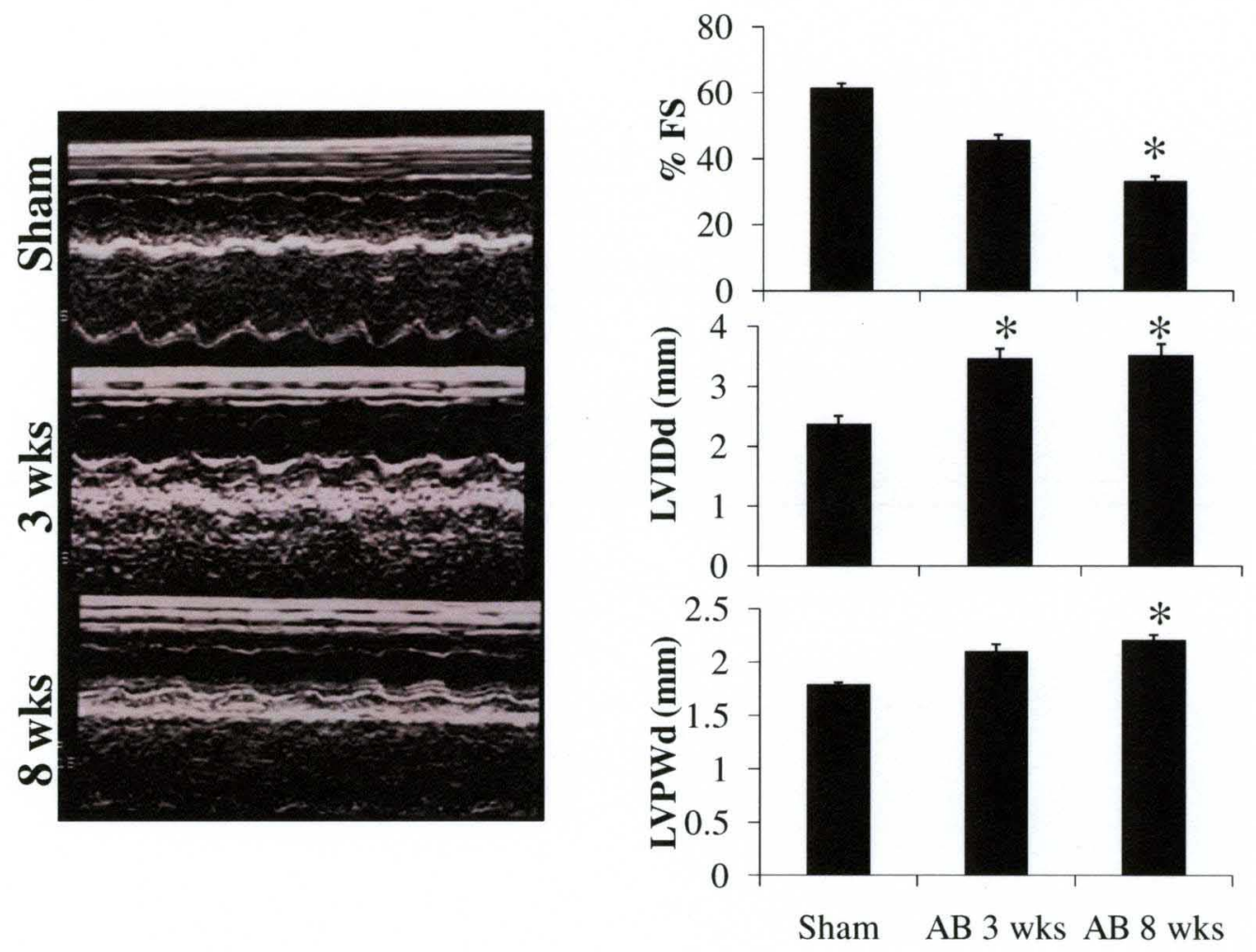

Figure 23: Aortic banding induced changes in cardiac function

Panels represent M-mode echocardiography of sham (8 weeks), 3 weeks and 8 weeks after aortic banding. The bars graphs represented percentage of fraction shortening (FS), LVIDd (left ventricular internal dimension in diastole), and LVPWd (left ventricular posterior wall dimension in diastole). $\quad{ }^{*} p<0.05$ compared with sham. Data are mean $\pm \mathrm{SE} ; n=5 /$ group 


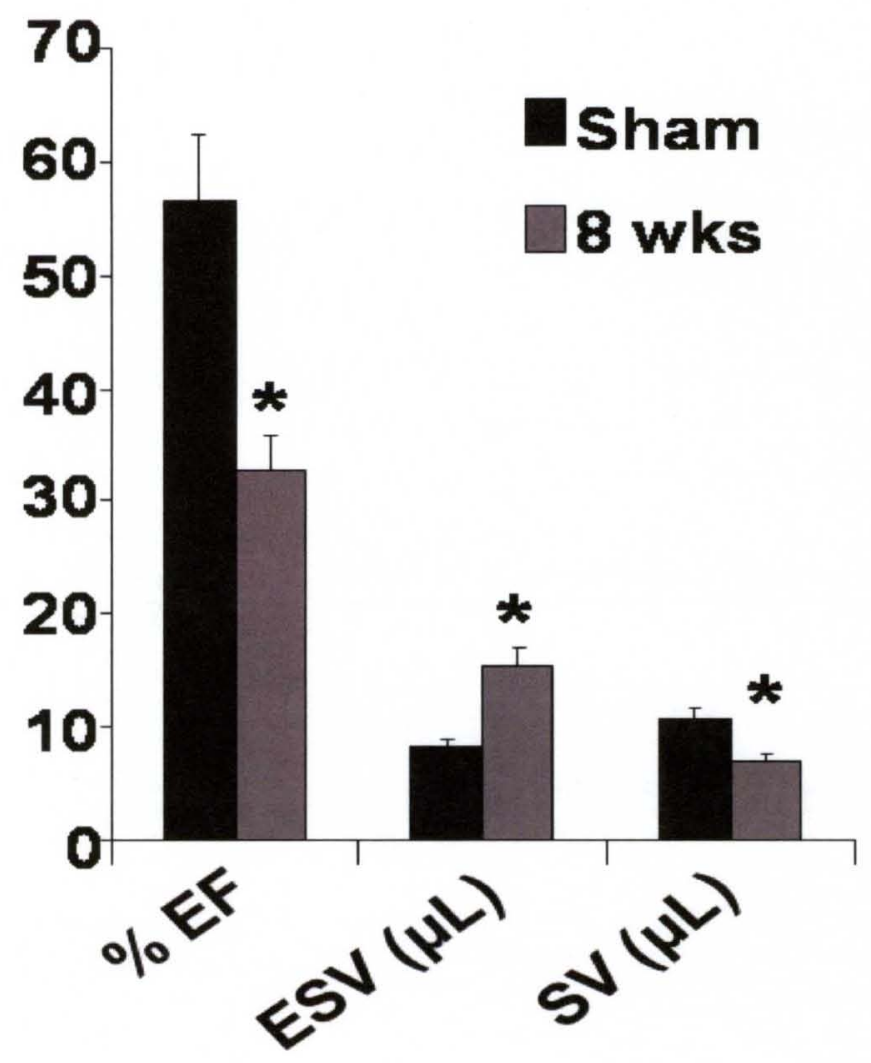

Figure 24: Changes in cardiac function due to aortic banding

Pressure-volume loop by Millar catheter of sham and 8 weeks aortic banding mice: The bar graphs depict \% ejection fraction (EF), ESV (End systolic stroke volume); and stroke volume (SV) in sham and 8 weeks aortic banding mice. Data are mean $\pm S E ; n=5 /$ group ${ }^{*} p<0.05$ vs sham. 


\section{A. Gross images of the heart}

$$
\text { Sham }
$$

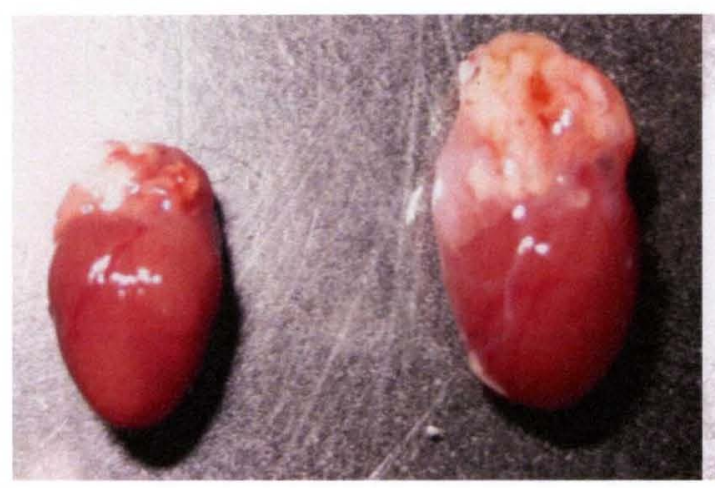

B. Gravimetric data
AB 8wks
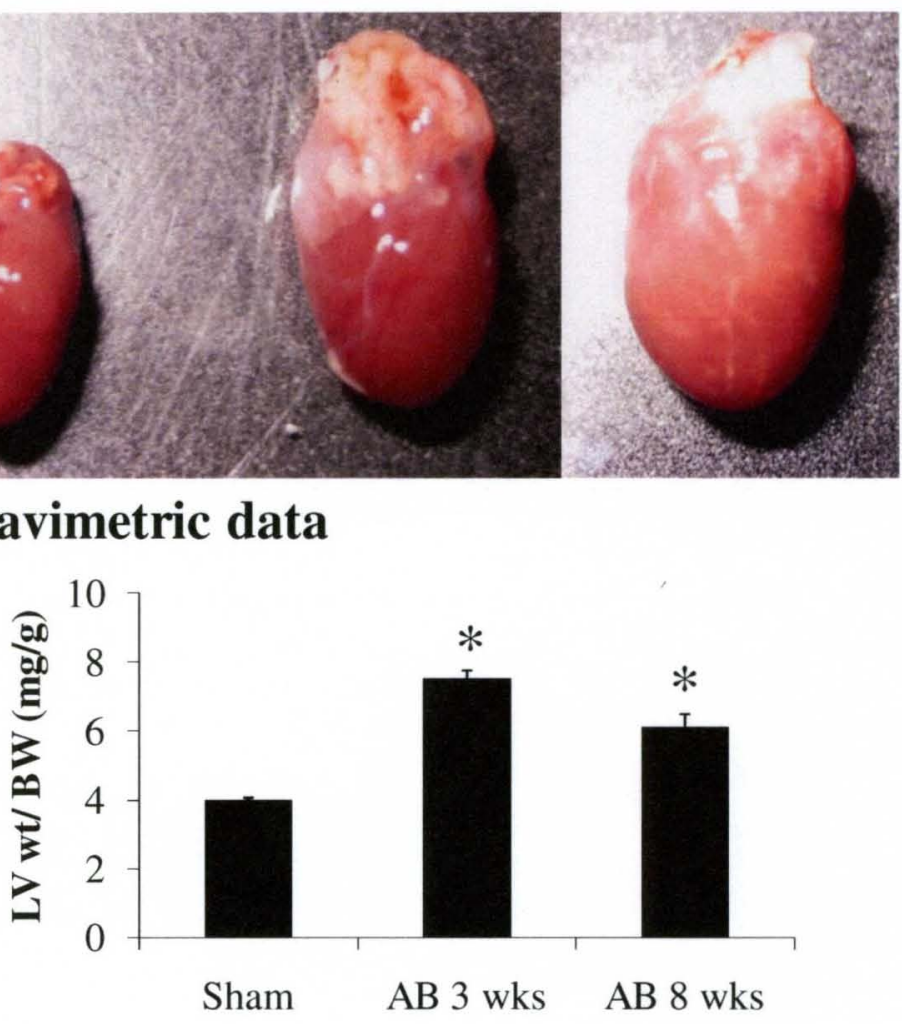

Figure 25: Aortic banding increase cardiac mass.

A) The gross images of the whole heart of sham, 3 weeks, and 8 weeks aortic banding. Hearts were cleaned in phosphate buffered saline. The left ventricle was separated. B) The ratio of left ventricle (LV) weight (wt) to body weight (BW) was depicted in bar graph. Data are mean \pm SE; $n=5 /$ group. ${ }^{*} \mathrm{p}<0.01$ vs sham. 
leeks

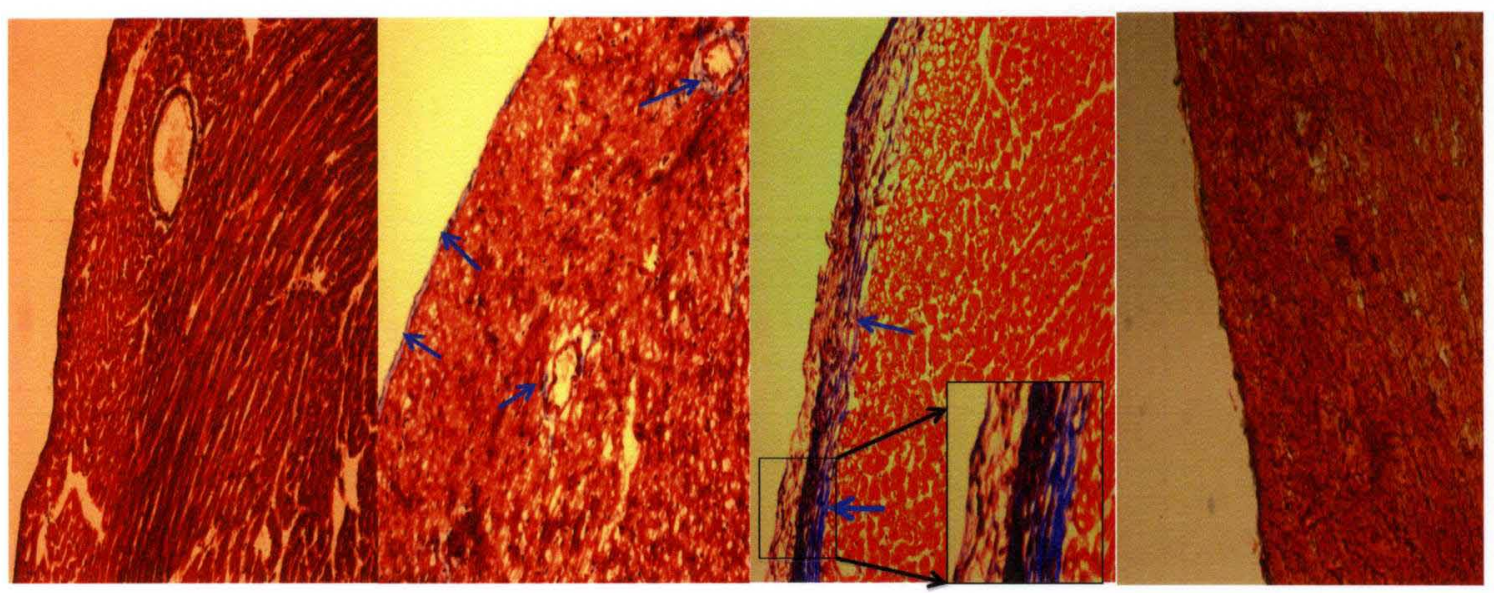

Figure 26: Aortic banding induced changes in cardiac morphology Representative microphotographs of Masson's-trichrome blue histological staining of frozen heart sections: The hearts from sham, 3 weeks, 8 weeks and MMP-9 KO 8 weeks aortic banding were analyzed. Arrow indicates endocardial and peri-capillary fibrosis. $20 \mathrm{x}$ magnifications. The insert box, $100 \mathrm{x}$ magnifications. 


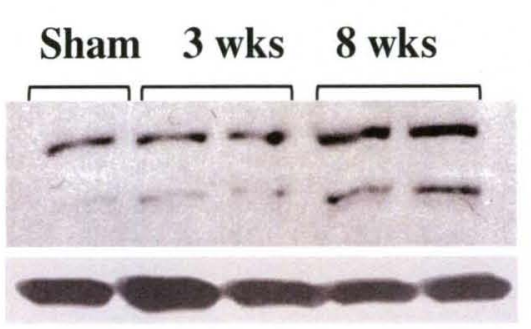

pro MMP-9 active MMP-9

GAPDH

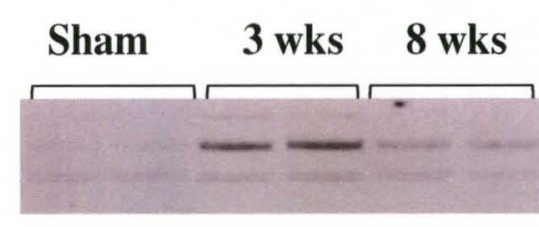

-

pro MMP-2 active MMP-2
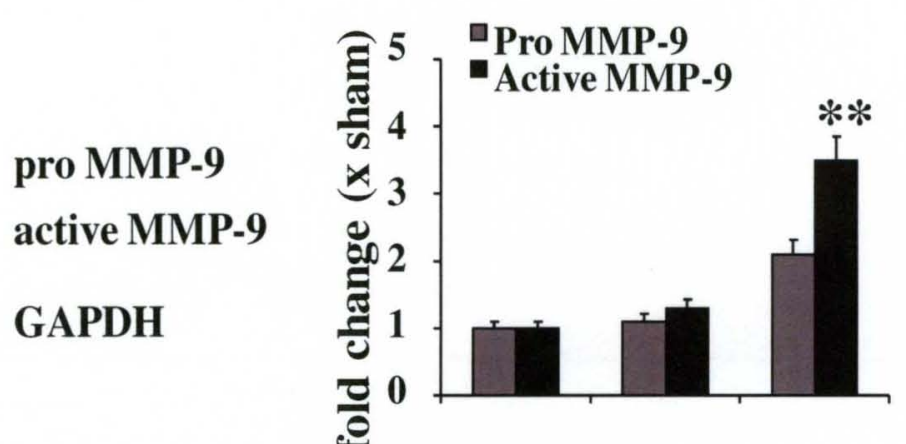

GAPDH

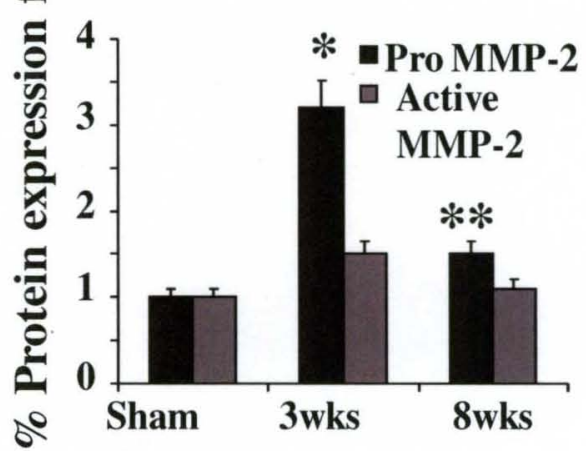

Figure 27: Western blot analyses of MMP-9 and MMP-2 expression in Sham, 3 weeks and 8 weeks of aortic banding: Bar graphs showed densitometric analysis of MMP-9 and MMP-2 expression over sham groups (protein normalized with GAPDH). Each bar represents mean $\pm \mathrm{SE},{ }^{*} \mathrm{p}<0.05$ vs sham, ${ }^{\star \star}$ compared with 3 weeks, from $n=5$ in each group. The percent protein expression on $Y$-axis is the protein expression calculated as fold change vs. sham. 
Sham 3wks 8wks

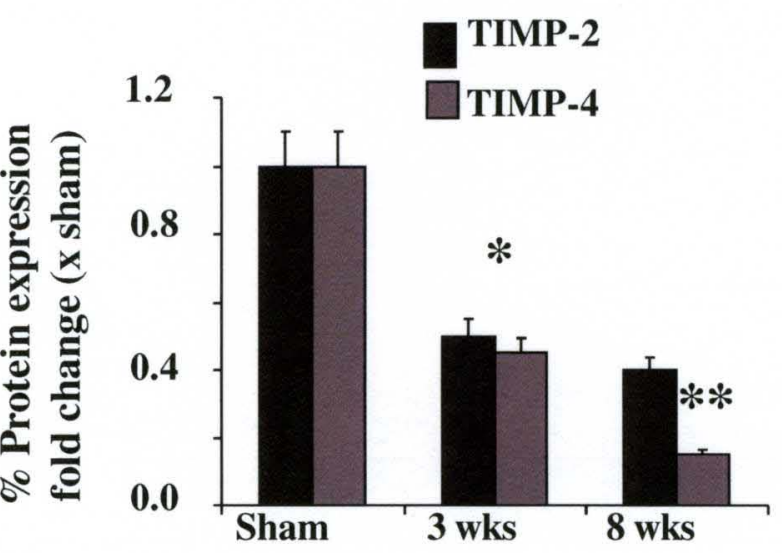

GAPDH

Figure 28: Western blot analyses of TIMP-2 and TIMP-4 expression in Sham, 3 weeks and 8 weeks of aortic banding: Bar graphs showed densitometric analyses of TIMP-2 and TIMP-4 expression over sham groups (protein normalized with GAPDH). Each bar represents mean $\pm \mathrm{SE},{ }^{*} \mathrm{p}<0.05$ vs sham, ${ }^{*}$ compared with 3 weeks, from $n=5$ in each group. The percent protein expression on $Y$-axis is the protein expression calculated as fold change vs. sham. 


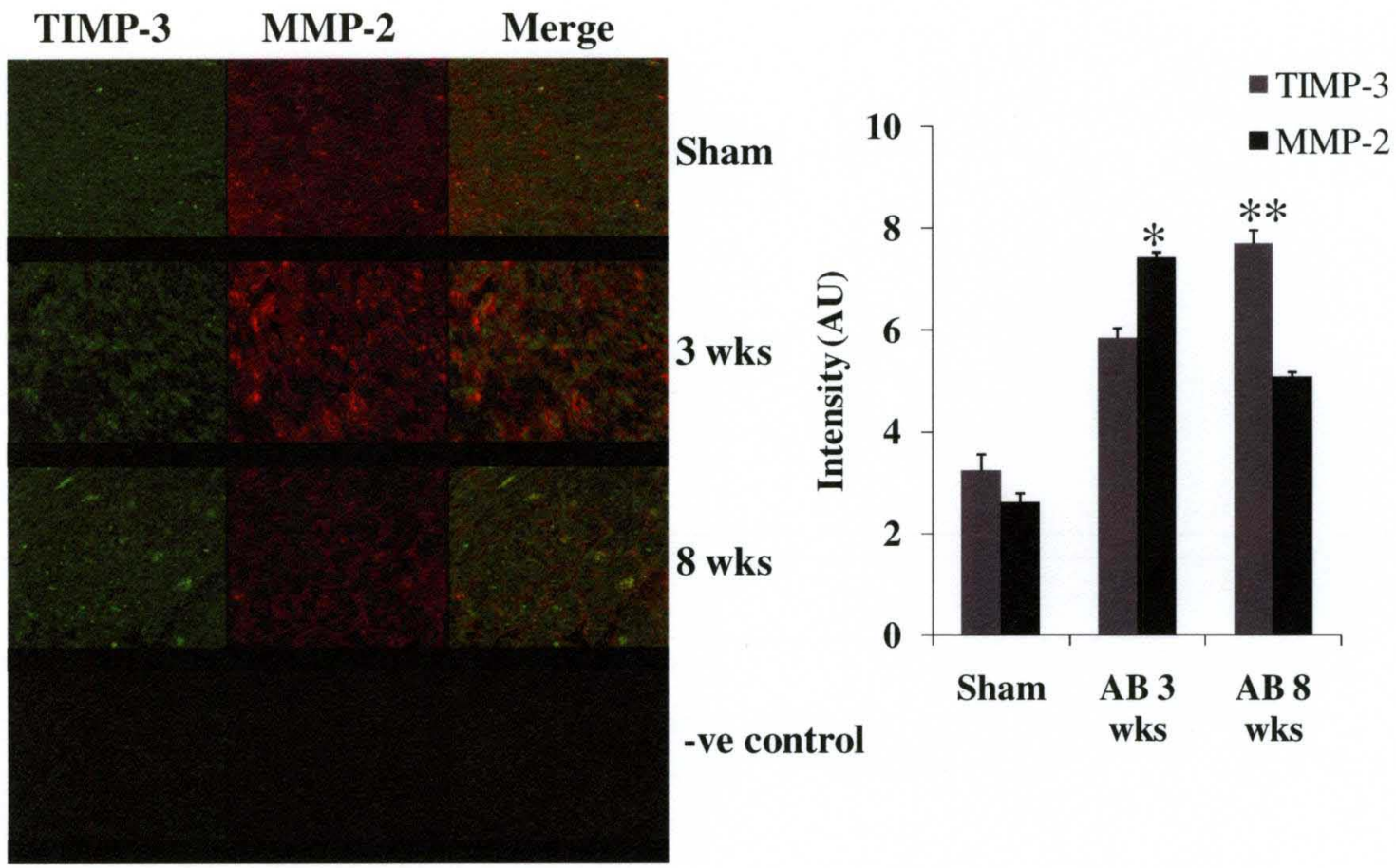

Figure 29: Left ventricle Immunohistochemical staining and co-localization of TIMP-3 and MMP-2: Cryocut frozen sections of $(8-10 \mu \mathrm{m})$ were stained and secondarily conjugated with FITC for TIMP-3 and texas red for MMP-2 (white arrows indicate capillaries). The bar diagrams depicted the intensity quantification of TIMP-3 and MMP-2 by Fluoview software, in sham, 3 weeks and 8 weeks aortic banding. Data presented mean $\pm S E ;{ }^{*} p<0.01$ vs sham; ${ }^{*} p<0.05$ vs 3 weeks; $n=5$ animals per group. 


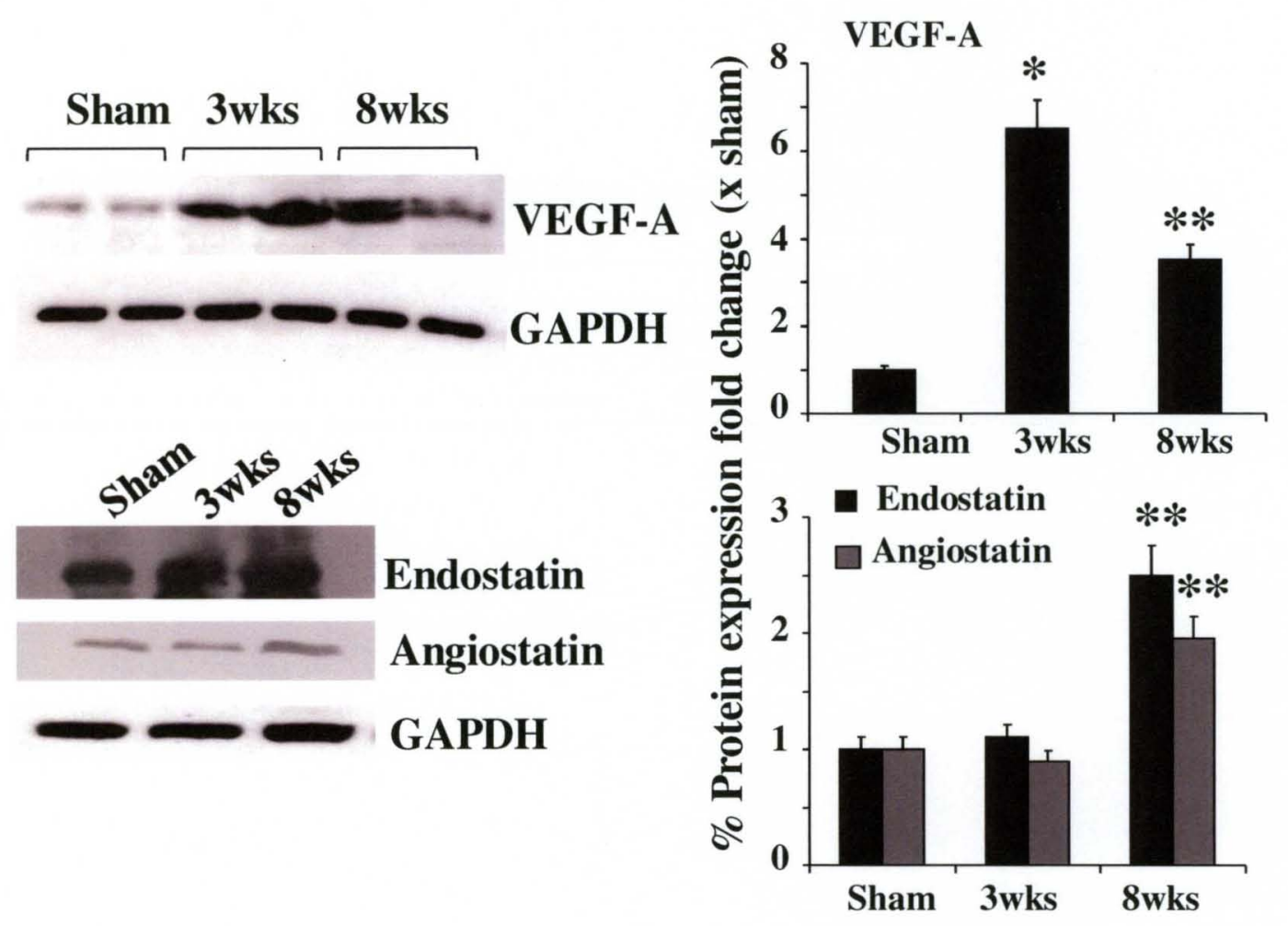

Figure 30: Measurement of angiogenic and anti-angiogenic factors: Western blot analyses of VEGF-A, endostatin and angiostatin. Bar graphs showed the relative expression of VEGF-A, endostatin, and angiostatin over sham group (after normalization with GAPDH). The data presented mean $\pm \mathrm{SE},{ }^{*} p<0.05$ vs sham; ${ }^{\star *}$, compared with 3 weeks. The percent protein expression on $Y$-axis is the protein expression calculated as fold change vs. sham. 


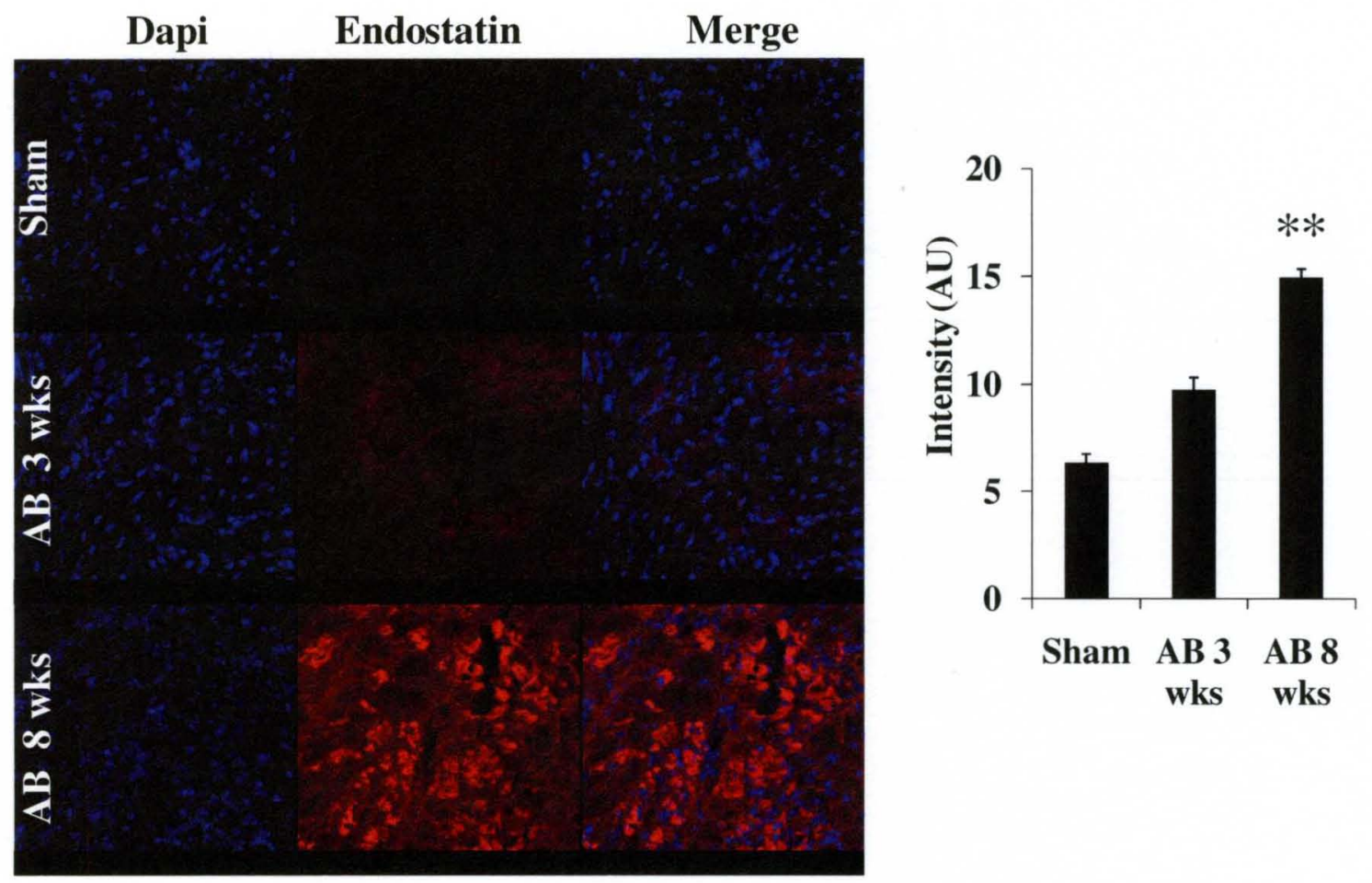

Figure 31: Immunohistochemical staining of endostatin. Cryocut frozen tissue sections $(5 \mu \mathrm{m})$ are stained with anti-endostatin antibody secondarily conjugated with Texas red dye. Nuclei are stained with DAPI. Bar diagrams depicted intensity quantification by image pro-software. Each bar representative mean \pm SE, ${ }^{\star *} p<0.05$ vs sham or 3 weeks, $n=5$ animals/group. 


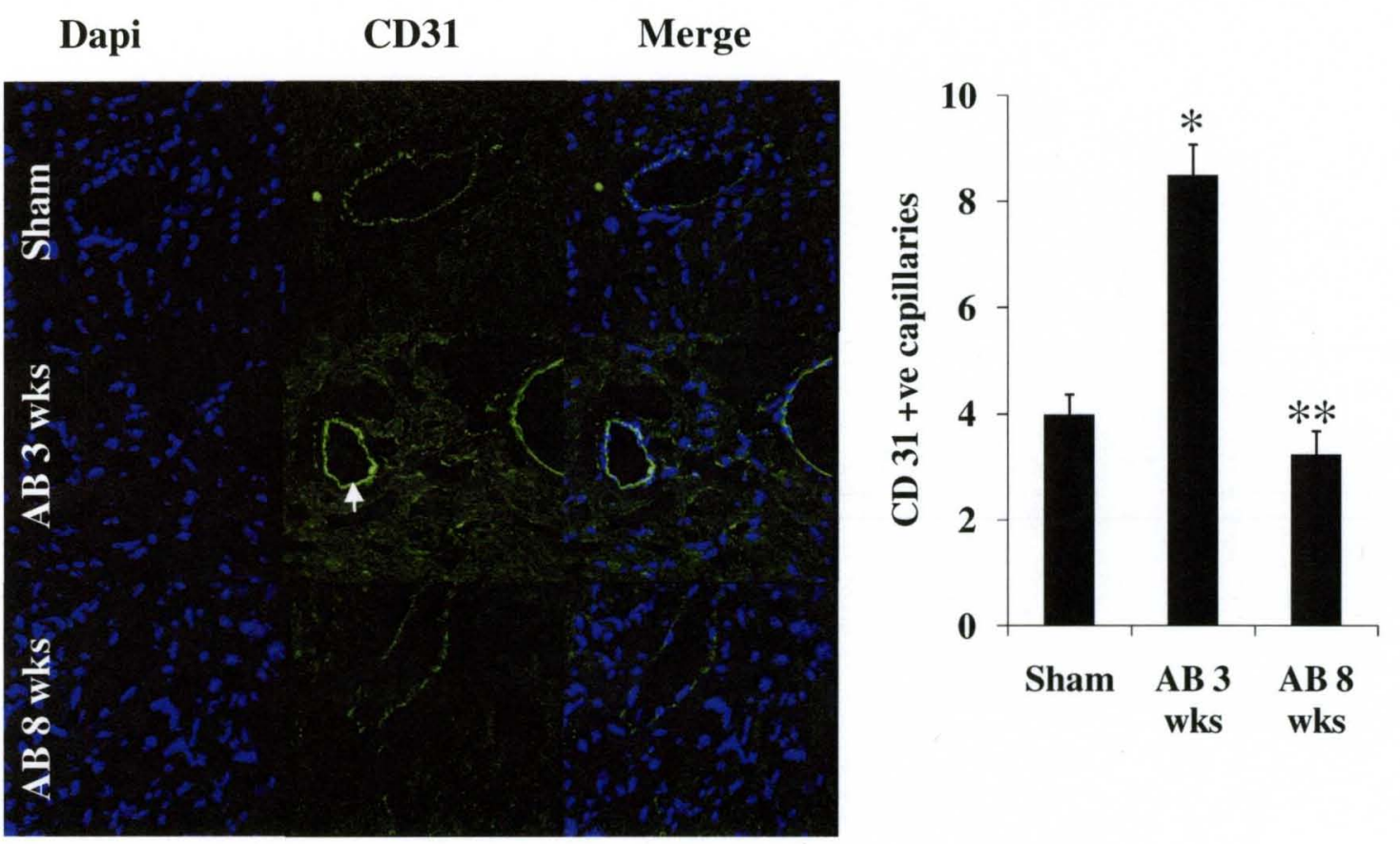

Figure 32: Immunohistochemical staining with CD31 (PECAM) in sham, 3 weeks and 8 weeks aortic banding groups. DAPI was used for nuclear staining. The images were merged. The arrows point to capillary structure. Bar diagrams represent quantified arbitrary number of $C D$ 31staining endothelial cell in capillaries per each field randomly selected with the help of Image-Pro software. The data presented mean $\pm S E, n=5 /$ group. ${ }^{*} p<0.01$ vs Sham; ${ }^{* *} p<0.05$ vs 3 weeks. 

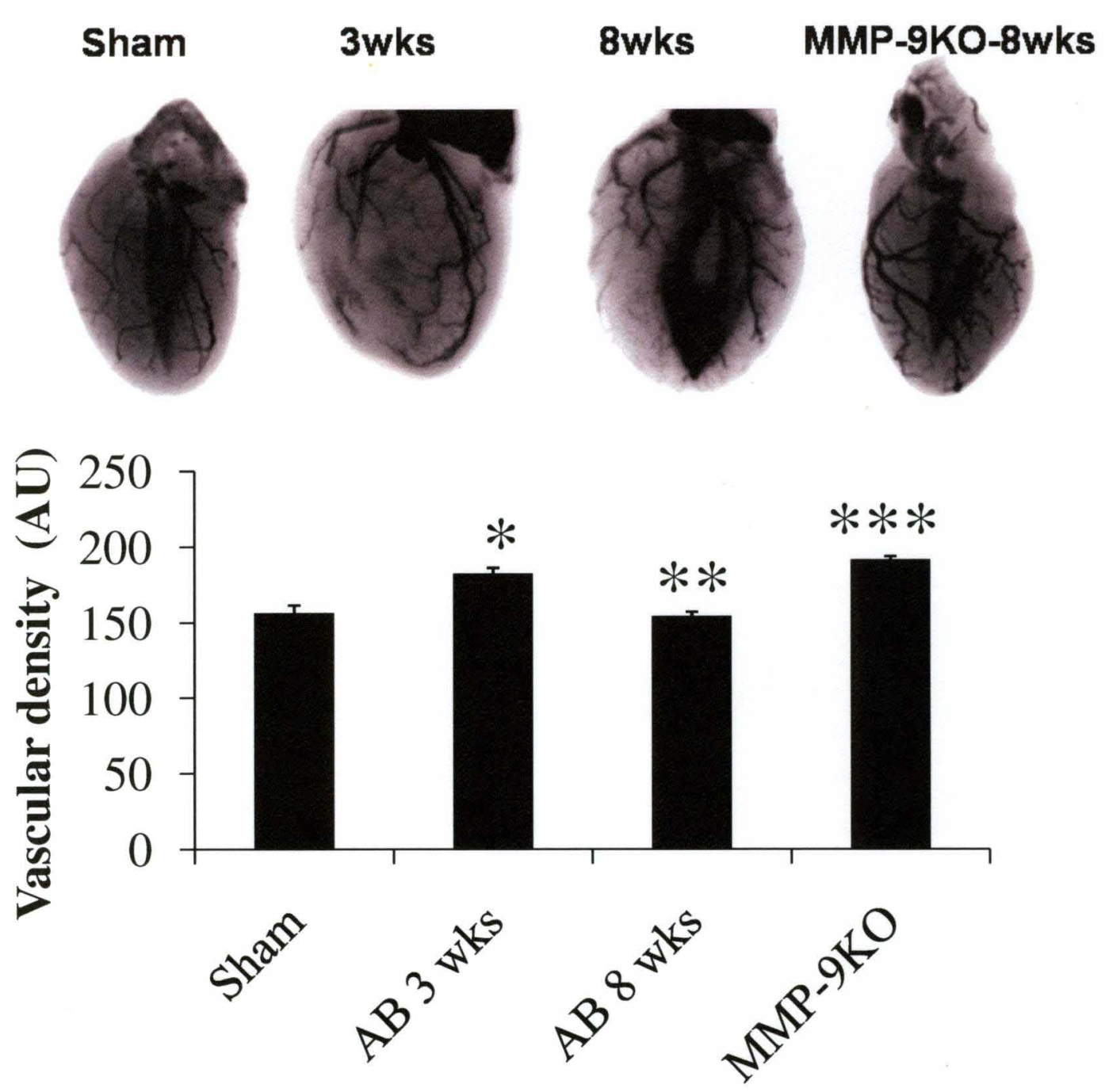

Figure 33: Barium-contrast $x$-ray angiograms, to demonstrate gross variability in vasculature among sham, 3 weeks, 8 weeks and MMP-9KO (at 8 weeks). In vivo hearts were perfused with Barium sulfate solution and $\mathrm{x}$-ray imaging was taken with KODAK MM4000 both in whole body and in isolated hearts. The bar diagrams depicted quantified intensity of the images from randomly chosen areas of same size, with Image-J software. The data presented mean \pm SE, ${ }^{*} p<0.05$ vs sham; ${ }^{* \star} p<0.01$ vs 3 weeks; ${ }^{\star \star *}$, compared with 8 weeks. $n=5$ animals per group. 


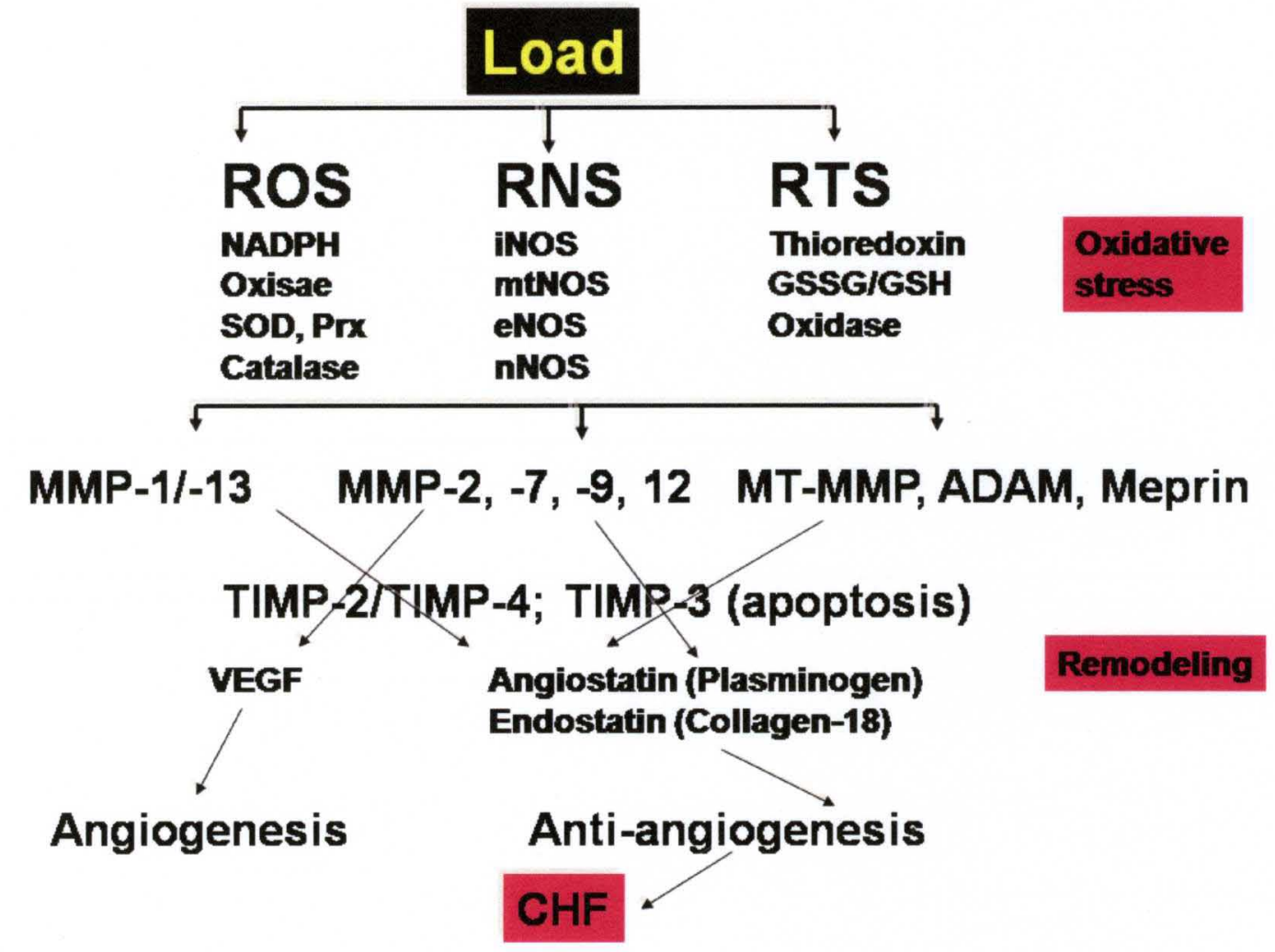

Figure 34: Hypothetical presentation of latent MMP activation under chronic oxidative load condition. The imbalance in MMP/ TIMP axis and remodeling, generating angiogenic, anti-angiogenic, factors, leading to apoptosis and chronic heart failure (CHF). Abbreviations: ROS, reactive oxygen species; RNS, reactive nitrogen species; RTS, reactive thiol species; NADH, nicotinamide adenine dinucleotide (reduced); SOD, superoxide dismutase; Prx, peroxiredoxin; VEGF, vascular endothelial growth factor; ADAM, a disintegrin and metalloproteinase; Meprins, metalloproteinase in renal; iNOS, inducible nitric oxide synthase; eNOS, endothelial nitric oxide synthase; GSSG/GSH, oxidized glutathione/reduced glutathione; MT-MMP, membrane type-MMP. 


\section{Discussion:}

Systemic hypertension causing left ventricular pressure overload, is one of the leading risk factors of cardiac hypertrophy that eventually leads to heart failure. These hypertrophied hearts exhibit contractile dysfunction, dilation of the ventricular wall and increased wall thickness (136). In the normal human heart, after acute ischemic injury, LV wall stress increases, whereas wall thickness and ejection fraction decreases. To compensate for the overload, the entire myocardium undergoes compensatory hypertrophy/remodeling, i.e; enlargement of the muscle tissue and remodeling of the entire chamber. The ejection fraction and wall thickness decreased significantly during decompensatory phase, though it is maintained near normal level during compensatory phase (17). Our studies suggest that there is an increase in MMP-2, decrease in TIMP-2 and -4 , increase in angiogenic factors and vascularization in compensatory hearts. However, in decompensatory hearts there was an increase in MMP-9, TIMP-3, endostatin, angiostatin, and vascular rarefaction. The increased expression of VEGF-A during 3 weeks post aortic banding showed the importance of angiogenesis during hypertrophy. There was an increase in the expression of angiostatin and endostatin in the 8 weeks post aortic banding. These data suggest that higher levels of angiogenic factors provide impulse for cardiac compensation while upregulation of anti-angiogenic factors promotes decompensatory heart failure. 
During angiogenesis, increased expression of VEGF was associated with a simultaneous decrease in anti-angiogenic factors, such as endostatin and angiostatin. Endostatin is derived from collagen XVIII, inhibits angiogenesis (84) and induces endothelial cell apoptosis $(85,137)$. Angiostatin is a cleavage product of plasminogen. Angiostatin is reported to induce endothelial cell death (138-140), inhibits endothelial cell proliferation, (141) migration and tube formation (142). Our study demonstrated that increased capillary density, as evidenced by increased endothelial cell population, was observed during 3 weeks of aortic banding, and this was supported by the evidence of up- regulated VEGF-A and basal level of endostatin and angiostatin expression. Conversely, during decompensatory heart failure (8 weeks aortic banding), VEGF-A was diminished and up regulation of endostatin and angiostatin was observed resulting in a decrease in capillary density.

The endogenous inhibitors of MMPs, TIMPs, inhibit MMP activity; therefore, the balance of MMPs/TIMPs is very important in order to maintain normal physiological matrix architecture (143). MMP-2 and 9 both are able to cleave collagen and play a major role in ECM remodeling. During cardiac hypertrophy and chronic heart failure, the imbalance of MMPs/TIMPs caused changes in matrix composition, resulting in cardiac fibrosis. TIMP-2 and TIMP-4 inhibit both MMP-2, and -9 , and therefore, a decrease in TIMP-2 and TIMP-4 augments MMP-2 and -9 activities that promote cardiac fibrosis. The results of this study show that increased fibrosis was observed at 8 weeks post aortic banding. This is consistent with up regulation of MMP-9. Interestingly, an up 
regulation of MMP-2 was observed at 3 weeks and a down regulation of MMP-2 was observed in 8 weeks aortic banding. This suggests possible differential regulation of these two MMPs by TIMP-2 and TIMP-4 during compensatory cardiac hypertrophy leading to decompensatory heart failure. Moreover, TIMP-3 expression increased at 3 weeks and continued to increase at 8 weeks aortic banding. This may suggest TIMP-3 associated cell death (133).

In conclusion, our study showed that pressure overload cardiac hypertrophy was compensated with increased angiogenesis and MMP-2, whereas decompensatory heart failure was accompanied with an increase in MMP-9 and TIMP-3, resulting in non-specific collagen cleavage and up regulation of potent antiangiogenic factors that eventually led to heart failure (Figure 34). The novelty of this study was the mechanistic disconnect between angiogenesis/hypertrophy in compensatory heart to antiangiogenesis/hypertrophy in decompensatory heart failure.

Limitations: Although we do not have a direct connection as to whether the MMP-2 releases angiogenic factors and MMP-9/TIMP-3 releases anti-angiogenic factors in stressed hearts, we show data that the levels of MMP-2 and -9, TIMP$2,-3$ and -4 , VEGF, angiostatin and endostatin are modified in the direction suggested by the hypothesis, which suggests a causal relationship. With immuno-labeling, presumably, we detected both inactive pro and active MMP-2. Also, the histochemical data shown in Figure 29 detected total active and pro MMP-2. However, without a change in active MMP-2, we cannot infer specifically 
that MMP-2 elevation was responsible for the pro-angiogenic changes at 3 weeks. Because the blood flow in coronary arteries was pulsatile, we may be unclear whether we really estimated the vascular density by measuring black pixels. However, we have taken the images of the heart in diastole using $\mathrm{KCl}$ at the same time of cardiac cycle. In MMP-9KO mice, the amelioration of cardiac dysfunction in many cardiac disorders were already demonstrated (144-146), here we showed that in the MMP-9 KO AB 8 weeks mice, there was absolute decrease in fibrosis (Figure 26), and also there was an increase in vascular density (Figure 33). 


\section{CHAPTER V}

\section{ROLE OF HYDROGEN SULFIDE DURING TRANSITION FROM CARDIAC HYPERTROPHY TO HEART FAILURE}

Introduction: Cardiovascular disease (CVD) is the leading cause of death for both men and women. Hypertension is the major risk factor of CVD (1). Although initial pressure overload during hypertension is compensated by cardiac hypertrophy, sustained overload results in progression towards heart failure due to an imbalance in myocyte-capillary ratio $(15,147)$. In previous studies we demonstrated that during the compensatory hypertrophy phase, MMP-2 is induced and leads to the production of angiogenic growth factors like VEGF and promotes angiogenesis. In later stages of compensatory hypertrophy, MMP-9 and TIMP-3 are induced and play a significant role in the production of antiangiogenic growth factors like endostatin and angiostatin. This leads to apoptosis and causes transition from compensatory cardiac hypertrophy to decompensatory heart failure (41). Recent studies report that the endogenous gaseous transmitter, hydrogen sulfide $\left(\mathrm{H}_{2} \mathrm{~S}\right)$ plays an important role in cardiac protection during ischemia, infarction and heart failure $(108,116,148-149) . \mathrm{H}_{2} \mathrm{~S}$ is endogenously generated by pyridoxal-5' phosphate dependent enzymes, cystathione $\beta$ synthase (CBS) and cystathione $y$ lyase (CSE) using L-cysteine as a substrate (103). CBS is highly expressed in the brain whereas CSE is mostly 
found in vasculature (104-105). $\mathrm{H}_{2} \mathrm{~S}$ promotes vascular relaxation and also has a negative inotropic effect on cardiac muscle. Both effects are attributed to the ability of $\mathrm{H}_{2} \mathrm{~S}$ to open potassium sensitive ATP channels (K $\left.\mathrm{K}_{\mathrm{ATP}}\right)$, which are widely distributed in coronary vasculature and myocardium (150). Studies quantify the expression of CSE in the heart and correlate it with levels of $\mathrm{H}_{2} \mathrm{~S}$. The results suggest that the heart is one of the major sources of endogenous $\mathrm{H}_{2} \mathrm{~S}$ (108). Mutant mice lacking CSE exhibit pronounced hypertension and diminished endothelium dependent vasorelaxation (112). This provides evidence that $\mathrm{H}_{2} \mathrm{~S}$ is a physiological vasodilator and regulator of blood pressure. Exogenous supplementation of $\mathrm{H}_{2} \mathrm{~S}$ decreases medial thickening of intracardiac coronary vessels and reduced interstitial fibrosis in spontaneously hypertensive rats, suggesting that $\mathrm{H}_{2} \mathrm{~S}$ increases the coronary reserve in hypertrophied hearts (114). Hypertrophied hearts are protected against severe ischemia by promoting angiogenesis (151). In vitro, VEGF causes an increase in $\mathrm{H}_{2} \mathrm{~S}$ release in endothelial cells while pharmacological inhibition of $\mathrm{H}_{2} \mathrm{~S}$ production or $\mathrm{K}_{\text {ATP }}$ channels attenuates VEGF signaling and EC migration (113). The pro-angiogenic effect of $\mathrm{H}_{2} \mathrm{~S}$ involves the signaling mechanism via AKT phosphorylation and activation of the MAPK pathway (152).

MMPs and their natural endogenous inhibitors, TIMPs are predominantly present in the heart and their expression is upregulated under pathological conditions (153). MMP-2 and MMP-9 are the two important gelatinases that play an important role in the development and remodeling of the heart and vasculature (154). Previous studies report that MMP-2 plays a significant role in 
angiogenesis and heart valve development (155-156). Knockout mice deficient in MMP-2 have various anomalies of the heart during embryogenesis $(42,46,157$ 158). Brooks and colleagues report that an angiogenic stimulus induces vascular remodeling through activation of MMP-2 and integrin ( $\alpha v \beta 3)(44-45)$. Although previous studies report that the MMP-2 expression and activity were significantly elevated in VEGF treated hypertrophied hearts (42), only few studies have examined the role of endostatin and angiostatin in heart failure $(41,48)$. We previously reported that MMP-9 induces endostatin and angiostatin production, which contribute to transition towards the decompensatory phase of heart failure (41). Studies in MMP-9 knockout mice have shown attenuation of ventricular enlargement, collagen deposition, and facilitation of angiogenesis following experimental myocardial infarction $(144-145,159)$. There is evidence that TIMP-3 plays an important role in inducing apoptosis as well as inhibiting angiogenesis $(41,58,133)$. The purpose of this study was to determine whether $\mathrm{H}_{2} \mathrm{~S}$ could mitigate the transition from compensatory cardiac hypertrophy to heart failure. We hypothesize that $\mathrm{H}_{2} \mathrm{~S}$ induces MMP-2 expression and inhibits MMP-9/TIMP-3 expression, thereby promoting angiogenesis which mitigates the transition from compensatory cardiac hypertrophy to heart failure. 


\section{MATERIAL AND METHODS}

\section{Animals}

Wild type mice (WT, C57BL6/J) aged 8 weeks were obtained from Jackson Laboratories (Bar Harbor, Me.; USA) and housed in the animal care facility at University of Louisville with access to standard chow and water. At the age of 12 weeks with an approximate weight of 23-25 grams, animals underwent pressure overload aortic banding $(A B)$ surgery and divided into 2 groups: one group received $30 \mu \mathrm{mol} /$ liter of sodium hydrogen sulfide (NaHS) in the drinking water and other received plain water (untreated control). Each group was further subdivided into sham, 3 weeks after $A B$ surgery ( $A B$ weeks group) and 8 weeks after $A B$ surgery ( $A B 8$ weeks group) with respect to the time points they attain hypertrophy and heart failure. 6 animals per group was used $(n=6)$. After the study period, animals were euthanized in accordance with National Institute of Health Guidelines for animal research. The protocol was reviewed and approved by the Institutional Animal Care and Use Committee (IACUC) of the University of Louisville.

\section{Pressure overload animal model}

Animals were anesthetized with sodium pentobarbital, intubated and ventilated with Harvard mini ventilator. Body temperature was maintained with a heating pad (TR 200, Fine Science Tools, Foster City, CA). Under sterile conditions the thorax was opened by left parasternal thoracotomy, and the ascending aorta was dissected and separated from adjacent structures. Care 
was taken to maintain proper hemostasis. Aortic banding was performed by placing a $26 \mathrm{~g}$ needle on the aorta and ligating around the vessel with 6-0 silk. The needle was quickly removed to keep the constricted aorta patent. The induced pressure overload effectively produced LV hypertrophy within 3 weeks after $A B$. The wound was closed in layers using 6-0 vicryl for subcutaneous tissues and 5-0 silk for the skin (130). All animals received intraperitoneal injection of Ketofen, $5 \mathrm{mg} / \mathrm{Kg}$ body weight for post operative analgesia. Animals in the sham subgroups underwent similar procedures except aortic banding.

\section{Hydrogen sulfide treatment}

Animals were given 6 weeks of $\mathrm{H}_{2} \mathrm{~S}$ in the drinking water in the form of NaHS (Sigma), which in aqueous solution releases $\mathrm{H}_{2} \mathrm{~S}$. A $30 \mu \mathrm{mol} / \mathrm{liter}$ concentration was supplemented to keep the hydrogen sulfide in physiological range $(10-100 \mu \mathrm{mol} / \mathrm{l})$. The diffusion of $\mathrm{H}_{2} \mathrm{~S}$ into room air is minimal since its density is $18 \%$ higher than that of air. Furthermore the drinking water was changed daily with fresh NaHS solution to provide adequate levels of $\mathrm{H}_{2} \mathrm{~S}$ to the mice (160).

\section{Antibodies and Reagents}

The following primary antibodies were used for studies: rabbit polyclonal anti-angiostatin, mouse monoclonal anti-endostatin, rabbit polyclonal MMP-2, and rabbit polyclonal MMP-9, rabbit polyclonal antibody against TIMP-3; (Abcam, Cambridge, MA); anti-mouse VEGF antibody ( R\&D systems, Minneapolis, MN) and mouse monoclonal anti-GAPDH (Sigma-Aldrich, St. Louis, MO). 
Following fluorescent secondary antibodies for Immunohistochemistry (IHC) were ordered from Invitrogen (Carlsbad, CA), Texas Red raised in mouse and Alexa Fluor 488 and 594 raised in rabbit.

\section{Western blot analysis}

Heart tissue from experimental animals and control animals was harvested and washed thoroughly in PBS and snap-frozen in liquid nitrogen. Protein extraction was done using 1X RIPA buffer (Tris-HCl 50 mM, pH7.4; NP40 1\%; Na-deoxycholate 0.25\%; $\mathrm{NaCl} 150 \mathrm{mM}$; EDTA $1 \mathrm{mM}$; PMSF $1 \mathrm{mM}$; Na3VO4 $1 \mathrm{mM}$; NaF $1 \mathrm{mM}$; protease inhibitor cocktail $1 \mu \mathrm{g} / \mathrm{ml}$ ). Estimation of protein was done by BCA method (Thermo fisher, Pittsburgh, PA). 50-75 $\mu \mathrm{g}$ of protein was fractionated by SDS-PAGE and transferred onto PVDF membrane (BioRad, Hercules, CA) by wet transfer method. The transferred proteins were processed for immunodetection of specific antigens. Briefly, non-specific sites were blocked with $5 \%$ nonfat dry milk in TBS-T $(50 \mathrm{mM}$ Tris-HCl, $150 \mathrm{mM} \mathrm{NaCl}$, $0.1 \%$ Tween- 20, $\mathrm{pH} 7.4$ ) for $1 \mathrm{~h}$ at room temperature. The blot was then incubated with appropriate primary antibody in blocking solution according to the supplier's specific instructions. The blots were washed with TBS-T ( 3 times, 10 min each) and incubated with appropriate HRP-conjugated secondary antibody for $1 \mathrm{~h}$ at room temperature. After washing, ECL Plus substrate (Amersham Biosciences, Pittsburgh, PA) was applied to the blot for $1 \mathrm{~min}$. The blot was developed using BIO-RAD Chemi Doc XRS + (BIO-RAD Laboratories, Hercules, CA). The blots were stripped and re-probed with GAPDH. The immuno reactive 
bands were scanned and densitometry analyzed by Un-Scan-It software (Silk Scientific, Orem, UT).

\section{Echocardiography}

Transthoracic echocardiography was performed on mice to achieve two dimensional left ventricle images from an apical view using a SONOS 1500 or 2500; Hewlett-Packard, Inc. and a $12.5 \mathrm{MHz}$ transducer. The procedure was performed as previously published (41) using tribromo ethanol (TBE) anesthesia to minimize the cardio depressing actions produced by other anesthetics (135). First mice were anesthetized with intraperitoneal injection of TBE, $(240 \mathrm{mg} / \mathrm{kg}$ body weight dose), depilated with hair removal cream (Nair) and placed on a heating pad to maintain body temperature. The functional status of the heart was assessed by LVIDd, LVIDs, LVPWD and \%FS. In murine echocardiography \%FS is the most common method to evaluate left ventricular function (161).

\section{Cryosectioning}

After mice were euthanized, hearts were harvested and thoroughly washed in PBS and preserved in Peel-A-Way disposable plastic tissue embedding moulds (Polysciences inc., Warrington, PA.,USA) filled with tissue freezing media (Triangle Biomedical Sciences, Durham, N.C., USA) and stored at $\square 70^{\circ} \mathrm{C}$ until analysis. Tissue sections $5 \mu \mathrm{m}$ in thickness were made using Leica CM 1850 Cryocut (Bannockburn, IL, USA). Sections were placed on Super frost plus glass slides, air-dried and processed for histological and Immunohistochemistry (IHC) staining. 


\section{Immunohistochemistry}

Immunohistochemistry was performed on $5 \mu \mathrm{m}$ thick frozen tissue sections using a standard IHC protocol (Abcam). Primary antibodies applied overnight and included anti-endostatin, anti-TIMP-3 (Abcam) and VEGF antibody (R\&D). A secondary antibody labeled with Texas Red (Invitrogen) was applied for immunodetection of these proteins. Similarly, primary antibodies anti-MMP-2 and anti-MMP-9 (Abcam) were applied overnight and secondarily conjugated with Alexa fluor 488 (Invitrogen) to detect expression of these MMPs. Stained slides protocol slides were analyzed for fluorescence using a laser scanning confocal microscope (Olympus FluoView1000) set at the appropriate filter settings.

\section{Masson's Trichrome Staining}

Collagen expression in tissue sections was assessed by Masson's trichrome staining according to the manufacturer's instructions (Richard-Allan Scientific, Kalamazoo, MI., USA). Collagen identified as blue staining.

\section{Image Proplus software}

Images from Immunohistochemistry and Masson's trichrome staining were analyzed with Image Proplus software.

\section{Pressure volume loop study (P-V loop)}

To assess the left ventricular function, pressure-volume study was done using Millar Pressure-Volume system (Millar Instruments Inc, Houston,TX). 
Following standard Millar protocol, steady state P-V loops were recorded followed by saline bolus and cuvette calibration for the conversion of RVU (relative volume units) to $\mu \mathrm{L}$. Hemodynamic variables obtained were analyzed by pressure volume analysis (PVAN) software. The results were used to substantiate echocardiography findings. \% ejection fraction (\%EF) was used to assess the functional status of the left ventricle.

\section{Statistical analysis}

All data are expressed as mean \pm SE. Data were analyzed using a oneway analysis of variance (ANOVA) to test for treatment effects, and differences between groups were determined using Tukey's post-hoc test. A p value $<0.05$ was considered to be significant. 


\section{RESULTS}

To determine the effects of $\mathrm{H}_{2} \mathrm{~S}$ on minimizing the remodeling of heart in a pressure overload mouse model, LV function was evaluated. Echocardiography data showed a decreased in left ventricular chamber diameter in $\mathrm{H}_{2} \mathrm{~S}$ treated $A B$ 3 weeks group and AB 8 weeks group compared to untreated controls. These findings suggest that dilatation of the heart decreases with $\mathrm{H}_{2} \mathrm{~S}$ treatment (Figure 35). The \%FS and the \%EF of the heart, representing ventricular function, were significantly improved in $A B 3$ weeks and $A B 8$ weeks $H 2 S$ treated groups compared to untreated controls (Figure 36).

Tissue sections were analyzed for changes in fibrosis content following AB. Interstitial and perivascular collagen deposition analysis demonstrated an increase in fibrosis after 8 weeks of $A B$ in comparison to sham controls and animals 3 weeks post-AB. Collagen deposition was significantly reduced in $\mathrm{H}_{2} \mathrm{~S}$ treated animals at 3 and 8 weeks post-AB compared to untreated controls (Figure 37). These findings suggest that $\mathrm{H}_{2} \mathrm{~S}$ decreases vascular resistance and reduces the effect of pressure overload on heart.

To assess the effect of $\mathrm{H}_{2} \mathrm{~S}$ on angiogenesis, VEGF was quantified in tissue sections by $\mathrm{IHC}$ and by Western blot analysis. VEGF expression significantly increased in $\mathrm{H}_{2} \mathrm{~S}$-treated animals at 8 weeks post- $\mathrm{AB}$ compared to untreated controls (Figures 39 and 49).

To assess the effect of $\mathrm{H}_{2} \mathrm{~S}$ on the transition from compensatory to decompensatory heart failure, anti-angiogenic factor levels were quantified. Endostatin and angiostatin levels increased in untreated controls, 8 weeks post 
$A B$ compared to sham and in animals 3 weeks post $A B$. Increasing levels of endostatin and angiostatin suggest that post- $A B$ angiogenesis at 8 weeks decreased and led to decompensatory heart failure. $\dot{H}_{2} S$ treatment significantly reduced the expression of endostatin and angiostatin in 8 weeks post-AB animals, compared with untreated control at 8 weeks. These results suggest the inhibitory action of $\mathrm{H}_{2} \mathrm{~S}$ on anti-angiogenic factors endostatin and angiostatin (Figures 41 and 49).

To assess the effect of $\mathrm{H}_{2} \mathrm{~S}$ on the MMP/TIMP axis in heart failure, expression of MMP-2, -9 , and TIMP-3 levels were quantified. MMP-2 expression increased in untreated mice 3 weeks post-AB compared to sham and 8 weeks post-AB mice. Expression of MMP-9 and TIMP-3 increased in untreated mice 8 weeks post-AB compared to sham and 3 weeks post-AB mice. $H_{2} S$ treatment increased the expression of MMP-2 after 8 weeks post-AB compared to untreated controls of same group (Figures 43 and 50). In contrast, $\mathrm{H}_{2} \mathrm{~S}$ treatment decreased the expression of both MMP-9 and TIMP-3 at 8 weeks post-AB compared to untreated controls at 8 weeks (Figures $45,47 \& 50$ ). These findings suggest the beneficial effect of $\mathrm{H}_{2} \mathrm{~S}$ is associated with the inhibiton of antiangiogenic factors, controlled by the MMP/TIMP axis. 
:eks
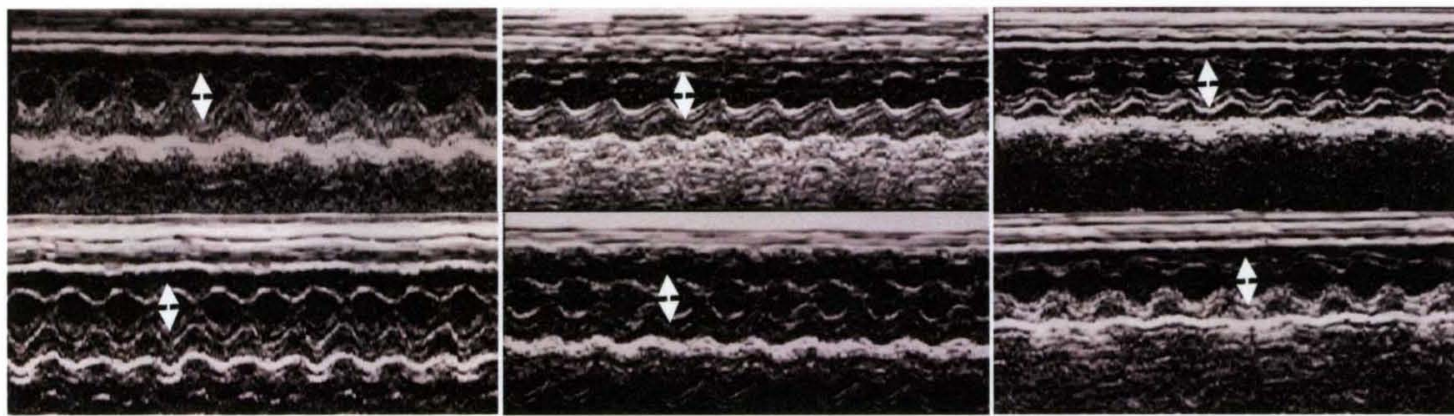

Control

$\mathrm{H}_{2} \mathrm{~S}$

Figure 35: Changes in left ventricular (LV) function following aortic banding (AB) and the effects of hydrogen sulfide $\left(\mathrm{H}_{2} \mathrm{~S}\right)$ treatment. Representative M-mode echocardiography images from sham group, $A B 3$ weeks and $A B 8$ weeks group. The effect of $\mathrm{H}_{2} \mathrm{~S}$ on LV function is shown in lower panel. Arrows show the differences in LV internal diameter between treated and untreated animals compared to their corresponding controls. 


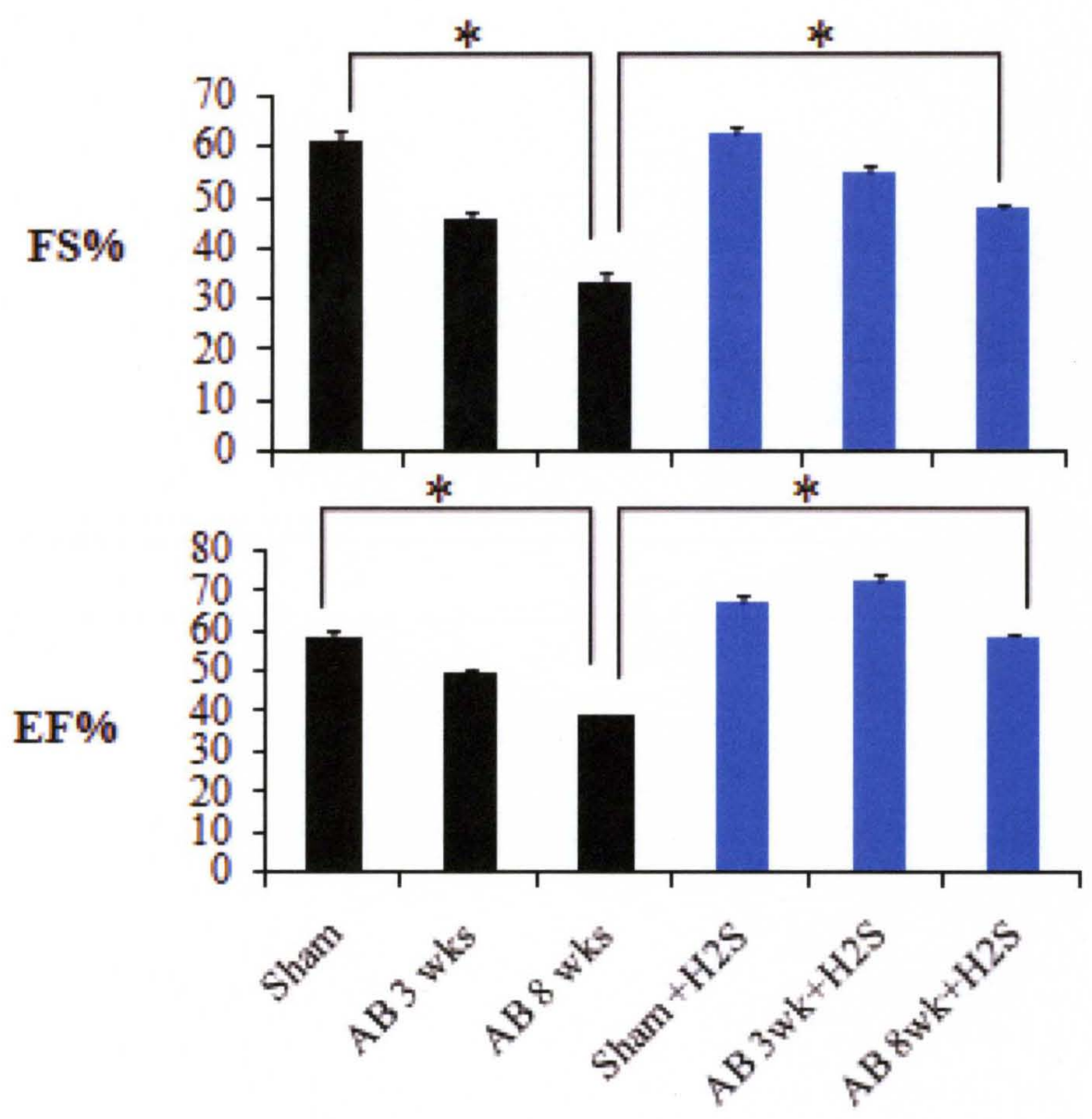

Figure 36: The bar graphs represent \%FS and \%EF obtained by echocardiography and pressure-volume loop study. Each bar represents mean \pm SE, $n=6$ per group. ${ }^{*} p<0.05$, considered as siginificant. 


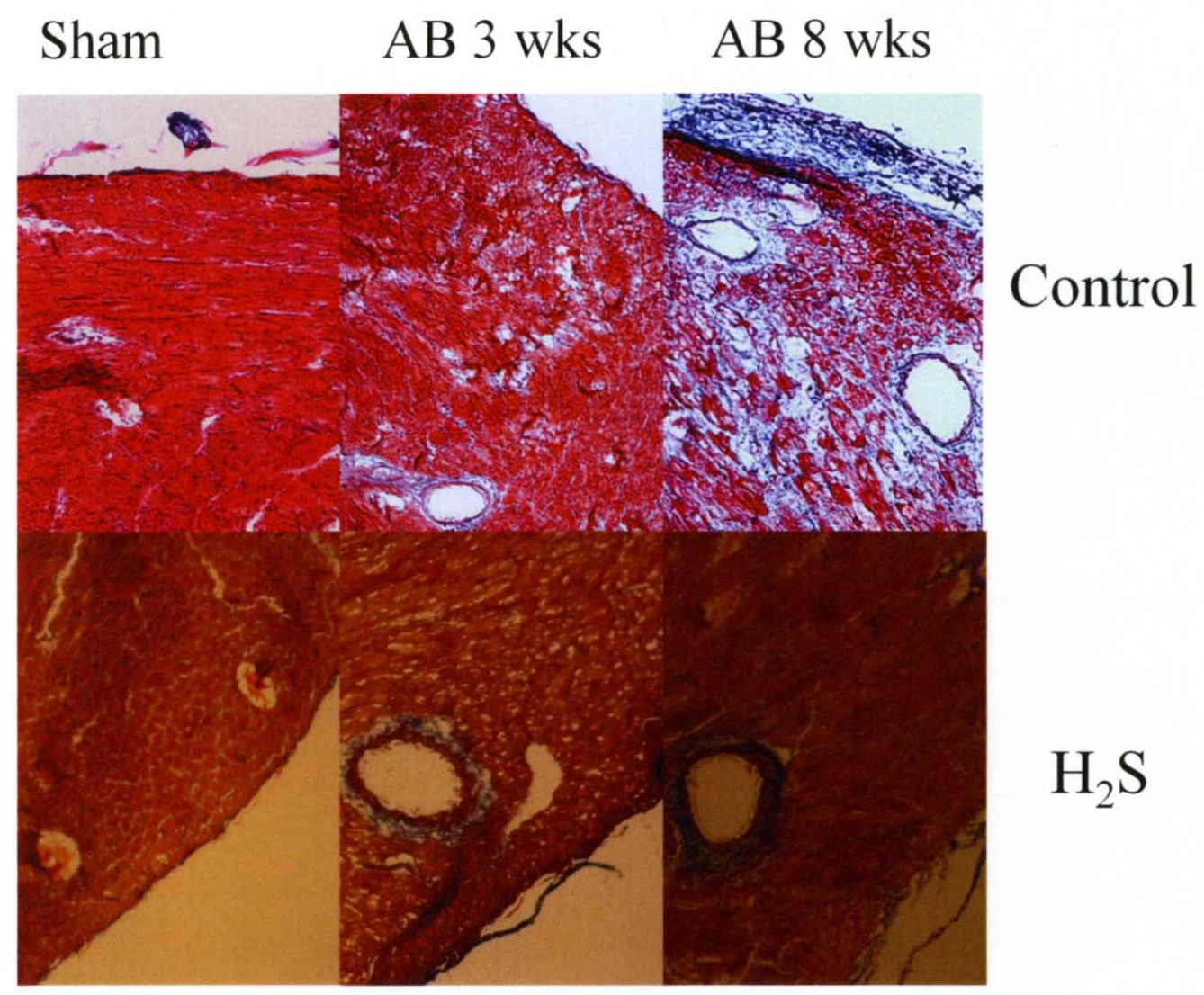

Figure 37: Masson's trichrome blue staining of collagen depicting intracardiac and perivascular fibrosis. Top panel represents heart sections from untreated sham, 3 weeks post-AB (AB 3 wks) and 8 weeks post-AB (AB 8 wks) groups. Bottom panel shows the corresponding groups treated with hydrogen sulfide $\left(\mathrm{H}_{2} \mathrm{~S}\right)$. 


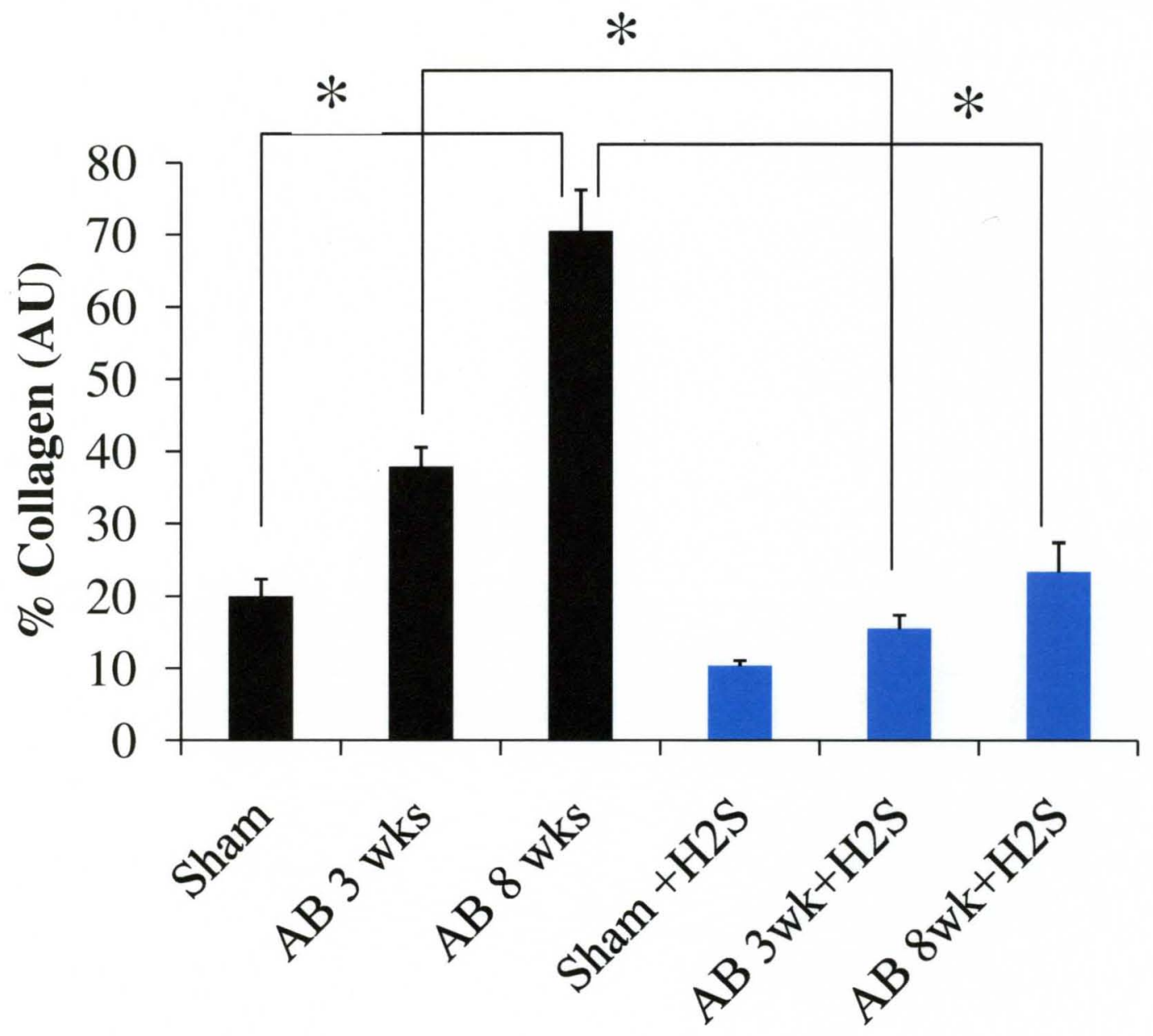

Figure 38: Quantification of collagen (blue staining) was done with the help of Image proplus software and represented in bar diagram. Data represents mean \pm SE from $n=6$ per group; ${ }^{*} p<0.05$ considered as significant. 


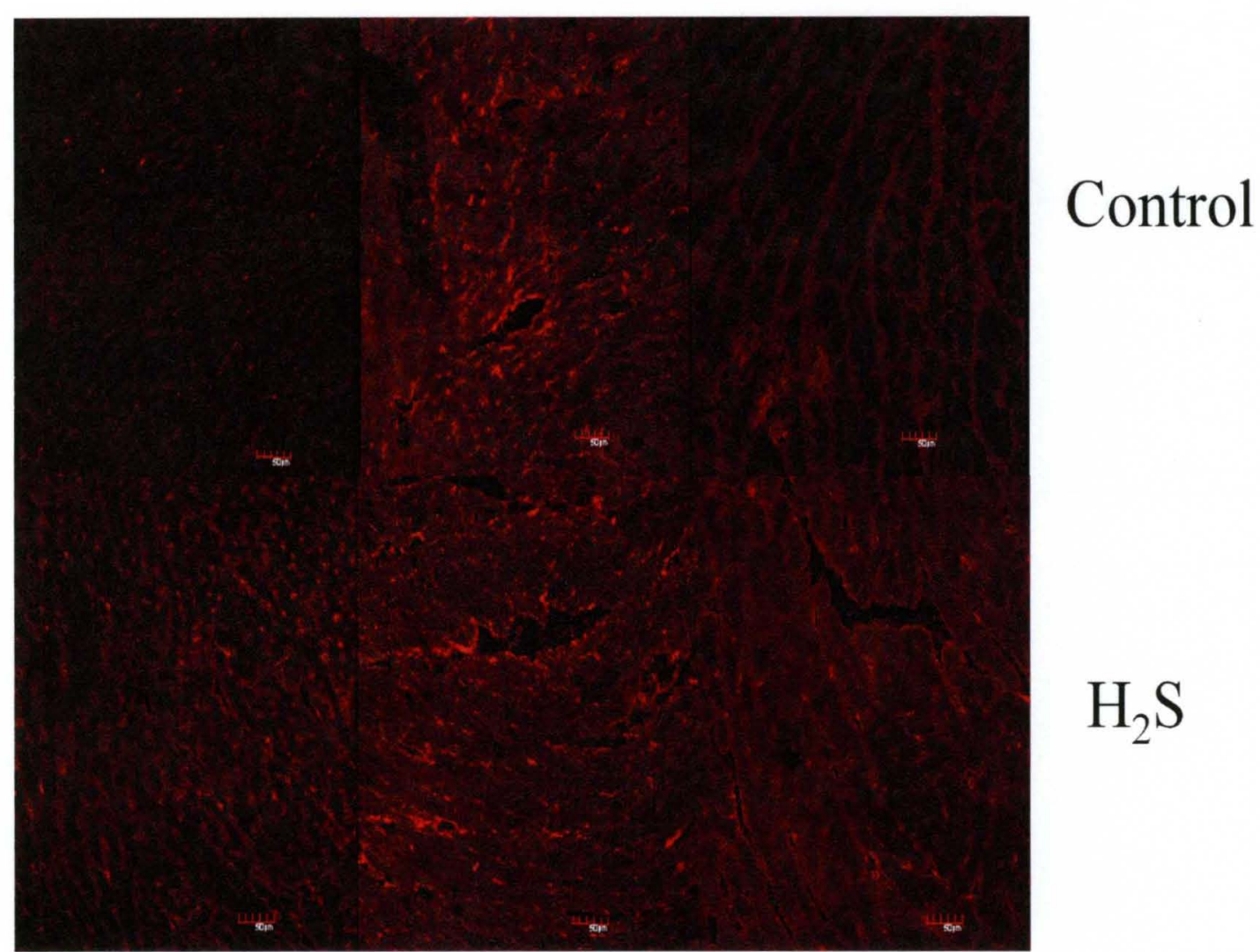

Figure 39: Immunohistochemical $(\mathrm{IHC})$ staining of heart sections with vascular endothelial growth factor (VEGF), secondarily stained with alexaflour 594 in sham, 3 weeks post-AB (AB 3 wks) and 8 weeks post-AB (AB 8 wks) in the top panel and corresponding $\mathrm{H}_{2} \mathrm{~S}$ treated groups in the bottom panel. The expression of VEGF is seen as red fluorescence intensity. 


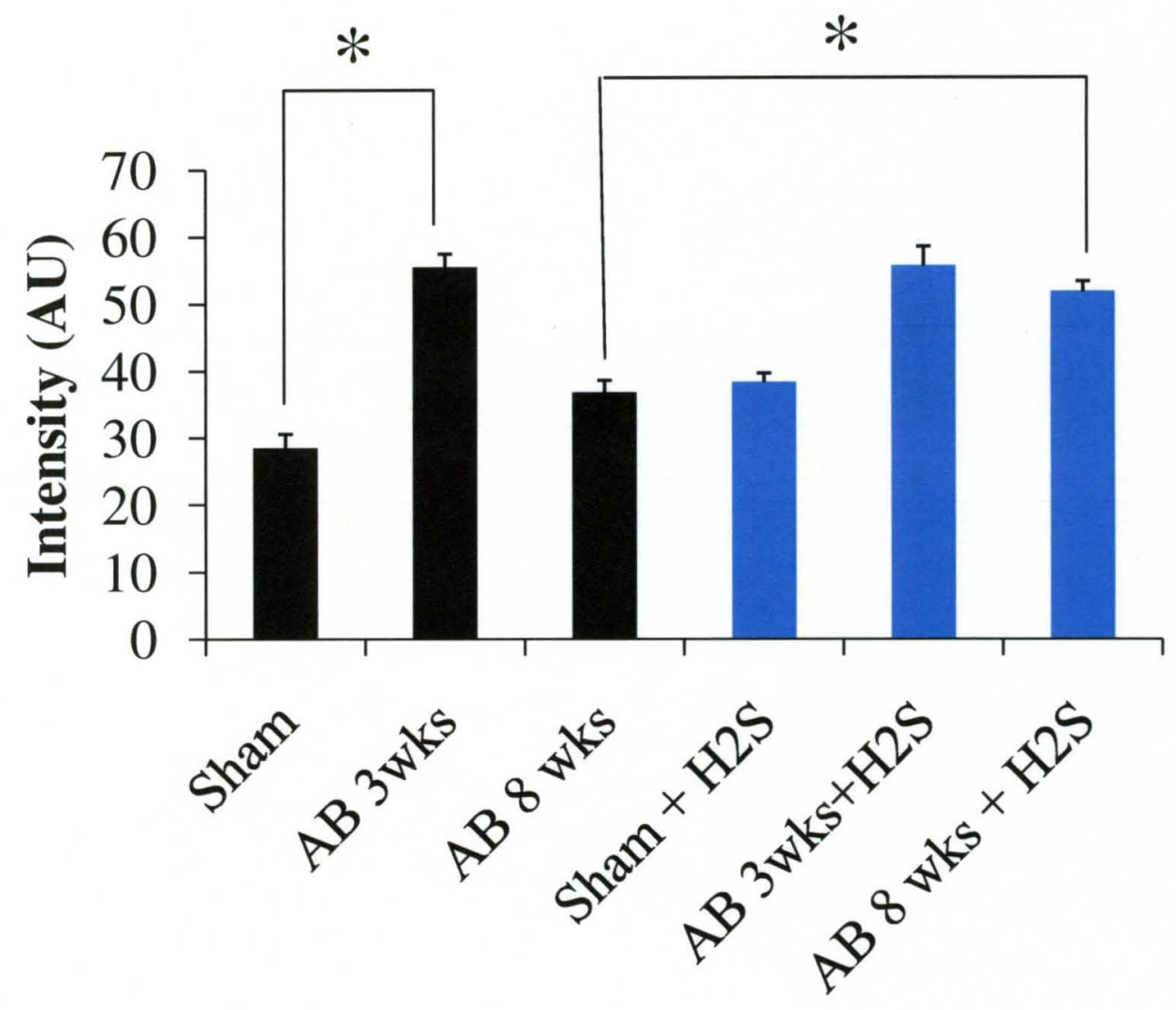

Figure 40: Quantification of VEGF stained heart sections in sham, 3 weeks after aortic banding ( $A B \quad 3$ wks), and 8 weeks after aortic banding ( $A B \quad$ wks) in untreated controls and their corresponding hydrogen sulfide $\left(\mathrm{H}_{2} \mathrm{~S}\right)$ treated groups. Data represents mean $\pm S E$ from $n=6$ per group; ${ }^{*} p<0.05$ was considered significant. 

Sham
AB 3 wks
AB 8 wks

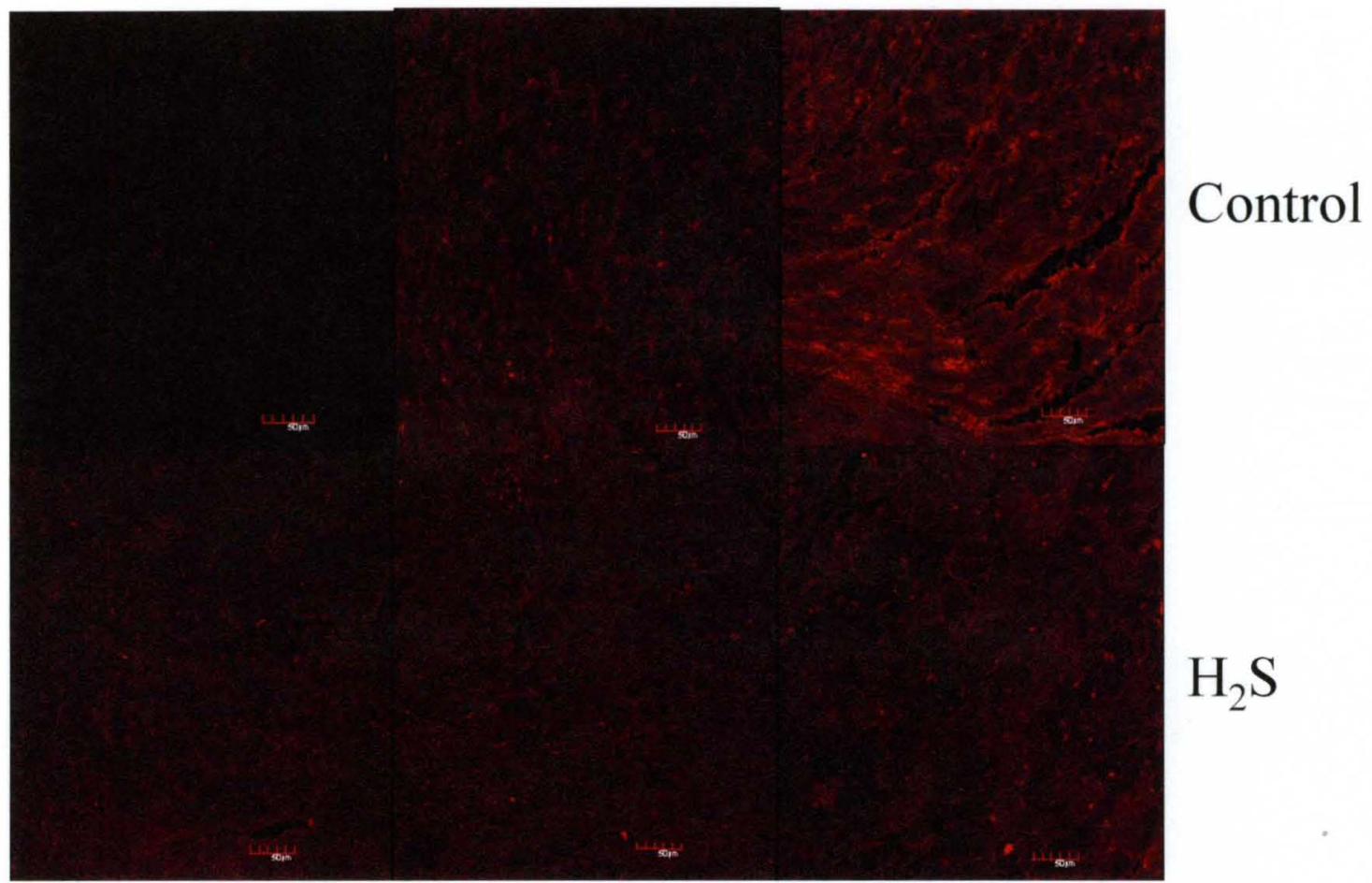

Figure 41: Immunohistochemical (IHC) staining of heart sections with endostatin, secondarily stained with texas red fluorescent antibody in sham, 3 weeks post$A B$ ( $A B \quad 3$ wks) and 8 weeks post-AB ( $A B \quad 8$ wks) in the top panel and corresponding $\mathrm{H}_{2} \mathrm{~S}$ treated groups in the bottom panel. The expression of endostatin is seen as red fluorescence intensity. 


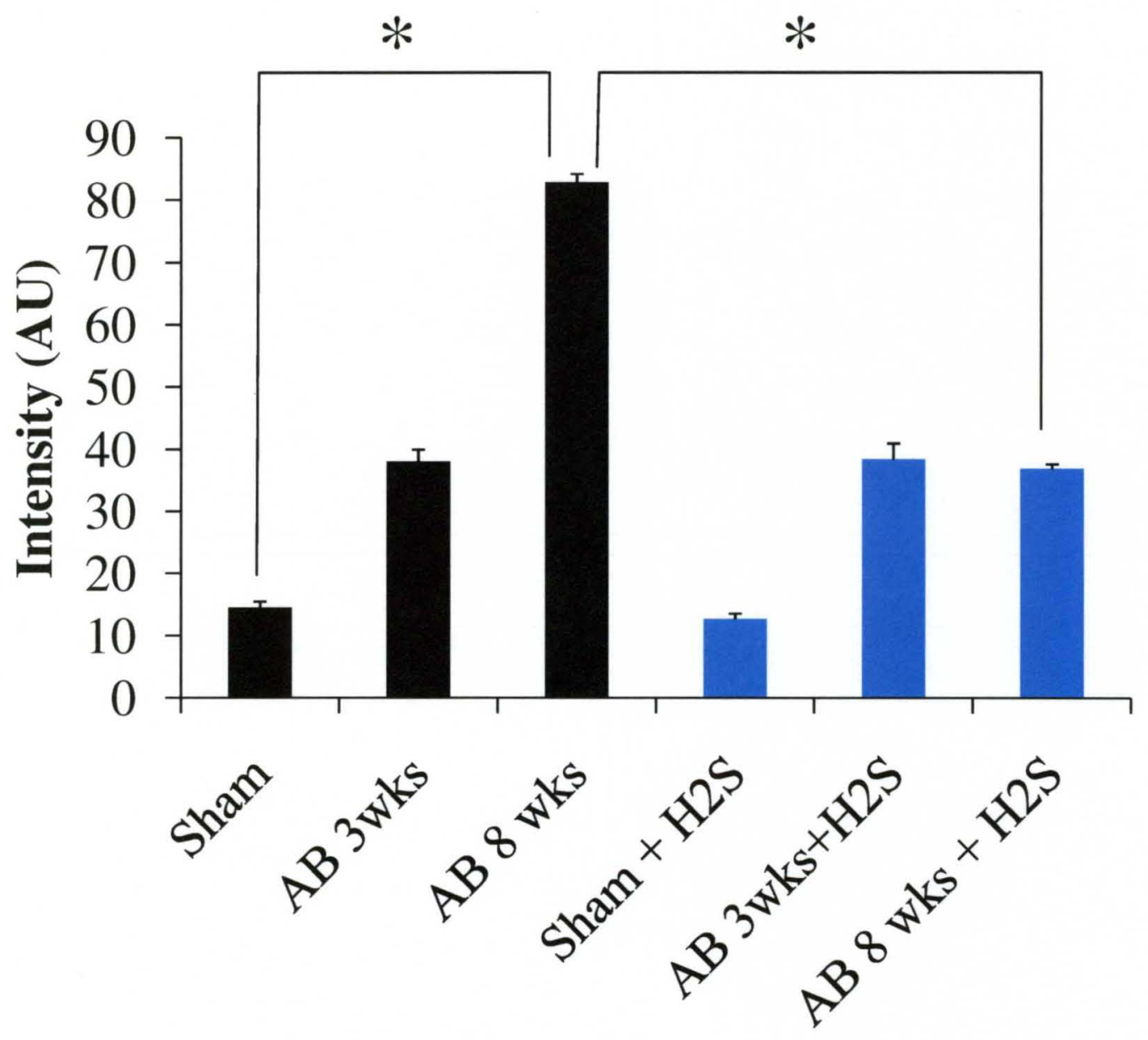

Figure 42: Quantification of endostatin stained heart sections in sham, 3 weeks after aortic banding ( $A B 3$ wks), and 8 weeks after aortic banding ( $A B 8$ wks) in untreated controls and their corresponding hydrogen sulfide $\left(\mathrm{H}_{2} \mathrm{~S}\right)$ treated groups. Data represents mean $\pm S E$ from $n=6$ per group; ${ }^{*} p<0.05$ was considered significant. 




Figure 43: Immunohistochemical (IHC) staining of heart sections with MMP-2 antibody, secondarily stained with alexaflour 488 fluorescent antibody in sham, 3 weeks post-AB ( $A B 3$ wks) and 8 weeks post-AB ( $A B 8$ wks) in the top panel and corresponding $\mathrm{H}_{2} \mathrm{~S}$ treated groups in the bottom panel. The expression of MMP-2 is seen as green fluorescence intensity. 


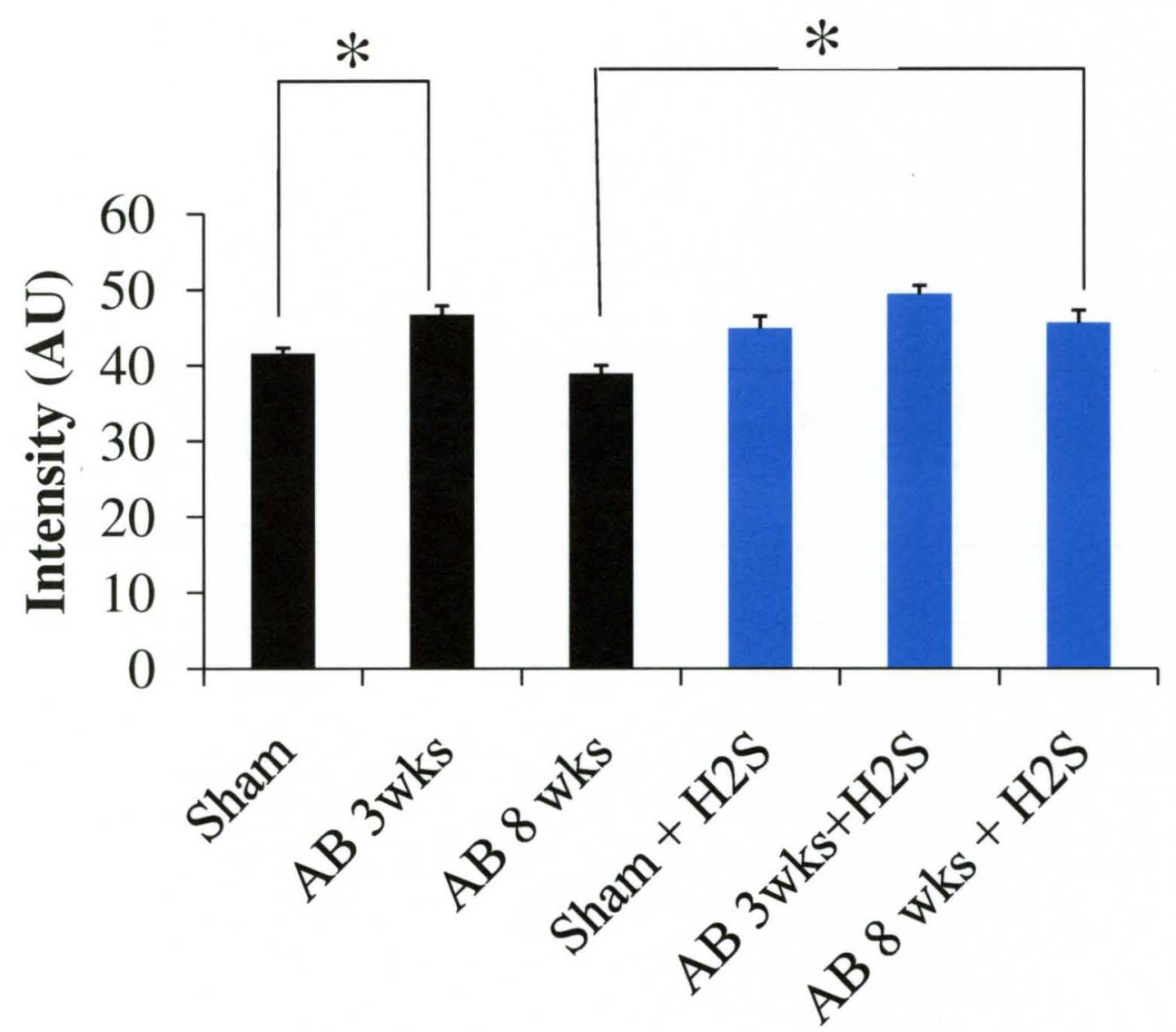

Figure 44: Quantification of MMP-2 stained heart sections in sham, 3 weeks after aortic banding ( $A B 3$ wks), and 8 weeks after aortic banding ( $A B 8$ wks) in untreated controls and their corresponding hydrogen sulfide $\left(\mathrm{H}_{2} \mathrm{~S}\right)$ treated groups. Data represents mean $\pm S E$ from $n=6$ per group; ${ }^{*} \mathrm{p}<0.05$ was considered significant. 
Sham

AB 3 wks

AB 8 wks

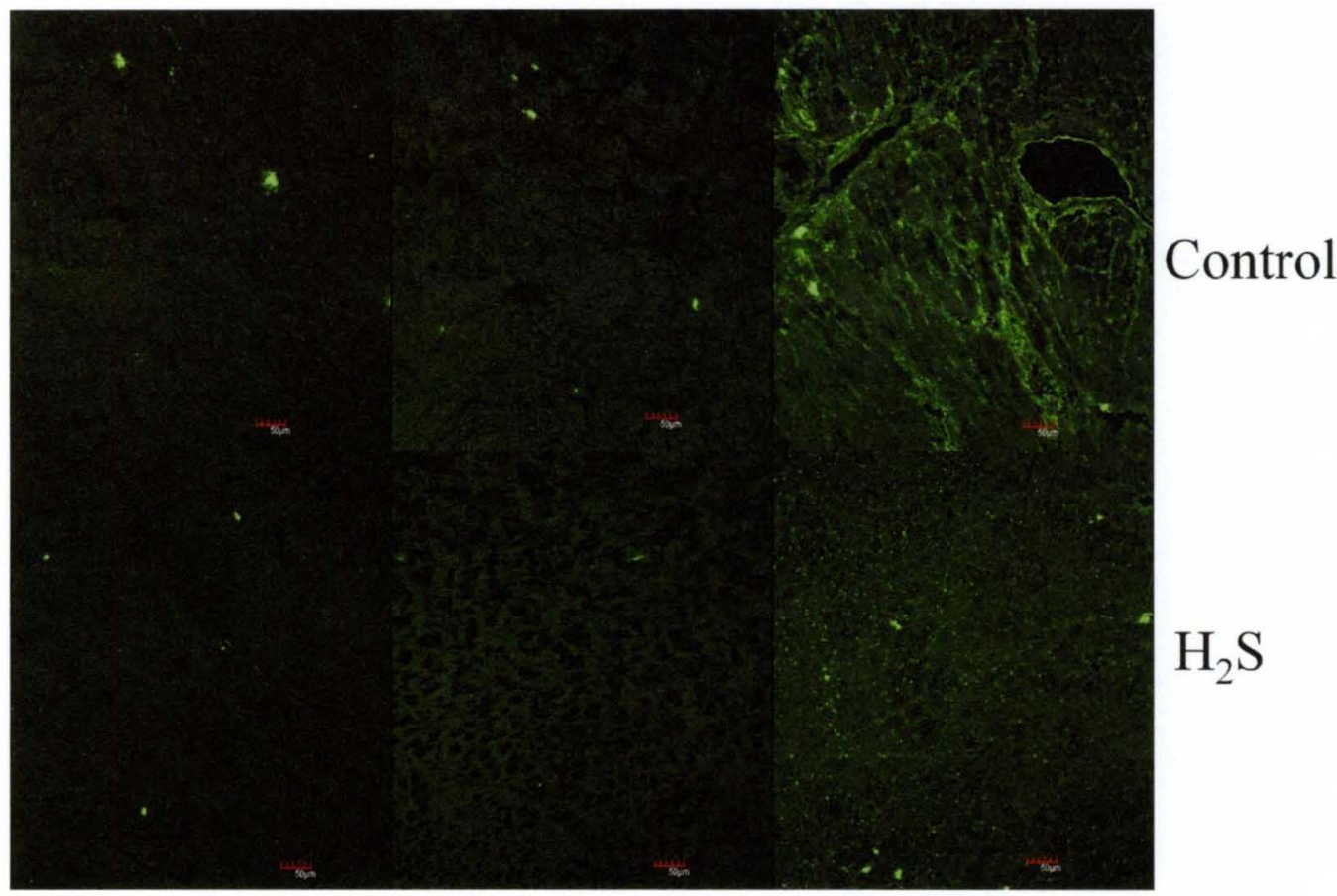

Figure 45: Immunohistochemical (IHC) staining of heart sections with MMP-9 antibody, secondarily stained with alexaflour 488 fluorescent antibody in sham, 3 weeks post-AB ( $A B 3$ wks) and 8 weeks post-AB ( $A B 8$ wks) in the top panel and corresponding $\mathrm{H}_{2} \mathrm{~S}$ treated groups in the bottom panel. The expression of MMP-9 is seen as green fluorescence intensity. 


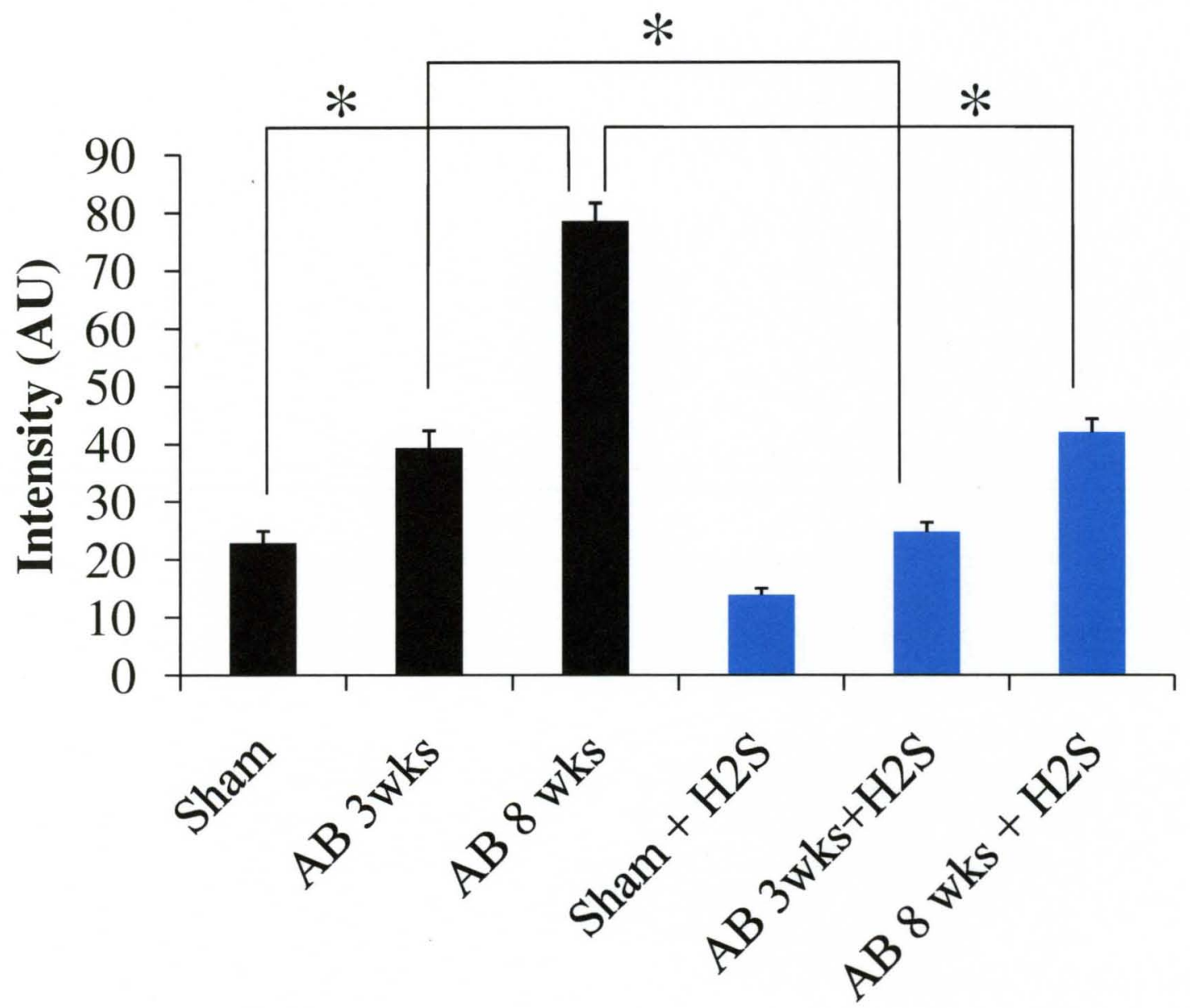

Figure 46: Quantification of MMP-9 stained heart sections in sham, 3 weeks after aortic banding (AB 3 wks), and 8 weeks after aortic banding (AB 8 wks) in untreated controls and their corresponding hydrogen sulfide $\left(\mathrm{H}_{2} \mathrm{~S}\right)$ treated groups. Data represents mean \pm SE from $n=6$ per group; ${ }^{*} p<0.05$ was considered significant. 


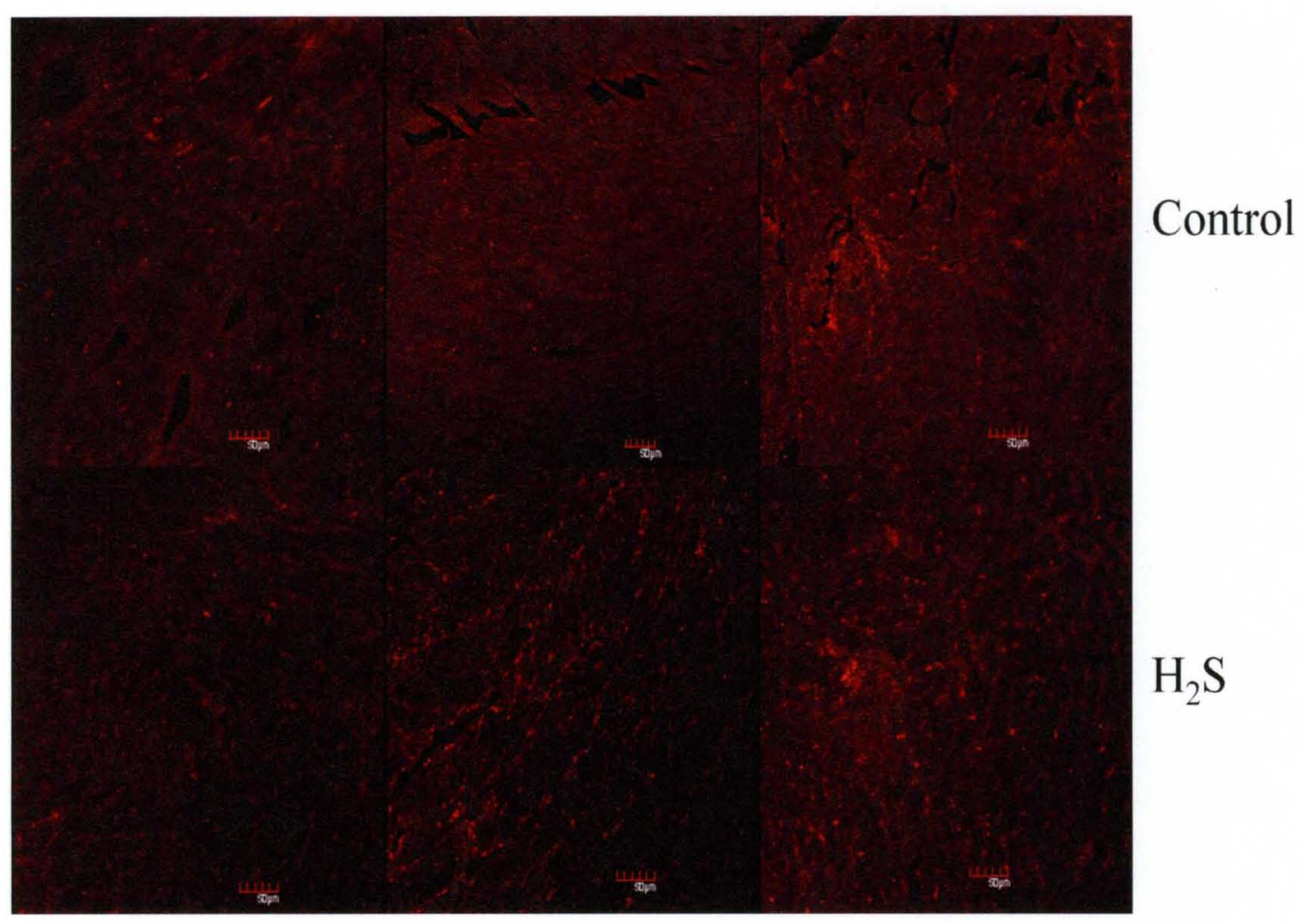

Figure 47: Immunohistochemical (IHC) staining of heart sections with TIMP-3, secondarily stained with texas red fluorescent antibody in sham, 3 weeks post$A B$ ( $A B \quad 3$ wks) and 8 weeks post-AB ( $A B \quad 8$ wks) in the top panel and corresponding $\mathrm{H}_{2} \mathrm{~S}$ treated groups in the bottom panel. The expression of TIMP-3 is seen as red fluorescence intensity. 


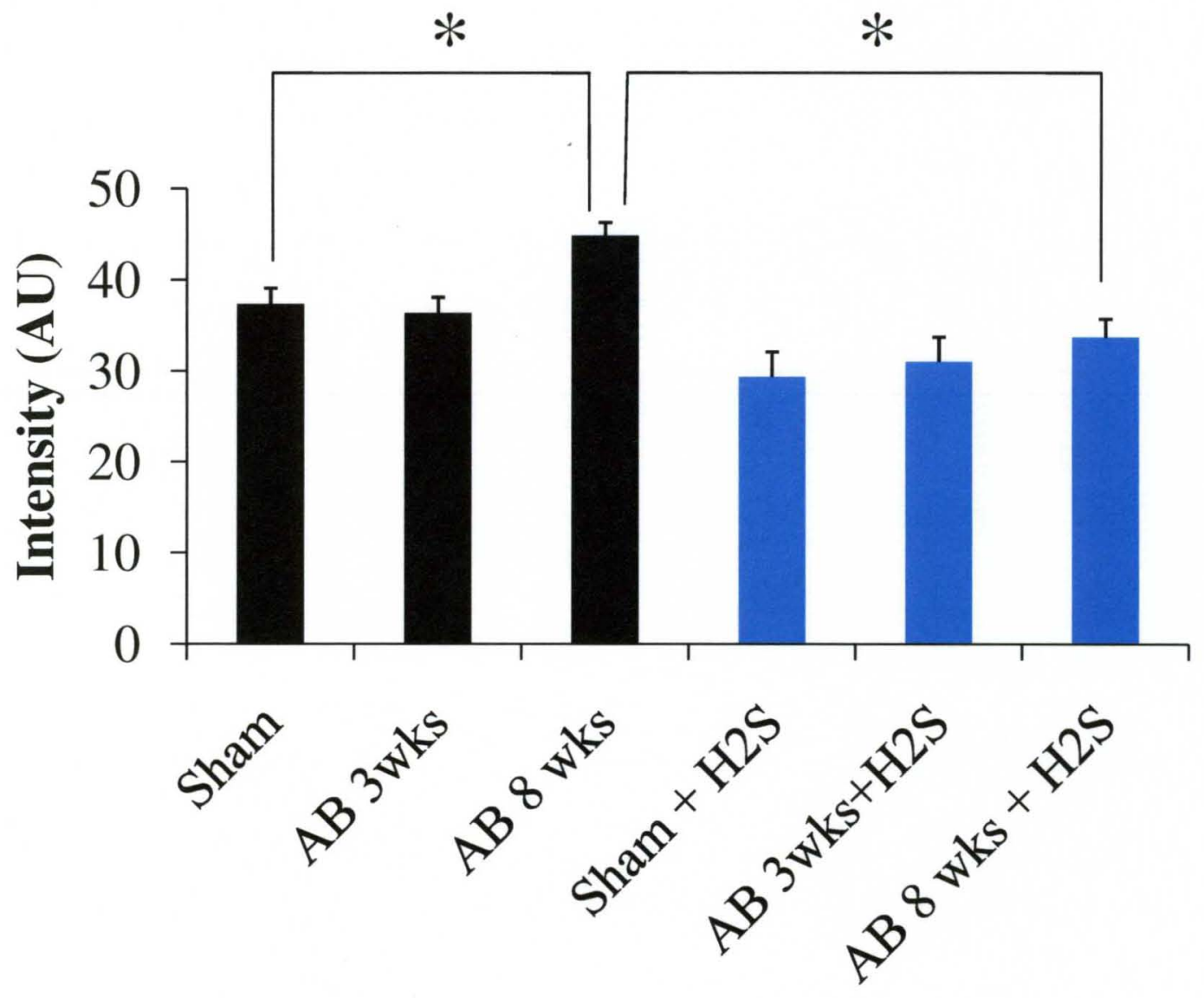

Figure 48: Quantification of TIMP-3 stained heart sections in sham, 3 weeks after aortic banding ( $A B 3$ wks), and 8 weeks after aortic banding ( $A B 8$ wks) in untreated controls and their corresponding hydrogen sulfide $\left(\mathrm{H}_{2} \mathrm{~S}\right)$ treated groups. Data represents mean $\pm S E$ from $n=6$ per group; ${ }^{*} p<0.05$ was considered significant. 
VEGF-A

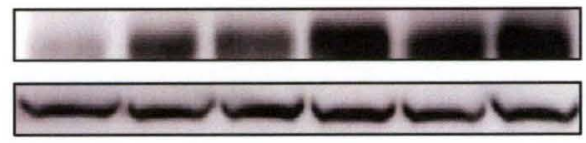

Angiostatin

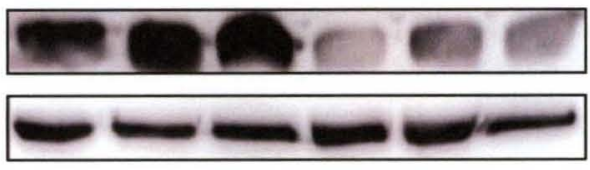

Endostatin

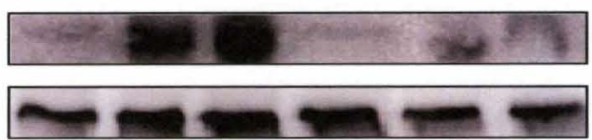

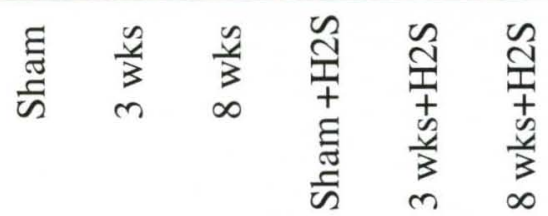
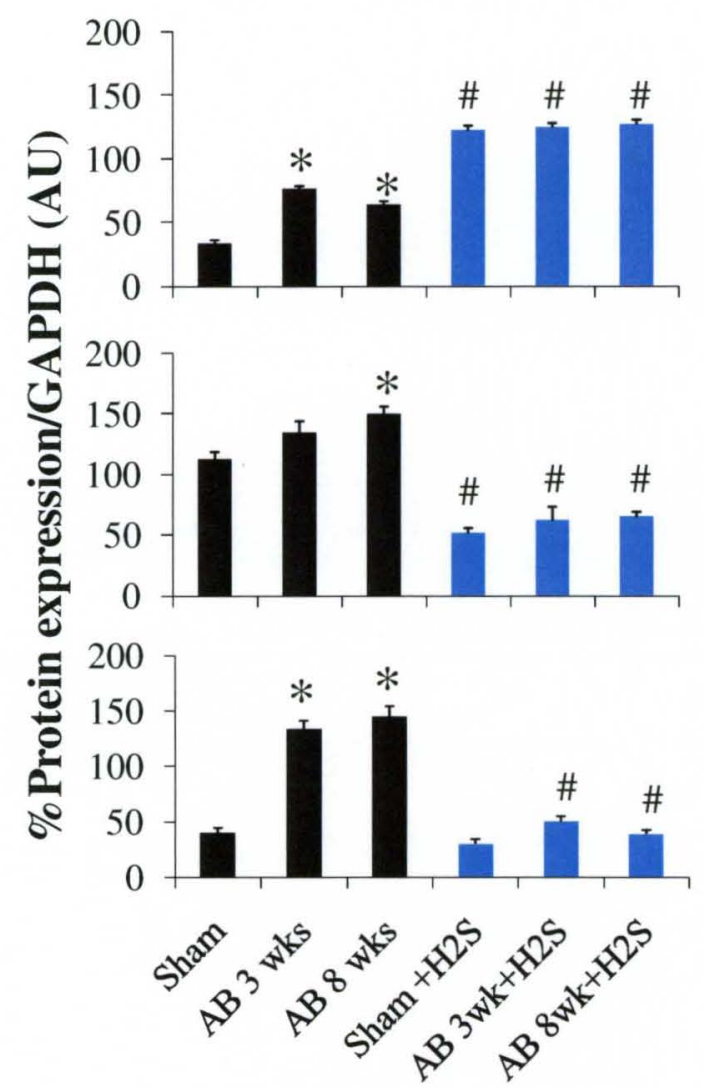

Figure 49: Western blot analysis of VEGF-A, angiostatin and endostatin expression in sham, 3 weeks after aortic banding ( $A B 3$ wks) and 8 wks after aortic banding ( $A B \quad 8$ wks) in untreated control (first 3 lanes) and their corresponding hydrogen sulfide $(\mathrm{H} 2 \mathrm{~S})$ treated groups (last 3 lanes).Densitometry analysis of the protein expression in arbitrary units was depicted in bar diagram. Each bar represents mean \pm SE from $n=6$ per group and ${ }^{*} p<0.05$ compared with untreated sham, $\# p<0.05$ compared to their corresponding untreated controls. 
MMP-2

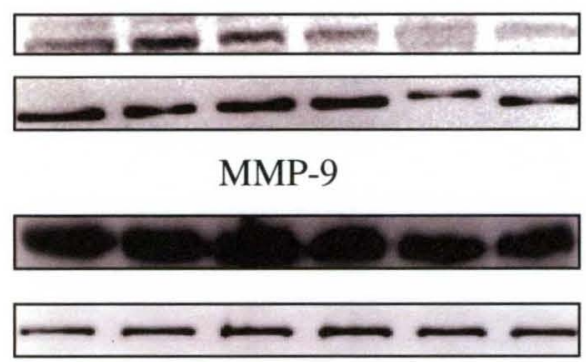

Timp-3

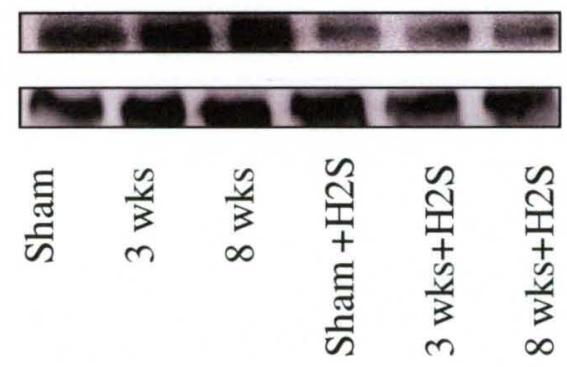

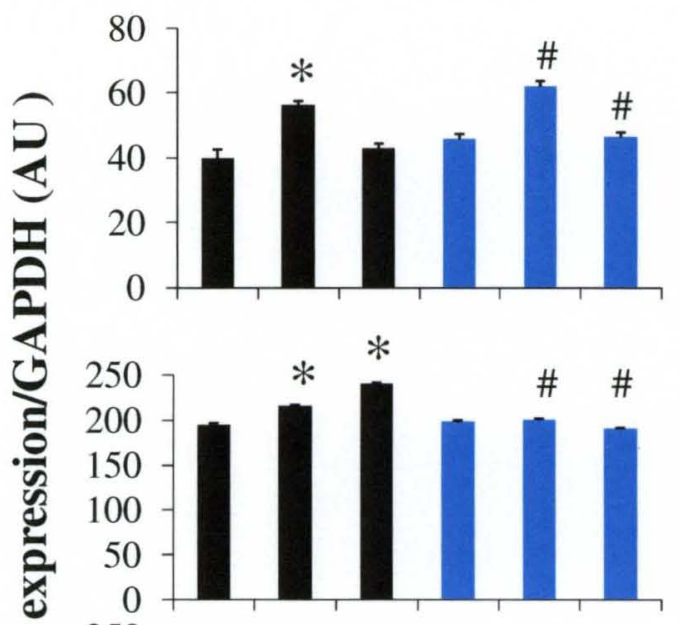

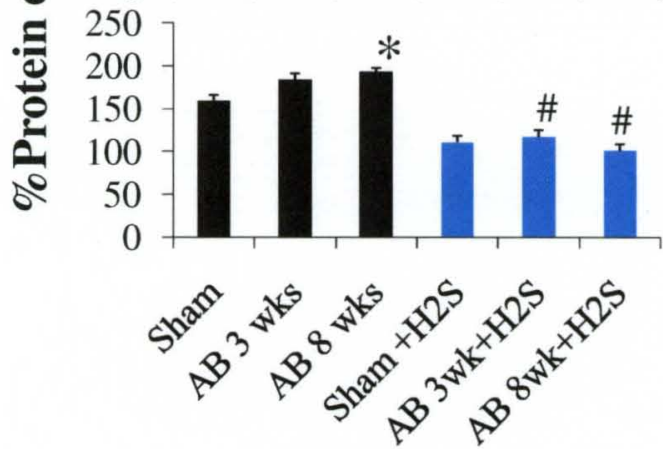

Figure 50: Western blot analysis of matrix metalloproteinases-2 \&-9 (MMP-2,-9) and tissue inhibitor of matrix metalloproteinase-3 (TIMP-3) in sham, 3 weeks after aortic banding ( $A B 3$ wks) and 8 wks after aortic banding ( $A B 8$ wks) in untreated control (first 3 lanes) and their corresponding hydrogen sulfide (H2S) treated groups (last 3 lanes). Densitometry analysis of protein expression in arbitrary units was depicted in bar diagram. Each bar represents mean \pm SE from $\mathrm{n}=6$ per group. ${ }^{*} \mathrm{p}<0.05$ compared with untreated sham, $\# \mathrm{p}<0.05$ compared to their corresponding untreated controls. 


\section{Discussion}

Previously we have reported that during compensatory hypertrophy, there was increase in the expression of MMP-2, which promotes the production of VEGF. Subsequently, we have shown that in decompensatory phase, MMP-9 expression supersedes MMP-2 expression and induces the production of anti angiogenic factors, endostatin and angiostatin. This causes the release of TIMP3 , resulting in decreased angiogenesis and progression to heart failure.

In the present study, we show that $\mathrm{H}_{2} \mathrm{~S}$ promotes angiogenesis by inducing MMP-2 production and by inhibiting anti-angiogenic factors endostatin and angiostatin. $\mathrm{H}_{2} \mathrm{~S}$ also decreases the level of MMP-9 and TIMP-3, thereby arresting the conversion from compensatory cardiac hypertrophy to heart failure (Figure 19). Our results showed that the treatment of pressure overload mice with $\mathrm{H}_{2} \mathrm{~S}$ increases the production of angiogenic factors like VEGF. This promotes the increase in angiogenesis, and thereby, normalizes the capillary density and myocyte imbalance. Similarly, MMP-2 expression also increased in the $\mathrm{H}_{2} \mathrm{~S}$ treated groups, especially in $\mathrm{AB} 8$ weeks group, supporting the hypothesis that MMP-2 as an angiogenic promoter, induced VEGF production. Interestingly, we observed that MMP-9 expression decreased in the $\mathrm{H}_{2} \mathrm{~S}$ treated groups along with the expression of anti angiogenic factors like angiostatin, endostatin and TIMP-3. Since we previously reported that MMP-9 promotes antiangiogenic factor production and TIMP-3 instigates apoptosis, these results 
suggest the role of hydrogen sulfide in inhibiting both anti-angiogenic factor production and apoptosis by regulating the MMP/TIMP axis.

Previous studies show that TIMP-3 has strong anti-angiogenic activity that can be seen in all stages of angiogenesis (57). MMP-9 is shown to be induced in heart failure and generates anti-angiogenic factors, endostatin and angiostatin $(41,47-48)$. Researchers report that the MMP-2 expression and activity is significantly elevated in VEGF treated hypertrophied hearts (42). This unequivocally suggests that MMP-9 is an anti-angiogenic and MMP-2 is a proangiogenic factor. The treatment with $\mathrm{H}_{2} \mathrm{~S}$ promotes angiogenesis and thereby, inhibits the transition from compensatory cardiac hypertrophy to heart failure. Functional data from echocardiography and pressure-volume study also showed improvement in left ventricular function after treating with $\mathrm{H}_{2} \mathrm{~S}$ in comparison to untreated control groups.

Clinically, it is well known that heart disease is the leading cause of mortality not only in the United States but also in rest of the world. Hypertension is one of the main risk factors leading to heart disease. Our research provides an insight into the transition mechanism from compensatory cardiac hypertrophy to heart failure. The beneficial effects of $\mathrm{H}_{2} \mathrm{~S}$ in impeding the transition will help in clinical outcomes of heart failure. 


\title{
Conclusions
}

\begin{abstract}
Based on our results, we conclude that $\mathrm{H}_{2} \mathrm{~S}$ plays a role in a) ameliorating left ventricular dysfunction following pressure overload, b) minimizing accumulation of collagen deposition in the perivascular and intracardiac parenchymal tissue, c) altering expression of MMPs and TIMPs and thus regulating ECM remodeling, d) promoting angiogenesis by stimulating the production of VEGF, e) inhibiting anti-angiogenic factors like endostatin and angiostatin.
\end{abstract}




\section{CHAPTER VI}

\section{SUMMARY AND CONCLUSION}

Heart failure is the number one cause of mortality in both men and women and is a major public health problem around the world. Heart failure is defined as a pathophysiological state in which an abnormality of cardiac function is responsible for the failure of the heart to pump blood at a rate commensurate with the requirements of the metabolizing tissues. The most important risk factors leading to heart failure are hypertension, myocardial ischemia, myocardial infarction, valvular disease, and diabetes.

During hypertension, the increase in pressure overload on the heart produces a compensatory hypertrophy which slowly progresses to decompensatory heart failure. The relationship between capillary density and the size of myofiber is important in heart failure, as the fiber diameter increases the number of capillaries per square $\mathrm{mm}$ decreases (15). The data suggest that as the myocyte to capillary ratio increases during compensatory hypertrophy, it eventually will progress to terminal heart failure. The discovery of the involvement of MMPs and their natural inhibitors TIMPs, in the cardiac remodeling revolutionized the field of cardiac failure research. Investigators demonstrate that the alterations in the normal MMP/TIMP balance induce cardiac 
matrix remodeling, which plays an important role in the pathogenesis of hypertension-induced heart failure. Disruption of coordinated cardiac hypertrophy and angiogenesis leads to heart failure, suggesting the role of angiogenesis in the pathogenesis of heart failure. Promoting angiogenesis in severely hypertrophied hearts protects them from ischemic injury. Although the role of hypertension in the pathogenesis of heart failure is well established, the treatment of hypertension induced heart failure is unclear. The relatively recent discovery of $\mathrm{H}_{2} \mathrm{~S}$, as an endogenous gaseous transmitter has prompted investigators to use $\mathrm{H}_{2} \mathrm{~S}$ as a therapeutic agent. Studies report that $\mathrm{H}_{2} \mathrm{~S}$ is cardio protective in hypertension, ischemia/reperfusion injury, and infarction, but its potential role as a therapeutic agent during transition from compensatory cardiac hypertrophy to heart failure has not been elucidated.

In the present study, we propose that cardiac matrix remodeling during pressure overload is induced by an increase in angiogenic factors during compensatory cardiac hypertrophy. Sustained pressure overload causes an increase in anti-angiogenic factors that leads to decompensatory heart failure. We also hypothesize that $\mathrm{H}_{2} \mathrm{~S}$ treatment mitigates the transition from compensatory hypertrophy to decompensatory heart failure.

In the first set of experiments, we found that the pressure overload due to aortic banding increases expression of pro-angiogenic MMP-2, which in turn induces production of VEGF during compensatory cardiac hypertrophy. Overtime, chronic pressure overload induces an increase in expression of MMP- 
9 and TIMP-3, which induce collagen deposition and release of anti-angiogenic factors like endostatin and angiostatin, contributing to a decrease in angiogenesis and thus leading to decompensatory heart failure.

In the second set of experiments, we showed that $\mathrm{H}_{2} \mathrm{~S}$ treatment promotes angiogenesis through increased expression of MMP-2 and VEGF. H2S also inhibits the production of anti-angiogenic factors by blocking MMP-9/TIMP-3 expression thus mitigating the transition from compensatory cardiac hypertrophy to heart failure. Therefore, $\mathrm{H}_{2} \mathrm{~S}$ therapy may become a useful therapeutic agent, if applied during the compensatory phase of the hypertensive heart failure.

Additional studies are needed to explore further mechanistic details to understand the pathological mechanism of transition from compensatory hypertrophy to heart failure.

\section{FUTURE STUDIES}

To further elucidate the mechanisms of heart failure due to pressure overload, it would be interesting to use transgenic mice models of MMP- $2^{-/}$, TIMP $-3^{-/}$and MMP $-9^{-/}$mice and study the effects of aortic banding in these animals. Results from these studies will provide confirmatory evidence of the proangiogenic role of MMP-2 and anti-angiogenic role of MMP-9/TIMP-3. Also studies that selectively inhibit angiostatin and endostatin formation may promote angiogenesis and may reverse the decompensatory phase of heart failure. 


\section{REFERENCES}

1. Lloyd-Jones D, Adams RJ, Brown TM, Carnethon M, Dai S, De Simone G, et al. Heart disease and stroke statistics--2010 update: a report from the American Heart Association. Circulation. 2010;121(7):e46-e215.

2. Robert M. Berne MNL. Physiology. Robert M. Berne MNL, editor. the University of Michigan: Mosby, 1998; 1998.

3. Nag AC. Study of non-muscle cells of the adult mammalian heart: a fine structural analysis and distribution. Cytobios. 1980;28(109):41-61.

4. Braunwald.E. Heart Disease: A Textbook of Cardiovascular Medicine. Philadelphia, PA: W. B. Saunders; 1980.

5. Fields LE, Burt VL, Cutler JA, Hughes J, Roccella EJ, Sorlie P. The burden of adult hypertension in the United States 1999 to 2000: a rising tide. Hypertension. 2004;44(4):398-404.

6. Poole-Wilson GSFEHSWHWTP. Pathophysiology of Heart Failure Hurst's The Heart The McGraw-Hill Companies; 2008. p. 689-791.

7. Yip GW, Fung JW, Tan YT, Sanderson JE. Hypertension and heart failure: a dysfunction of systole, diastole or both? J Hum Hypertens. 2009;23(5):295-306.

8. Olivetti G, Capasso JM, Meggs LG, Sonnenblick EH, Anversa P. Cellular basis of chronic ventricular remodeling after myocardial infarction in rats. Circ Res. 1991;68(3):856-69. 
9. Richey PA, Brown SP. Pathological versus physiological left ventricular hypertrophy: a review. J Sports Sci. 1998;16(2):129-41.

10. Levy D, Garrison RJ, Savage DD, Kannel WB, Castelli WP. Prognostic implications of echocardiographically determined left ventricular mass in the Framingham Heart Study. N Engl J Med. 1990;322(22):1561-6.

11. Weber KT, Brilla CG, Janicki JS. Myocardial fibrosis: functional significance and regulatory factors. Cardiovasc Res. 1993;27(3):341-8.

12. Grossman W, Jones D, McLaurin LP. Wall stress and patterns of hypertrophy in the human left ventricle. J Clin Invest. 1975;56(1):56-64. PMCID: 436555.

13. Lorell BH, Carabello BA. Left ventricular hypertrophy: pathogenesis, detection, and prognosis. Circulation. 2000;102(4):470-9.

14. Tyagi SC, Hayden MR. Role of nitric oxide in matrix remodeling in diabetes and heart failure. Heart Fail Rev. 2003;8(1):23-8.

15. Roberts JT, Wearn JT. Quantitative changes in the capillary-muscle relationship in human hearts during normal growth and hypertrophy. American Heart Journal. 1941;21(5):617-33.

16. Hunt SA, Abraham WT, Chin MH, Feldman AM, Francis GS, Ganiats TG, et al. ACC/AHA 2005 Guideline Update for the Diagnosis and Management of Chronic Heart Failure in the Adult: a report of the American College of Cardiology/American Heart Association Task Force on Practice Guidelines (Writing Committee to Update the 2001 Guidelines for the Evaluation and Management of Heart Failure): developed in collaboration with the American College of Chest Physicians and the International Society for Heart and Lung Transplantation: endorsed by the Heart Rhythm Society. Circulation. 2005;112(12):e154-235. 
17. Pouleur HG, Konstam MA, Udelson JE, Rousseau MF, The SI. Changes in ventricular volume, wall thickness and wall stress during progression of left ventricular dysfunction. Journal of the American College of Cardiology. 1993;22(4, Supplement 1):A43-A8.

18. Burgess ML, Carver WE, Terracio L, Wilson SP, Wilson MA, Borg TK. Integrin-mediated collagen gel contraction by cardiac fibroblasts. Effects of angiotensin II. Circ Res. 1994;74(2):291-8.

19. Carver W, Molano I, Reaves TA, Borg TK, Terracio L. Role of the alpha 1 beta 1 integrin complex in collagen gel contraction in vitro by fibroblasts. $J$ Cell Physiol. 1995;165(2):425-37.

20. Medugorac I. Collagen content in different areas of normal and hypertrophied rat myocardium. Cardiovasc Res. 1980;14(9):551-4.

21. Weber KT, Janicki JS, Shroff SG, Pick R, Chen RM, Bashey RI. Collagen remodeling of the pressure-overloaded, hypertrophied nonhuman primate myocardium. Circ Res. 1988;62(4):757-65.

22. Weber KT, Sun Y, Tyagi SC, Cleutjens JP. Collagen network of the myocardium: function, structural remodeling and regulatory mechanisms. $J$ Mol Cell Cardiol. 1994;26(3):279-92.

23. Kassiri Z, Khokha R. Myocardial extra-cellular matrix and its regulation by metalloproteinases and their inhibitors. Thromb Haemost. 2005;93(2):212-9.

24. Swynghedauw B. Molecular mechanisms of myocardial remodeling. Physiol Rev. 1999;79(1):215-62.

25. Brilla CG, Rupp H. Myocardial collagen matrix remodeling and congestive heart failure. Cardiologia. 1994;39(12 Suppl 1):389-93. 
26. Gross J, Lapiere CM. Collagenolytic activity in amphibian tissues: a tissue culture assay. Proc Natl Acad Sci U S A. 1962;48:1014-22. PMCID: 220898.

27. Parks WC, Wilson CL, Lopez-Boado YS. Matrix metalloproteinases as modulators of inflammation and innate immunity. Nat Rev Immunol. 2004;4(8):61729.

28. Dabek J, Kulach A, Gasior Z. The role of matrix metalloproteinases in acute coronary syndromes. Eur J Intern Med. 2007;18(6):463-6.

29. Puente XS, Sanchez LM, Overall CM, Lopez-Otin C. Human and mouse proteases: a comparative genomic approach. Nat Rev Genet. 2003;4(7):544-58.

30. Egeblad M, Werb Z. New functions for the matrix metalloproteinases in cancer progression. Nat Rev Cancer. 2002;2(3):161-74.

31. Tyagi SC, Ratajska A, Weber KT. Myocardial matrix metalloproteinase(s): localization and activation. Mol Cell Biochem. 1993;126(1):49-59.

32. Mann DL, Spinale FG. Activation of matrix metalloproteinases in the failing human heart: breaking the tie that binds. Circulation. 1998;98(17):1699-702.

33. Vincenti MP, Coon CI, Mengshol JA, Yocum S, Mitchell P, Brinckerhoff CE. Cloning of the gene for interstitial collagenase-3 (matrix metalloproteinase-13) from rabbit synovial fibroblasts: differential expression with collagenase-1 (matrix metalloproteinase-1). Biochem J. 1998;331 ( Pt 1):341-6. PMCID: 1219357.

34. Pei D, Weiss SJ. Transmembrane-deletion mutants of the membrane-type matrix metalloproteinase-1 process progelatinase $A$ and express intrinsic matrixdegrading activity. J Biol Chem. 1996;271(15):9135-40.

35. Steffensen B, Wallon UM, Overall CM. Extracellular matrix binding properties of recombinant fibronectin type II-like modules of human $72-\mathrm{kDa}$ 
gelatinase/type IV collagenase. High affinity binding to native type I collagen but not native type IV collagen. J Biol Chem. 1995;270(19):11555-66.

36. Sternlicht MD, Werb Z. How matrix metalloproteinases regulate cell behavior. Annu Rev Cell Dev Biol. 2001;17:463-516. PMCID: 2792593.

37. Hojilla CV, Mohammed FF, Khokha R. Matrix metalloproteinases and their tissue inhibitors direct cell fate during cancer development. $\mathrm{Br} \mathrm{J}$ Cancer. 2003;89(10):1817-21. PMCID: 2394437.

38. Folgueras AR, Pendas AM, Sanchez LM, Lopez-Otin C. Matrix metalloproteinases in cancer: from new functions to improved inhibition strategies. Int J Dev Biol. 2004;48(5-6):411-24.

39. Toy LW. Matrix metalloproteinases: their function in tissue repair. J Wound Care. 2005;14(1):20-2.

40. Vu TH, Werb Z. Matrix metalloproteinases: effectors of development and normal physiology. Genes Dev. 2000;14(17):2123-33.

41. Givvimani S, Tyagi N, Sen U, Mishra PK, Qipshidze N, Munjal C, et al. MMP2/TIMP-2/TIMP-4 versus MMP-9/TIMP-3 in transition from compensatory hypertrophy and angiogenesis to decompensatory heart failure. Arch Physiol Biochem. 2010;116(2):63-72. PMCID: 2879167.

42. Friehs I, Margossian RE, Moran AM, Cao-Danh H, Moses MA, del Nido PJ. Vascular endothelial growth factor delays onset of failure in pressure-overload hypertrophy through matrix metalloproteinase activation and angiogenesis. Basic Res Cardiol. 2006;101(3):204-13.

43. Sang QX. Complex role of matrix metalloproteinases in angiogenesis. Cell Res. 1998;8(3):171-7. 
44. Brooks PC, Stromblad S, Sanders LC, von Schalscha TL, Aimes RT, StetlerStevenson WG, et al. Localization of matrix metalloproteinase MMP-2 to the surface of invasive cells by interaction with integrin alpha $v$ beta 3 . Cell. 1996;85(5):683-93.

45. Brooks PC, Silletti S, von Schalscha TL, Friedlander M, Cheresh DA. Disruption of angiogenesis by PEX, a noncatalytic metalloproteinase fragment with integrin binding activity. Cell. 1998;92(3):391-400.

46. Tyagi SC. Proteinases and myocardial extracellular matrix turnover. Mol Cell Biochem. 1997;168(1-2):1-12.

47. Tyagi SC, Kumar SG, Haas SJ, Reddy HK, Voelker DJ, Hayden MR, et al. Post-transcriptional regulation of extracellular matrix metalloproteinase in human heart end-stage failure secondary to ischemic cardiomyopathy. $\mathrm{J}$ Mol Cell Cardiol. 1996;28(7):1415-28.

48. Sodha NR, Clements RT, Boodhwani M, Xu SH, Laham RJ, Bianchi C, et al. Endostatin and angiostatin are increased in diabetic patients with coronary artery disease and associated with impaired coronary collateral formation. Am J Physiol Heart Circ Physiol. 2009;296(2):H428-34. PMCID: 2643884.

49. Phatharajaree W, Phrommintikul A, Chattipakorn N. Matrix metalloproteinases and myocardial infarction. Can J Cardiol. 2007;23(9):727-33. PMCID: 2651917.

50. Gomez DE, Alonso DF, Yoshiji H, Thorgeirsson UP. Tissue inhibitors of metalloproteinases: structure, regulation and biological functions. Eur $\mathrm{J}$ Cell Biol. 1997;74(2):111-22.

51. Lambert E, Dasse E, Haye B, Petitfrere E. TIMPs as multifacial proteins. Crit Rev Oncol Hematol. 2004;49(3):187-98. 
52. Wilhelm SM, Collier IE, Marmer BL, Eisen AZ, Grant GA, Goldberg GI. SV40transformed human lung fibroblasts secrete a 92-kDa type IV collagenase which is identical to that secreted by normal human macrophages. $J$ Biol Chem. 1989;264(29):17213-21.

53. Ward RV, Hembry RM, Reynolds JJ, Murphy G. The purification of tissue inhibitor of metalloproteinases-2 from its $72 \mathrm{kDa}$ progelatinase complex. Demonstration of the biochemical similarities of tissue inhibitor of metalloproteinases-2 and tissue inhibitor of metalloproteinases-1. Biochem J. 1991;278 ( Pt 1):179-87. PMCID: 1151465.

54. Howard EW, Banda MJ. Binding of tissue inhibitor of metalloproteinases 2 to two distinct sites on human 72-kDa gelatinase. Identification of a stabilization site. J Biol Chem. 1991;266(27):17972-7.

55. Butler GS, Apte SS, Willenbrock F, Murphy G. Human tissue inhibitor of metalloproteinases 3 interacts with both the $\mathrm{N}$ - and $\mathrm{C}$-terminal domains of gelatinases A and B. Regulation by polyanions. J Biol Chem. 1999;274(16):1084651.

56. Bigg HF, Shi YE, Liu YE, Steffensen B, Overall CM. Specific, high affinity binding of tissue inhibitor of metalloproteinases-4 (TIMP-4) to the COOH-terminal hemopexin-like domain of human gelatinase A. TIMP-4 binds progelatinase A and the COOH-terminal domain in a similar manner to TIMP-2. $J$ Biol Chem. 1997;272(24):15496-500.

57. Takigawa M, Nishida Y, Suzuki F, Kishi J, Yamashita K, Hayakawa T. Induction of angiogenesis in chick yolk-sac membrane by polyamines and its inhibition by tissue inhibitors of metalloproteinases (TIMP and TIMP-2). Biochem Biophys Res Commun. 1990;171(3):1264-71. 
58. Kang JA, Kim JT, Song HS, Bae MK, Yi EY, Kim KW, et al. Anti-angiogenic and anti-tumor invasive activities of tissue inhibitor of metalloproteinase-3 from shark, Scyliorhinus torazame. Biochim Biophys Acta. 2003;1620(1-3):59-64.

59. Seo DW, Li H, Guedez L, Wingfield PT, Diaz T, Salloum R, et al. TIMP-2 mediated inhibition of angiogenesis: an MMP-independent mechanism. Cell. 2003;114(2):171-80.

60. Vanhoutte D, Heymans S. TIMPs and cardiac remodeling: 'Embracing the MMP-independent-side of the family'. J Mol Cell Cardiol. 2010;48(3):445-53.

61. Risau W. Mechanisms of angiogenesis. Nature. 1997;386(6626):671-4.

62. Heil M, Eitenmuller I, Schmitz-Rixen T, Schaper W. Arteriogenesis versus angiogenesis: similarities and differences. J Cell Mol Med. 2006;10(1):45-55.

63. Pandya NM, Dhalla NS, Santani DD. Angiogenesis--a new target for future therapy. Vascul Pharmacol. 2006;44(5):265-74.

64. Hanahan D, Folkman J. Patterns and emerging mechanisms of the angiogenic switch during tumorigenesis. Cell. 1996;86(3):353-64.

65. Schumacher B, Pecher P, von Specht BU, Stegmann T. Induction of neoangiogenesis in ischemic myocardium by human growth factors: first clinical results of a new treatment of coronary heart disease. Circulation. 1998;97(7):64550.

66. Rosengart TK, Lee LY, Patel SR, Kligfield PD, Okin PM, Hackett NR, et al. Six-month assessment of a phase I trial of angiogenic gene therapy for the treatment of coronary artery disease using direct intramyocardial administration of an adenovirus vector expressing the VEGF121 cDNA. Ann Surg. 1999;230(4):466-70; discussion 70-2. PMCID: 1420895. 
67. Laham RJ, Sellke FW, Edelman ER, Pearlman JD, Ware JA, Brown DL, et al. Local perivascular delivery of basic fibroblast growth factor in patients undergoing coronary bypass surgery: results of a phase I randomized, doubleblind, placebo-controlled trial. Circulation. 1999;100(18):1865-71.

68. Shiojima I, Sato K, Izumiya Y, Schiekofer S, Ito M, Liao R, et al. Disruption of coordinated cardiac hypertrophy and angiogenesis contributes to the transition to heart failure. J Clin Invest. 2005;115(8):2108-18. PMCID: 1180541.

69. Plouet J, Schilling J, Gospodarowicz D. Isolation and characterization of a newly identified endothelial cell mitogen produced by AtT-20 cells. EMBO J. 1989;8(12):3801-6. PMCID: 402066.

70. Leung DW, Cachianes G, Kuang WJ, Goeddel DV, Ferrara N. Vascular endothelial growth factor is a secreted angiogenic mitogen. Science. 1989;246(4935):1306-9.

71. Senger DR, Galli SJ, Dvorak AM, Perruzzi CA, Harvey VS, Dvorak HF. Tumor cells secrete a vascular permeability factor that promotes accumulation of ascites fluid. Science. 1983;219(4587):983-5.

72. Keck PJ, Hauser SD, Krivi G, Sanzo K, Warren T, Feder J, et al. Vascular permeability factor, an endothelial cell mitogen related to PDGF. Science. 1989;246(4935):1309-12.

73. Shweiki D, Itin A, Soffer D, Keshet E. Vascular endothelial growth factor induced by hypoxia may mediate hypoxia-initiated angiogenesis. Nature. 1992;359(6398):843-5.

74. Ferrara N. VEGF and the quest for tumour angiogenesis factors. Nat Rev Cancer. 2002;2(10):795-803. 
75. Shibuya M, Yamaguchi S, Yamane A, Ikeda T, Tojo A, Matsushime H, et al. Nucleotide sequence and expression of a novel human receptor-type tyrosine kinase gene (flt) closely related to the fms family. Oncogene. 1990;5(4):519-24.

76. Millauer B, Wizigmann-Voos S, Schnurch H, Martinez R, Moller NP, Risau W, et al. High affinity VEGF binding and developmental expression suggest Flk-1 as a major regulator of vasculogenesis and angiogenesis. Cell. 1993;72(6):835-46.

77. Quinn TP, Peters KG, De Vries C, Ferrara N, Williams LT. Fetal liver kinase 1 is a receptor for vascular endothelial growth factor and is selectively expressed in vascular endothelium. Proc Natl Acad Sci U S A. 1993;90(16):7533-7. PMCID: 47176.

78. Karkkainen MJ, Makinen T, Alitalo K. Lymphatic endothelium: a new frontier of metastasis research. Nat Cell Biol. 2002;4(1):E2-5.

79. Ferrara N, Gerber HP, LeCouter J. The biology of VEGF and its receptors. Nat Med. 2003;9(6):669-76.

80. Banai S, Jaklitsch MT, Shou M, Lazarous DF, Scheinowitz M, Biro S, et al. Angiogenic-induced enhancement of collateral blood flow to ischemic myocardium by vascular endothelial growth factor in dogs. Circulation. $1994 ; 89(5): 2183-9$.

81. Nyberg P, Xie L, Kalluri R. Endogenous inhibitors of angiogenesis. Cancer Res. 2005;65(10):3967-79.

82. Sund $M$, Xie $L$, Kalluri $R$. The contribution of vascular basement membranes and extracellular matrix to the mechanics of tumor angiogenesis. APMIS. 2004;112(7-8):450-62.

83. Ribatti D. Endogenous inhibitors of angiogenesis: a historical review. Leuk Res. 2009;33(5):638-44. 
84. O'Reilly MS, Boehm T, Shing Y, Fukai N, Vasios G, Lane WS, et al. Endostatin: an endogenous inhibitor of angiogenesis and tumor growth. Cell. 1997;88(2):277-85.

85. Dhanabal M, Ramchandran R, Waterman MJ, Lu H, Knebelmann B, Segal M, et al. Endostatin induces endothelial cell apoptosis. $J$ Biol Chem. 1999;274(17):11721-6.

86. Dhanabal $M$, Ramchandran $R$, Volk R, Stillman IE, Lombardo M, IruelaArispe $M L$, et al. Endostatin: yeast production, mutants, and antitumor effect in renal cell carcinoma. Cancer Res. 1999;59(1):189-97.

87. Dixelius J, Cross M, Matsumoto T, Sasaki T, Timpl R, Claesson-Welsh L. Endostatin regulates endothelial cell adhesion and cytoskeletal organization. Cancer Res. 2002;62(7):1944-7.

88. Kim YM, Jang JW, Lee OH, Yeon J, Choi EY, Kim KW, et al. Endostatin inhibits endothelial and tumor cellular invasion by blocking the activation and catalytic activity of matrix metalloproteinase. Cancer Res. 2000;60(19):5410-3.

89. Kim YM, Hwang S, Pyun BJ, Kim TY, Lee ST, Gho YS, et al. Endostatin blocks vascular endothelial growth factor-mediated signaling via direct interaction with KDR/FIk-1. J Biol Chem. 2002;277(31):27872-9.

90. Mitsuma W, Kodama M, Hanawa H, Ito M, Ramadan MM, Hirono S, et al. Serum endostatin in the coronary circulation of patients with coronary heart disease and its relation to coronary collateral formation. Am $J$ Cardiol. 2007;99(4):494-8.

91. O'Reilly MS, Holmgren L, Shing Y, Chen C, Rosenthal RA, Moses M, et al. Angiostatin: a novel angiogenesis inhibitor that mediates the suppression of metastases by a Lewis lung carcinoma. Cell. 1994;79(2):315-28. 
92. Ruegg C, Hasmim M, Lejeune FJ, Alghisi GC. Antiangiogenic peptides and proteins: from experimental tools to clinical drugs. Biochim Biophys Acta. 2006;1765(2):155-77.

93. Dass CR, Tran TM, Choong PF. Angiogenesis inhibitors and the need for anti-angiogenic therapeutics. J Dent Res. 2007;86(10):927-36.

94. Sim BK, MacDonald NJ, Gubish ER. Angiostatin and endostatin: endogenous inhibitors of tumor growth. Cancer Metastasis Rev. 2000;19(1-2):18190.

95. Cao Y. Antiangiogenic cancer therapy. Semin Cancer Biol. 2004;14(2):13945.

96. Claesson-Welsh L, Welsh M, Ito N, Anand-Apte B, Soker S, Zetter B, et al. Angiostatin induces endothelial cell apoptosis and activation of focal adhesion kinase independently of the integrin-binding motif RGD. Proc Natl Acad Sci U S A. 1998;95(10):5579-83. PMCID: 20420.

97. Yamahara K, Min KD, Tomoike H, Kangawa K, Kitamura S, Nagaya N. Pathological role of angiostatin in heart failure: an endogenous inhibitor of mesenchymal stem-cell activation. Heart. 2009;95(4):283-9.

98. Rege TA, Fears CY, Gladson CL. Endogenous inhibitors of angiogenesis in malignant gliomas: nature's antiangiogenic therapy. Neuro Oncol. 2005;7(2):10621. PMCID: 1871889.

99. Wang $R$. The gasotransmitter role of hydrogen sulfide. Antioxid Redox Signal. 2003;5(4):493-501.

100. Geng B, Yan H, Zhong GZ, Zhang CY, Chen XB, Jiang HF, et al. [Hydrogen sulfide: a novel cardiovascular functional regulatory gas factor]. Beijing Da Xue Xue Bao. 2004;36(1):106. 
101. Moore PK, Bhatia M, Moochhala S. Hydrogen sulfide: from the smell of the past to the mediator of the future? Trends Pharmacol Sci. 2003;24(12):609-11.

102. Wang R. Two's company, three's a crowd: can H2S be the third endogenous gaseous transmitter? FASEB J. 2002;16(13):1792-8.

103. Hosoki R, Matsuki N, Kimura $H$. The possible role of hydrogen sulfide as an endogenous smooth muscle relaxant in synergy with nitric oxide. Biochem Biophys Res Commun. 1997;237(3):527-31.

104. Abe K, Kimura $H$. The possible role of hydrogen sulfide as an endogenous neuromodulator. J Neurosci. 1996;16(3):1066-71.

105. Kamoun P. Endogenous production of hydrogen sulfide in mammals. Amino Acids. 2004;26(3):243-54.

106. Du J, Hui Y, Cheung Y, Bin G, Jiang H, Chen X, et al. The possible role of hydrogen sulfide as a smooth muscle cell proliferation inhibitor in rat cultured cells. Heart Vessels. 2004;19(2):75-80.

107. Zhao W, Zhang J, Lu Y, Wang R. The vasorelaxant effect of $H(2) S$ as a novel endogenous gaseous K(ATP) channel opener. EMBO J. 2001;20(21):6008-16. PMCID: 125693.

108. Geng B, Yang J, Qi Y, Zhao J, Pang Y, Du J, et al. H2S generated by heart in rat and its effects on cardiac function. Biochem Biophys Res Commun. 2004;313(2):362-8.

109. Zhong G, Chen F, Cheng Y, Tang C, Du J. The role of hydrogen sulfide generation in the pathogenesis of hypertension in rats induced by inhibition of nitric oxide synthase. J Hypertens. 2003;21(10):1879-85. 
110. Geng B, Chang L, Pan C, Qi Y, Zhao J, Pang Y, et al. Endogenous hydrogen sulfide regulation of myocardial injury induced by isoproterenol. Biochem Biophys Res Commun. 2004;318(3):756-63.

111. Su YW, Liang C, Jin HF, Tang XY, Han W, Chai LJ, et al. Hydrogen sulfide regulates cardiac function and structure in adriamycin-induced cardiomyopathy. Circ J. 2009;73(4):741-9.

112. Yang GD, Wu LY, Jiang B, Yang W, Qi JS, Cao K, et al. H2S as a physiologic vasorelaxant: Hypertension in mice with deletion of cystathionine gamma-lyase. Science. 2008;322(5901):587-90.

113. Papapetropoulos A, Pyriochou A, Altaany Z, Yang G, Marazioti A, Zhou Z, et al. Hydrogen sulfide is an endogenous stimulator of angiogenesis. Proc Natl Acad Sci U S A. 2009;106(51):21972-7. PMCID: 2799889.

114. Shi YX, Chen Y, Zhu YZ, Huang GY, Moore PK, Huang SH, et al. Chronic sodium hydrosulfide treatment decreases medial thickening of intramyocardial coronary arterioles, interstitial fibrosis, and ROS production in spontaneously hypertensive rats. Am J Physiol Heart Circ Physiol. 2007;293(4):H2093-100.

115. Zhu YZ, Wang ZJ, Ho P, Loke YY, Zhu YC, Huang SH, et al. Hydrogen sulfide and its possible roles in myocardial ischemia in experimental rats. $J$ Appl Physiol. 2007;102(1):261-8.

116. Pan TT, Feng ZN, Lee SW, Moore PK, Bian JS. Endogenous hydrogen sulfide contributes to the cardioprotection by metabolic inhibition preconditioning in the rat ventricular myocytes. $J$ Mol Cell Cardiol. 2006;40(1):119-30.

117. McMurray JJ, Pfeffer MA. Heart failure. Lancet. 2005;365(9474):1877-89.

118. Frey N, Olson EN. Cardiac hypertrophy: the good, the bad, and the ugly. Annu Rev Physiol. 2003;65:45-79. 
119. Choi YH, Cowan DB, Nathan M, Poutias D, Stamm C, del Nido PJ, et al. Myocardial hypertrophy overrides the angiogenic response to hypoxia. PLoS ONE. 2008;3(12):e4042. PMCID: 2603310.

120. Tomanek RJ. Response of the coronary vasculature to myocardial hypertrophy. J Am Coll Cardiol. 1990;15(3):528-33.

121. Marcus ML, Koyanagi S, Harrison DG, Doty DB, Hiratzka LF, Eastham CL. Abnormalities in the coronary circulation that occur as a consequence of cardiac hypertrophy. Am J Med. 1983;75(3A):62-6.

122. Conn G, Bayne ML, Soderman DD, Kwok PW, Sullivan KA, Palisi TM, et al. Amino acid and cDNA sequences of a vascular endothelial cell mitogen that is homologous to platelet-derived growth factor. Proc Natl Acad Sci U S A. 1990;87(7):2628-32. PMCID: 53743.

123. Ferrara $\mathrm{N}$, Davis-Smyth $\mathrm{T}$. The biology of vascular endothelial growth factor. Endocr Rev. 1997;18(1):4-25.

124. Ferrara N, Henzel WJ. Pituitary follicular cells secrete a novel heparinbinding growth factor specific for vascular endothelial cells. Biochem Biophys Res Commun. 1989;161(2):851-8.

125. Wu LW, Mayo LD, Dunbar JD, Kessler KM, Baerwald MR, Jaffe EA, et al. Utilization of distinct signaling pathways by receptors for vascular endothelial cell growth factor and other mitogens in the induction of endothelial cell proliferation. J Biol Chem. 2000;275(7):5096-103.

126. Norrby K. In vivo models of angiogenesis. J Cell Mol Med. 2006;10(3):588612.

127. Hajitou A, Grignet C, Devy L, Berndt S, Blacher S, Deroanne CF, et al. The antitumoral effect of endostatin and angiostatin is associated with a down- 
regulation of vascular endothelial growth factor expression in tumor cells. FASEB J. 2002;16(13):1802-4.

128. Dobryansky M, Galiano RD, Cetrulo CL, Jr., Bhatt KA, Michaels J, Ashinoff $R$, et al. Endostatin inhibits ischemia-induced neovascularization and increases ischemic tissue loss. Ann Plast Surg. 2004;52(5):512-8; discussion 8.

129. Boluyt MO, O'Neill L, Meredith AL, Bing OH, Brooks WW, Conrad $\mathrm{CH}$, et al. Alterations in cardiac gene expression during the transition from stable hypertrophy to heart failure. Marked upregulation of genes encoding extracellular matrix components. Circ Res. 1994;75(1):23-32.

130. Ding B, Price RL, Borg TK, Weinberg EO, Halloran PF, Lorell BH. Pressure overload induces severe hypertrophy in mice treated with cyclosporine, an inhibitor of calcineurin. Circ Res. 1999;84(6):729-34.

131. Lindsay MM, Maxwell P, Dunn FG. TIMP-1: a marker of left ventricular diastolic dysfunction and fibrosis in hypertension. Hypertension. 2002;40(2):13641.

132. Lovelock JD, Baker AH, Gao F, Dong JF, Bergeron AL, McPheat W, et al. Heterogeneous effects of tissue inhibitors of matrix metalloproteinases on cardiac fibroblasts. Am J Physiol Heart Circ Physiol. 2005;288(2):H461-8.

133. Baker AH, Zaltsman AB, George SJ, Newby AC. Divergent effects of tissue inhibitor of metalloproteinase-1, -2 , or $\mathbf{- 3}$ overexpression on rat vascular smooth muscle cell invasion, proliferation, and death in vitro. TIMP-3 promotes apoptosis. J Clin Invest. 1998;101(6):1478-87. PMCID: 508704.

134. Tummalapalli CM, Heath BJ, Tyagi SC. Tissue inhibitor of metalloproteinase-4 instigates apoptosis in transformed cardiac fibroblasts. $\mathbf{J}$ Cell Biochem. 2001;80(4):512-21. 
135. Papaioannou VE, Fox JG. Efficacy of tribromoethanol anesthesia in mice. Lab Anim Sci. 1993;43(2):189-92.

136. Allard MF, Flint JD, English JC, Henning SL, Salamanca MC, Kamimura CT, et al. Calcium overload during reperfusion is accelerated in isolated hypertrophied rat hearts. J Mol Cell Cardiol. 1994;26(12):1551-63.

137. Felbor U, Dreier L, Bryant RA, Ploegh HL, Olsen BR, Mothes W. Secreted cathepsin L generates endostatin from collagen XVIII. EMBO J. 2000;19(6):118794. PMCID: 305660.

138. Tarui T, Miles LA, Takada Y. Specific interaction of angiostatin with integrin alpha(v)beta(3) in endothelial cells. J Biol Chem. 2001;276(43):39562-8.

139. Moser TL, Kenan DJ, Ashley TA, Roy JA, Goodman MD, Misra UK, et al. Endothelial cell surface F1-FO ATP synthase is active in ATP synthesis and is inhibited by angiostatin. Proc Natl Acad Sci U S A. 2001;98(12):6656-61. PMCID: 34409.

140. Chen YH, Wu HL, Li C, Huang YH, Chiang CW, Wu MP, et al. Antiangiogenesis mediated by angiostatin K1-3, K1-4 and K1-4.5. Involvement of p53, FasL, AKT and mRNA deregulation. Thromb Haemost. 2006;95(4):668-77.

141. Sharma MR, Tuszynski GP, Sharma MC. Angiostatin-induced inhibition of endothelial cell proliferation/apoptosis is associated with the down-regulation of cell cycle regulatory protein cdk5. J Cell Biochem. 2004;91(2):398-409.

142. Troyanovsky B, Levchenko T, Mansson G, Matvijenko O, Holmgren L. Angiomotin: an angiostatin binding protein that regulates endothelial cell migration and tube formation. J Cell Biol. 2001;152(6):1247-54. PMCID: 2199208.

143. Sen U, Rodriguez WE, Tyagi N, Kumar M, Kundu S, Tyagi SC. Ciglitazone, a PPARgamma agonist, ameliorates diabetic nephropathy in part through 
homocysteine clearance. Am J Physiol Endocrinol Metab. 2008;295(5):E1205-12. PMCID: 2584817.

144. Lindsey ML, Escobar GP, Dobrucki LW, Goshorn DK, Bouges S, Mingoia JT, et al. Matrix metalloproteinase-9 gene deletion facilitates angiogenesis after myocardial infarction. Am J Physiol Heart Circ Physiol. 2006;290(1):H232-9.

145. Ducharme A, Frantz S, Aikawa M, Rabkin E, Lindsey M, Rohde LE, et al. Targeted deletion of matrix metalloproteinase- 9 attenuates left ventricular enlargement and collagen accumulation after experimental myocardial infarction. J Clin Invest. 2000;106(1):55-62. PMCID: 517910.

146. Camp TM, Tyagi SC, Senior RM, Hayden MR. Gelatinase B(MMP-9) an apoptotic factor in diabetic transgenic mice. Diabetologia. 2003;46(10):1438-45.

147. Gerdes AM, Kellerman SE, Moore JA, Muffly KE, Clark LC, Reaves PY, et al. Structural remodeling of cardiac myocytes in patients with ischemic cardiomyopathy. Circulation. 1992;86(2):426-30.

148. Elrod JW, Calvert JW, Morrison J, Doeller JE, Kraus DW, Tao L, et al. Hydrogen sulfide attenuates myocardial ischemia-reperfusion injury by preservation of mitochondrial function. Proc Natl Acad Sci $U$ S A. 2007;104(39):15560-5. PMCID: 2000503.

149. Mishra PK, Tyagi N, Sen U, Givvimani S, Tyagi SC. H2S ameliorates oxidative and proteolytic stresses and protects the heart against adverse remodeling in chronic heart failure. Am $\mathbf{J}$ Physiol Heart Circ Physiol. 2010;298(2):H451-6. PMCID: 2822570.

150. Zhang $Z$, Huang $H$, Liu P, Tang C, Wang J. Hydrogen sulfide contributes to cardioprotection during ischemia-reperfusion injury by opening K ATP channels. Can J Physiol Pharmacol. 2007;85(12):1248-53. 
151. Friehs I, Moran AM, Stamm C, Choi YH, Cowan DB, McGowan FX, et al. Promoting angiogenesis protects severely hypertrophied hearts from ischemic injury. Ann Thorac Surg. 2004;77(6):2004-10; discussion 11.

152. Hu Y, Chen X, Pan TT, Neo KL, Lee SW, Khin ES, et al. Cardioprotection induced by hydrogen sulfide preconditioning involves activation of ERK and PI3KJAkt pathways. Pflugers Arch. 2008;455(4):607-16.

153. Tyagi SC, Matsubara L, Weber KT. Direct extraction and estimation of collagenase(s) activity by zymography in microquantities of rat myocardium and uterus. Clin Biochem. 1993;26(3):191-8.

154. Chow AK, Cena J, Schulz R. Acute actions and novel targets of matrix metalloproteinases in the heart and vasculature. Br J Pharmacol. 2007;152(2):189205. PMCID: 1978261.

155. Alexander SM, Jackson KJ, Bushnell KM, McGuire PG. Spatial and temporal expression of the 72-kDa type IV collagenase (MMP-2) correlates with development and differentiation of valves in the embryonic avian heart. Dev Dyn. 1997;209(3):261-8.

156. Cai W, Vosschulte R, Afsah-Hedjri A, Koltai S, Kocsis E, Scholz D, et al. Altered balance between extracellular proteolysis and antiproteolysis is associated with adaptive coronary arteriogenesis. $J$ Mol Cell Cardiol. 2000;32(6):997-1011.

157. Robbins JR, McGuire PG, Wehrle-Haller B, Rogers SL. Diminished matrix metalloproteinase 2 (MMP-2) in ectomesenchyme-derived tissues of the Patch mutant mouse: regulation of MMP-2 by PDGF and effects on mesenchymal cell migration. Dev Biol. 1999;212(2):255-63. 
158. Itoh T, Ikeda T, Gomi H, Nakao S, Suzuki T, Itohara S. Unaltered secretion of beta-amyloid precursor protein in gelatinase A (matrix metalloproteinase 2)deficient mice. J Biol Chem. 1997;272(36):22389-92.

159. Romanic AM, Harrison SM, Bao W, Burns-Kurtis CL, Pickering S, Gu J, et al. Myocardial protection from ischemia/reperfusion injury by targeted deletion of matrix metalloproteinase-9. Cardiovasc Res. 2002;54(3):549-58.

160. Sen U, Basu P, Abe OA, Givvimani S, Tyagi N, Metreveli N, et al. Hydrogen sulfide ameliorates hyperhomocysteinemia-associated chronic renal failure. Am J Physiol Renal Physiol. 2009;297(2):F410-9. PMCID: 2724247.

161. Rottman JN, Ni G, Brown M. Echocardiographic evaluation of ventricular function in mice. Echocardiography. 2007;24(1):83-9. 


\section{LIST OF ABBREVIATIONS}

Aortic banding $(A B)$

American Heart Association (AHA)

Protein kinase $B(A K T)$

Adenosine tri phosphate (ATP)

Carbon monoxide (CO)

Coronary artery disease (CAD)

Cardiovascular disease (CVD)

Congestive heart failure (CHF)

Cluster of differentiation molecule 31(CD31)

Cyclic guanosine mono phosphate (cGMP)

Cystathionine $\beta$ synthase (CBS)

Cystathionine y lyase (CSE)

Endothelial cells (ECs)

Ejection fraction (EF)

Extracellular signal regulated kinase (ERK)

Extracellular matrix (ECM)

Fibroblast growth factor (FGF)

Focal adhesion kinase (FAK)

Fractional shortening (FS)

Guanosine triphosphate (GTP) 
Heam oxygenase $(\mathrm{HO})$

Hypoxia- inducible factor (HIF)

Hydrogen sulfide $\left(\mathrm{H}_{2} \mathrm{~S}\right)$

Institute Animal Care and use Committee (IACUC)

Integrin ( $a v \beta 3)$

Left ventricular internal dimension in diastole (LVIDd)

Left ventricular posterior wall dimension (LVPWD)

Matrix metalloproteinase (MMP)

Membrane-type matrix metalloproteinase (MT-MMP)

Mitogen-activated protein kinase (MAPK)

National center for health statistics (NCHS)

National Health and Nutrition Examination Survey (NHANES)

Nitric oxide (NO)

Nitric oxide synthase (NOS)

Phosphoglycerate kinase (PGK)

Phosphate buffered saline (PBS)

Platelet endothelial cell adhesion molecule (PECAM)

Pressure volume analysis (PVAN)

Sodium hydrosulfide (NaHS)

Tissue plasminogen activator (tPA)

Tissue inhibitor of matrix metalloproteinase (TIMP)

Tri-bromo ethanol (TBE)

Urikinase plasminogen activator (UPA)

Vascular endothelial growth factor (VEGF)

Vascular endothelial growth factor receptor (VEGFR) 


\title{
CURRICULUM VITAE \\ SRIKANTH GIVVIMANI MBBS \\ University of Louisville \\ AAMC ID: 12162853
}

1. Home Address:

\author{
Apt \#207, \\ 8904 Elks Bluff Dr \\ Louisville, KY 40220. \\ 502-777-5686 \\ e-mail: drshreek@gmail.com
}

2. Office Address: University of Louisville School of Medicine, HSC A 1210 500 South Preston Street Louisville, Kentucky 40292

FAX: (502) 852-6239

3. Place of Birth: Anantapur, India.

4. Citizenship: Indian.

5. Education: 2001

M.B.B.S (Bachelor of Medicine \& Bachelor of Surgery)

Sri Venkateswara Medical College, Tirupathi, India.

M.S in Physiology and Biophysics, University of Louisville

2010 Ph.D; Physiology and Biophysics, University of Louisville

6. Postgraduate Training and Fellowship Appointments:

$\begin{array}{cl}\text { 03/2010 - current } & \begin{array}{l}\text { Observer in Division of } \\ \text { Division of Nephrology, } \\ \text { Louisville,KY }\end{array} \\ 04 / 2008 \text { - Present } & \begin{array}{l}\text { Research Associate } \\ \text { University of Louisville, } \\ \text { Louisville, Kentucky. }\end{array}\end{array}$




\begin{tabular}{|c|c|}
\hline \multirow[t]{2}{*}{$09 / 2006-03 / 2008$} & Senior House Officer \\
\hline & $\begin{array}{l}\text { Department of Intensive Care and Anesthesia } \\
\text { Eric Williams Medical Sciences Complex, } \\
\text { Mt. Hope Hospital, Trinidad, West Indies. }\end{array}$ \\
\hline 08/2004- 09/2006 & $\begin{array}{l}\text { House Officer } \\
\text { Department of Surgery }\end{array}$ \\
\hline & $\begin{array}{l}\text { Eric Williams Medical Sciences Complex, } \\
\text { Mt. Hope Hospital, Trinidad, West Indies. }\end{array}$ \\
\hline $01 / 2003-06 / 2004$ & $\begin{array}{l}\text { Resident Physician } \\
\text { Medicity Hospitals } \\
\text { Hyderabad, India }\end{array}$ \\
\hline $01 / 2001-12 / 2002$ & $\begin{array}{l}\text { Resident Surgical Officer } \\
\text { Sri Sai Polyclinic \& Nursing Home } \\
\text { Hyderabad, India }\end{array}$ \\
\hline $12 / 1999-12 / 2000$ & $\begin{array}{l}\text { Internship } \\
\text { S.V.R.R. Govt. General Hospital, } \\
\text { Tirupathi, Andhra Pradesh, India }\end{array}$ \\
\hline
\end{tabular}

7. Licensure and Certification:

$\begin{array}{lll}\text { Certificates } & \text { Issued By } & \text { Issue Date } \\ \text { BLS } & \text { AHA } & 2003 \\ \text { ACLS } & \text { AHA } & 2003 \\ \text { ATLS } & \text { ACS } & 2006\end{array}$

Medical Registration: Medical Council of India (MCl).

Medical Board of Trinidad and Tobago.

8. USMLE and ECFMG Certification:

$\begin{array}{llll}\text { Passed } & \text { USMLE Step I } & \text { Feb } & 2006 \\ \text { Passed } & \text { USMLE Step II } & \text { April } & 2007 \\ \text { Passed } & \text { USMLE Step II Cs } & \text { May } & 2007 \\ \text { Certified } & \text { ECFMG } & \text { June } & 2007\end{array}$

9. Memberships in Professional and Honorary Societies:

Member, Andhra Pradesh Medical Council (State Medical council).

Member, House Surgeons Association, Tirupathi (Junior doctors association).

Volunteer, Jhanma bhumi Program, Andhra Pradesh (State government volunteer program).

Volunteer, Pulse polio Program, Andhra Pradesh.

11. Awards and Honours:

Received GSC travel funding to attend Experimental Biology 2010.

Received travel award (Roberts Gift Fund) from School of Medicine, University of Louisville. 
Received Travel award from Department of Physiology and Biophysics, University of Louisville.

\section{Bibliography}

I. Ph.D Dissertation Title: The role of matrix metalloproteinases induced angiogenesis during transition from compensatory cardiac hypertrophy to cardiac failure: Therapeutic effects of hydrogen sulfide.

\section{Manuscripts published:}

Givvimani S, Tyagi N, Sen U, Mishra PK, Quipshidze N, Munjal C, Abe QA, Tyagi SC. MMP2/TIMP-2/TIMP-4 versus MMP-9/TIMP-3 in transition from compensatory hypertrophy and angiogenesis to de-compensatory heart failure, Archives of Physiology \& Biophysics, May 2010.

Givvimani S, Sen U, Tygai N, Munjal C, Tyagi SC. X-ray imaging of differential vascular density in MMP-9-/-, PAR-1-/+, hyperhomocysteinemic (CBS-/+) and diabetic (Ins2-/+) mice ${ }^{\star}$ Archives of Physiology and Biochemistry, July 2010.

Tyagi N, Givvimani S, Qipshidze N, Kundu S, Kapoor S, Vacek JC, Tyagi SC. Hydrogen sulfide mitigates matrix metalloproteinase- 9 activity and neurovascular permeability in hyperhomocysteinemic mice. Neurochemistry International,56(2):301-7; Jan 2010.

Tyagi N, Vacek JC, Givvimani S, Sen U, Tyagi SC. Cardiac specific deletion of N-methyl-daspartate receptor 1 ameliorates mtMMP-9 mediated autophagy/mitophagy in hyperhomocysteinemia. J Recept Signal Transduct Res. Feb 22, 2010.

Maldonado C, Soni CV, Todnem ND, Pushpakumar S, Rosenberger D, Givvimani S, Villafane J, Tyagi SC. Hyperhomocysteinemia and Sudden Cardiac Death: Potential Arrhythmogenic Mechanisms. Curr Vasc Pharmacol. Jan 1,2010.

Mishra PK, Tyagi N, Sen U, Givvimani S, Tyagi SC. H2S ameliorates oxidative and proteolytic stresses and protects the heart against adverse remodeling in chronic heart failure. Am J Physiol Heart Circ Physiol. 2010 Feb;298(2):H451-6. Nov 20, 2009.

Sen U, Basu P, Abe OA, Givvimani S, Tyagi N, Metreveli N, Shah KS, Tyagi SC. Hydrogen sulfide ameliorates homocysteine-induced chronic renal failure, Am J Physiology, Renal, Aug:297(2):F410-9, 2009.

Kumar M, Tyagi N, Moshal KS, Sen U, Kundu S, Mishra PK, Givvimani S, Tyagi SC. Homocysteine decreases blood flow to the brain due to vascular resistance in carotid artery, Neurochemistry International, 53:214-219, 2008.

\section{Submitted:}

Givvimani S, munjal C, Gargoum R, Tyagi N, Sen U, Vacek J,Tyagi SC. Hydrogen sulfide mitigates transition from compensatory hypertrophy to heart failure through MMP-2 activation and angiogenesis. Circulation Journal, submitted July 2010.

Qipshidze N, Tyagi N, Sen U, Givvimani S, Metreveli N, Lominadze D, Tyagi SC. Folic Acid Mitigated Cardiac Dysfunction by Normalizing the Levels of Tissue Inhibitor of Metalloproteinase and homocysteine-metabolizing enzymes Post myocardial Infarction in Mice, Am J Physiol (Heart \& Circ Physiol), submitted, 2010. 
Soni CV, Maldonado C, Todnem ND, Givvimani S, Pushpakumar S, Patibandla PK, Villafane J, Tyagi SC. Hyperhomocysteinemia alters sinoatrial and atrioventricular nodal function: Role of the cardiac NMDA receptor. Journal of Cardiovascular Electrophysiology, August, 2010.

Mishra P.K, Givvimani S, Metreveli N, Tyagi SC. Beta 2-adrenergic receptors in diabetic cardiomyopathy of Insulin 2 mutant mice: a role of hyperhomocysteinemia, J. Cardiac Failure, July 2010.

\section{Abstracts and Posters:}

Cerebroprotective role of tetrahydro curcumin in hyperhomocysteinemic ischemic mine by regulating NF-kB. Kumar M, Givvimani S, Puspkumar SB, Mishra PK, Kundu S, RodriguezAlvarez WE, Tyagi N, Sen U, Tyagi SC. The FASEB Journal, 2009, 614.7.

Role of micriRNAs in homocysteine-induced oxidative stress. Mishra PK, Tyagi N, Kumar M, Kumar M, Kundu S, Givvimani S, Sen U, Tyagi SC. The FASEB Journal 2009, 1038.9.

Downregulation of dicer involved in MMP-9 mediated cardiomyocytes dysfunction. Mishra PK, Metreveli N, Givvimani S, Kundu S, Tyagi N, Qipshdze N, Sen U, Basu P, Abe OA, Gillespie WM, Munjal C, Vacek J, Tyagi SC. 63rd High Blood Pressure Conference, 2009, P111.

Ang II-induced hypertension: Role of homocysteine in vasculogenesis and cortical blood flow Sen U, Qipshidze N, Givvimani S, Abe OA, Metreveli N, Tyagi SC.. 63rd High Blood Pressure Conference, 2009, P433.

Functional heterogeneity in vascular remodeling (MMP-9-/- and PAR-1-/+) in hyperhomocysteinemic (CBS-/+) and diabetic (Akita, Ins2-/+) mice. Givvimani S, Jala R, Mishra PK, Sen U, Tyagi N, Qipshidze N, Munjal C, Tyagi SC. FASEB J, 2010.

Folic Acid Mitigated Cardiac Dysfunction by Normalizing the Levels of Tissue Inhibitor of Metalioproteinase and homocysteine-metabolizing enzymes Post myocardial Infarction in Mice. Qipshidze N, Tyagi N, Sen U, Givvimani S, Metreveli N, Abe OA, Lominadze D, Tyagi SC. FASEB J, 2010

Folic acid mitigated homocysteine-mediated decrease in bone blood flow and bone remodeling. Kandel M, Tyagi N, Qisphidze N, Munjal C, Basu P, Givvimani S, Abe O, Mishra PK, Sen U, Tyagi SC, FASEB J, 2010

Tetrahydrocurcumin ameliorates mtMMP- 9 mediated mitophagy and mitochondria remodeling in Stroke. Tyagi N, Qipshidze N, Givvimani S, Kandel M, Mishra PK, Sen U, Tyagi SC. FASEB $\mathrm{J}, 2010$

Curcumin mitigated ischemic and hyperhomocysteinemic cerebral microvascular mitochondrial mitophagy by decreasing oxidative and inflammatory stresses. Kapoor S, Tyagi N, Qipshidze.N , Givvimani S, Kandel M, Tyagi SC. FASEB J, 2010

Role of dicer in diabetic cardiomyopathy through dysregulation of MMP-9 and TIMP-4.Mishra PK, Givvimani S, Sen U, Abe OA, Tyagi N, Basu P, Munjal C, Tyagi SC. FASEB J, 2010

Mild hyperhomocysteinemia increases atrioventricular nodal conduction: Role of the cardiac NMDA receptor. Maldonado C, Todnem ND, Soni CV, Givvimani S, Pushpakumar S, Patibandla PK, Tyagi SC. FASEB J, 2010 
Curcumin ameliorates homocysteinylated cytochrome-c-mediated mitophagy/mitochondrial remodeling in hyperhomocysteinemia after cerebral ischemia. Tyagi N, Qipshidze N, Munjal C, Metreveli N, Shah K, Vacek J, Mishra P, Sen U, Givvimani S, Lominadze D, Tyagi SC. AHA , HBPR 2010.

Diosgenin protects against homocysteine-induced oxidative stress in brain microvascular endothelial cells. Munjal C, Tyagi N, Qipshidze N, Givvimani S, Mishra P, Sen U, Tyagi SC. AHA, HBPR 2010.

Hydrogen sulfide mitigates transition from compensatory hypertrophy to heart failure through MMP-2 activation and angiogenesis. Givvimani S, Munjal C, Gargoum R, Tyagi N, Sen U, Tyagi SC. AHA, HBPR 2010. 


\section{References:}

Dr.Suresh C. Tyagi Ph.D

Professor and Research Director

Dept of Physiology and Biophysics

University of Louisville

Louisville, KY.

Dr.Eleanor Lederer, M.D

Professor and Chief

Division of Nephrology

University of Louisville

Louisville-KY.

Dr.Julio Ramirez, M.D, FACP

Professor and Chief

Divison of infectious diseases

University of Louisville

Louisville-KY.

Dr.Ali Al-Khafaji M.D

Assistant Proffessor, CCU

UPMC, Pittsburgh- P.A

Dr.David Mc Adams M.D

Assistant Proffessor,

Internal medicine

UPMC, Pittsburgh- P.A

\section{Dr.Mark Richards}

Consultant \& Clinical Director, Department of ICU \& Anaesthesia EWMSC, Mt. Hope Hospital, Trinidad, West Indies

Dr.Solaiman Juman

Consultant \& Lecturer, UWI

Surgery-Otolaryngeology

EWMSC, Mt. Hope Hospital, Trinidad, West Indies.

Dr.Sushilla Maharaj FRCS.

Consultant \& Ag. Clinical Director

Department of Pediatric Surgery

EWMSC, Mt.Hope Hospital,

Trinidad, West Indies.

Dr.Deryk R .Chen FRCA,MBA

Consultant \&Acting Head, UWI

Department of ICU \& Anaesthesia EWMSC, Mt. Hope Hospital, Trinidad, West Indies 